\title{
COLHEDORA DE CANA-DE-AÇÚCAR (Saccharum spp) AVALIAÇÃO EM CANAVIAIS COM E SEM QUEIMA PRÉVIA
}

\author{
VICTÓRIO LAERTE FURLANI NETO \\ Engenheiro Agrônomo, M.S.
}

Orientador: NILSON AUGUSTO VILLA NOVA,

Tese apresentada à Escola Superior de Agricultura "Luiz de Queiroz", da Universidade de São Paulo, para obtenção do Título de Doutor em Agronomia, Área de Concentração: Solos e Nutrição de Plantas.

P I R A C I C A B A

Estado de São Paulo - Brasil

Julho - 1995 
CATALOGAGHO HA PUBLICACRO

DIUISAO DE GIBLIOTECA E DOCUMEMTACGO - CAMPUS "LUI? DE GUEJROZ" USF

Furlani Meto, Victurie Laerte

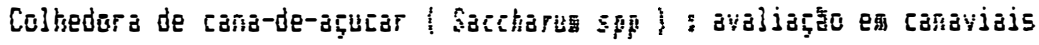
co耳 e sem queima previa. Firacicaba, 1995.

I1.p.

Tese - ESALB

Bibliogratia.

1. Cana-de-aร̧ucar - Colhejta mecanizada 2. Colhedura de cana-de-açucar Avaliaz̧ato ]. Escola Sugarior de Agricultura Luiz de Rueiroz, Piracicaba, SP

Coi 631.35

633.61 
COLHEDORA DE CANA-DE-AÇÚCAR (Saccharum spp) AVALIAÇÃO EM CANAVIAIS COM E SEM QUEIMA PRÉVIA

VICTÓRIO LAERTE FURLANI NETO

Aprovado em: 05./.09/95

Comissão Julgadora:

Prof. Dr. CARLOS ANTONIO GAMERO

UNESP/FCA

Prof. Assoc. NILSON AUGUSTO VILLA NOVA

USP/ESALQ

Prof. Dr. MARCOS MILAN

USP/ESALQ

Prof. Dr. MIGUEL ANGELO MANIERO

UFSCar/CCA

Prof. Dr. TOMAS CAETANO C. RIPOLI

USP/ESALQ

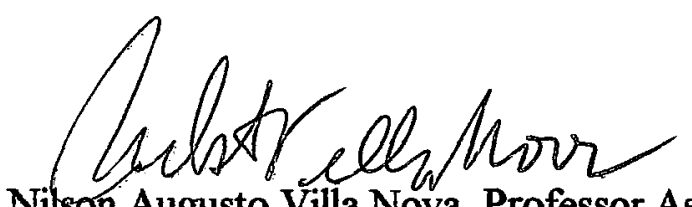

Nitson Augusto Villa Nova, Professor Associado

Orientador 
As donas-de-casa pela paciência e tolerância à poluição

ambiental causada pelas queimadas dos canaviais,

Ofereço

DA COLHEITA MECÂNICA DE CANA

SEM A QUEIMA PRÉVIA, NADA

SE PERDE, NADA SE DESTRÓI;

TUDO SE APROVEITA.

A minha esposa

VERA,

pela compreensão e apoio,

Dedico 


\section{AGRADECIMENTOS}

- Aos Profs. Dr. Nilson Augusto Villa Nova e Tomas Caetano C. Ripoli, pela dedicação, orientação e estímulo na execução desta tese.

- À Universidade Federal de São Carlos, que permitiu esta oportunidade de aprimoramento em minha carreira profissional.

- Ao Departamento de Solos e Nutrição da ESALQ/USP, na pessoa do Dr. Geraldo Victorino França que deu uma orientação segura no decorrer do curso de pós-graduação.

- Ao CNPq pelo auxilio financeiro prestado durante o decorrer do curso.

- À Usina Santa Lydia - Ribeirão Preto, na pessoa do Dr. Arlindo Approbato Filho e toda sua equipe técnica, que tornaram possível a realização deste trabalho.

- À Santal - Equipamentos por todo o apoio na revisão da colhedora "SantalAMAZÓN", durante a realização dos trabalhos de campo.

- Aos colegas do Departamento de Recursos Naturais e Proteção Ambiental da UFSCar que contribuiram com apoio, estímulo e sugestões na elaboração desta tese.

- Ao Departamento de Silvicultura/ESALQ através do Prof. Dr. Luiz E. G. Barrichello pela facilidade de análises caloríficas no laboratório de Engenharia Florestal.

- A Sueli Aparecida Metzker Pereira Ribeiro pela correção bibliográfica realizada.

- Ao Prof. Dr. Rubismar Stolf pelas sugestões e colaborações.

- Ao servidor da UFSCar/CCA Luís Carlos de Sá pelos serviços de digitação e diagramação gráfica final. 


\section{SUMÁRIO}

Página

LISTA DE FIGURAS .........................................................................iii

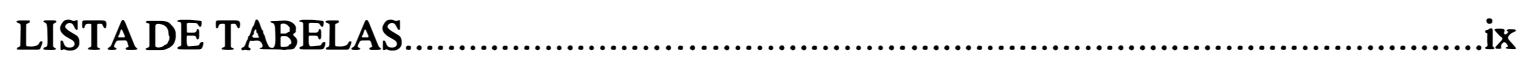

RESUMO

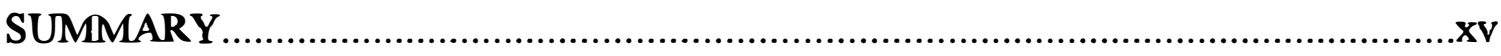

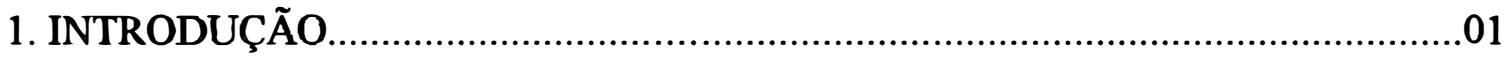

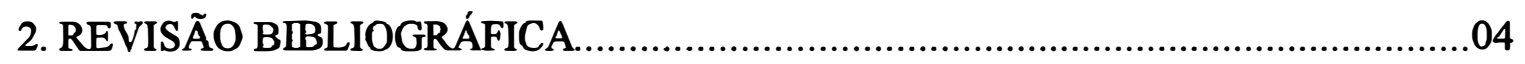

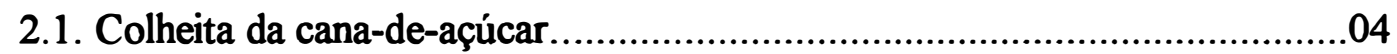

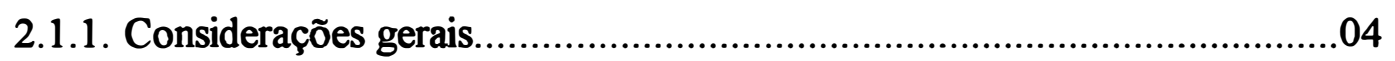

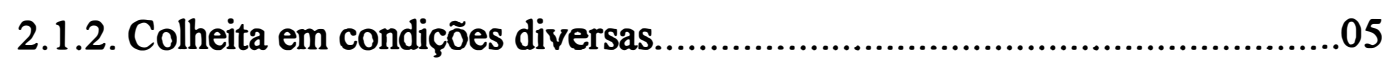

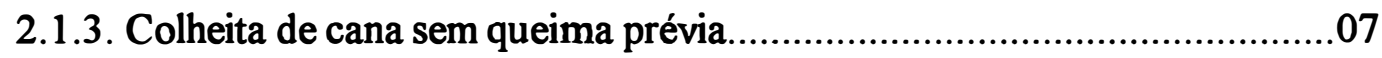

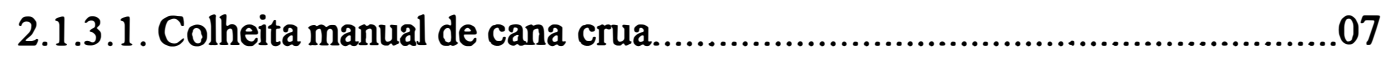

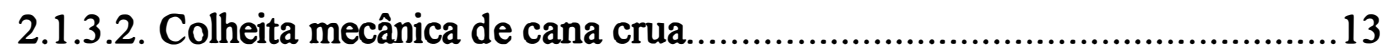

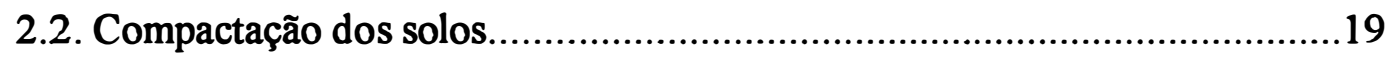

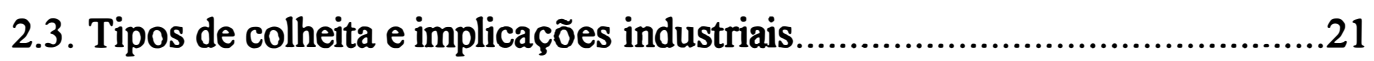

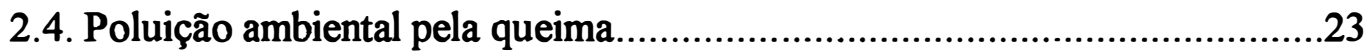

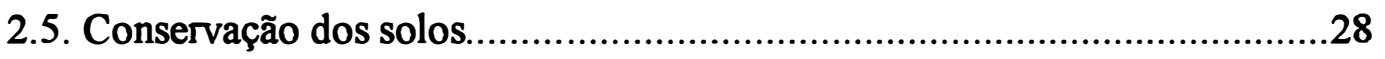

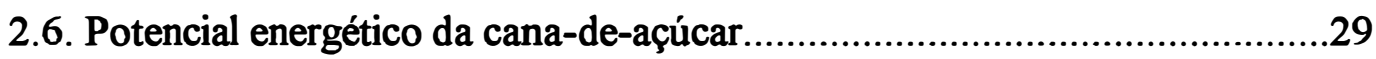

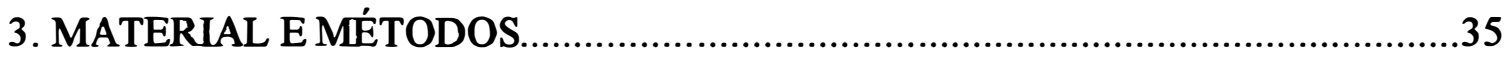

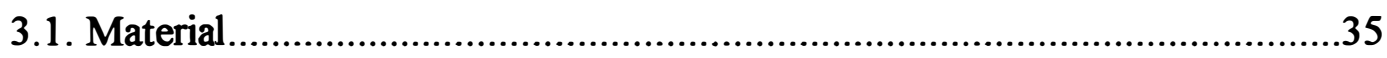

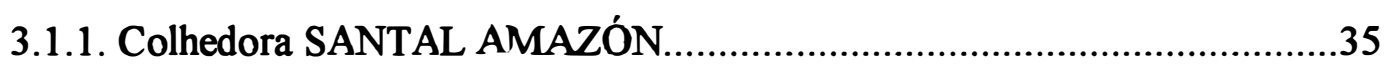

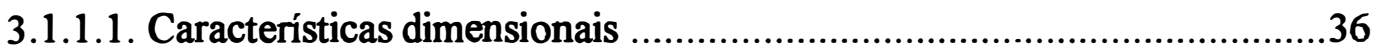

3.1.1.2. Características técnicas de funcionamento dos órgãos ativos da colhe-

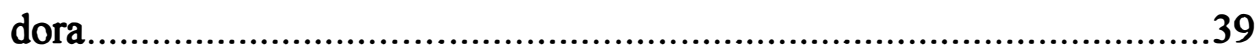

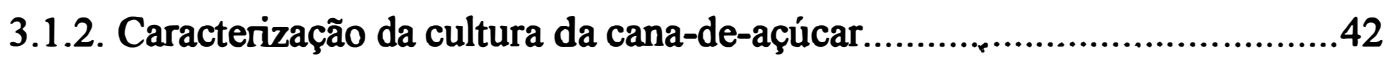

3.1.2.1. Material do primeiro experimento (Campo 1)...................................42 
3.1.2.2. Material do segundo experimento (Campo 2)..........................................

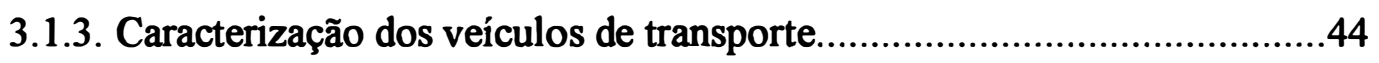

3.1.4. Equipamentos para determinações no campo...........................................45

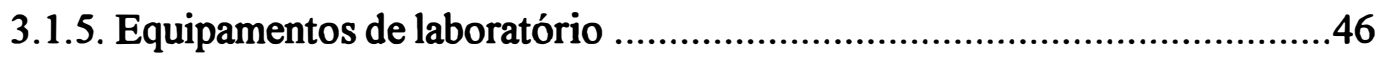

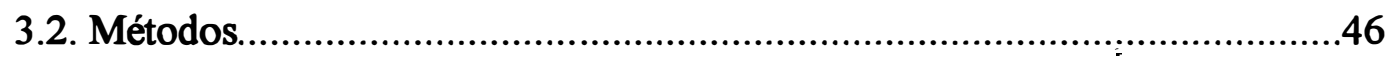

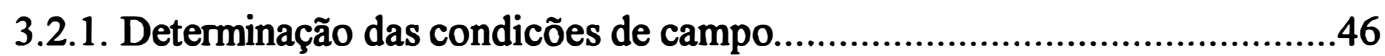

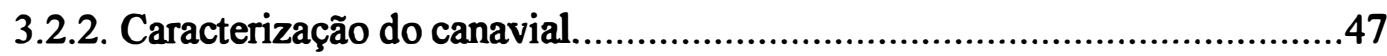

3.2.3. Avaliações de desempenho da colhedora................................................48

3.2.4. Análise granulométrica e teor de umidade (\%) no solo.............................48

3.2.5. Potencial residual de pós-colheita..........................................................

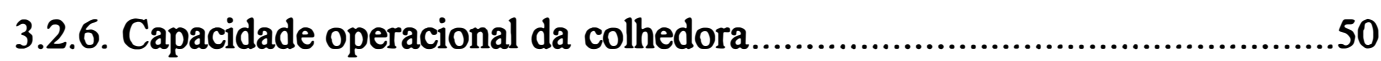

3.2.7. Determinações no laboratório de sacarose...............................................51

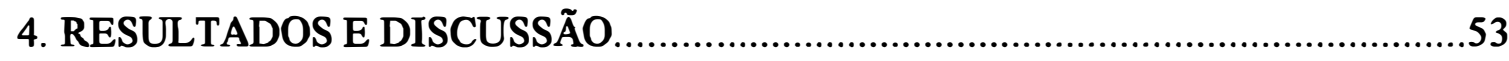

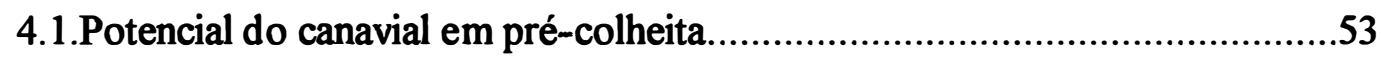

4.2. Resultados médios das determinações dimensionais e ponderais..................55

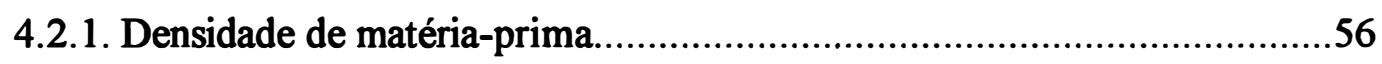

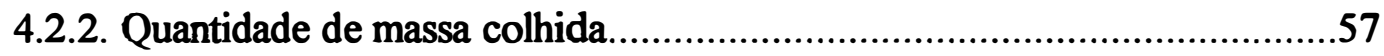

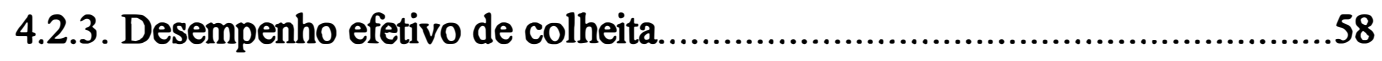

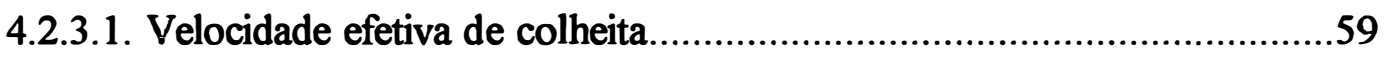

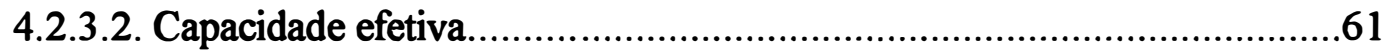

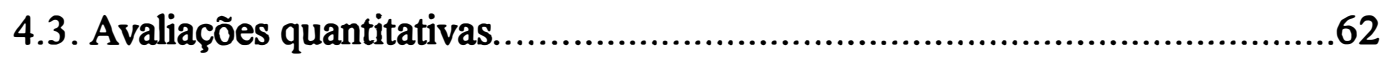

4.3.1. Percentagem de colmos contidos na matéria-prima...................................64

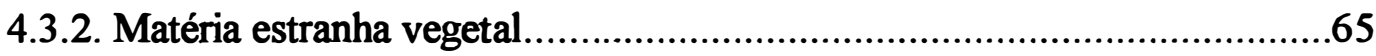

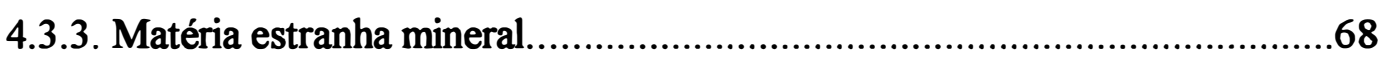

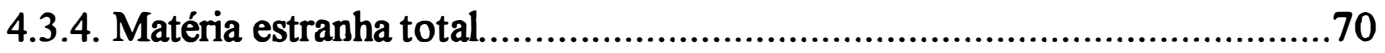

4.4. Análises tecnológicas nas massas colhidas mecanicamente.........................72

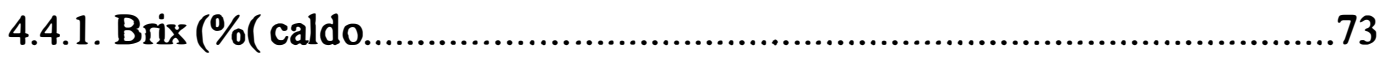

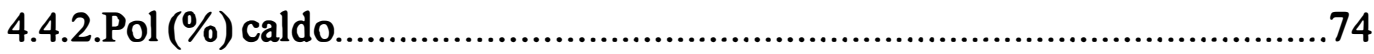

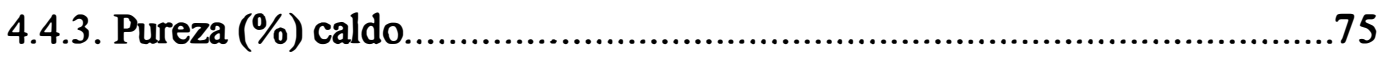

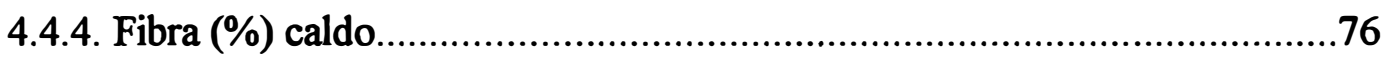




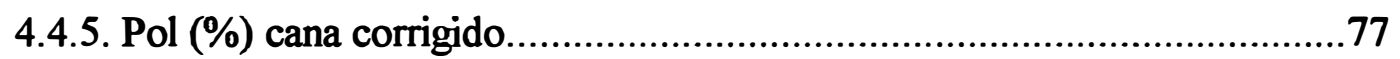

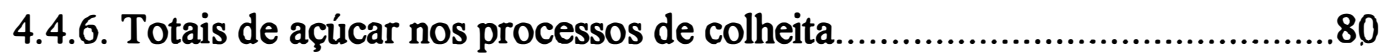

4.5. Perdas de material industrializável no campo após a colheita.......................81

4.5.1. Perda de frações de colmos agregados à ponteiro....................................82

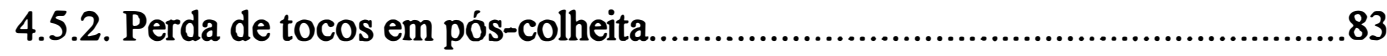

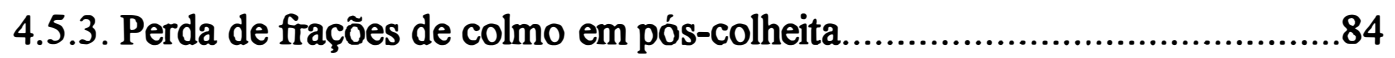

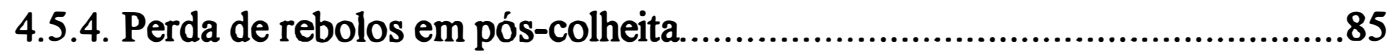

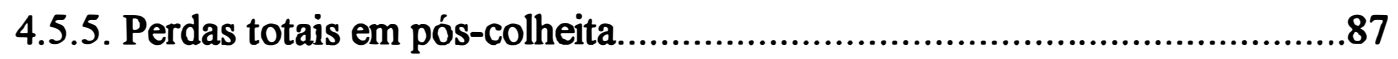

4.6. Potencial das perdas no campo em pós-colheita...........................................88

4.7. Totais de açúcar obtidos na usina e perdidos no campo nos tratamentos.....90

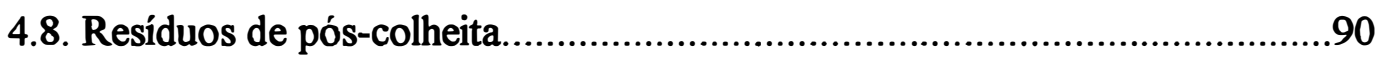

4.9. Determinação da energia contida nos resíduos de pós-colheita.....................93

4.10. Vantagens indiretas do resíduo da cana crua............................................95

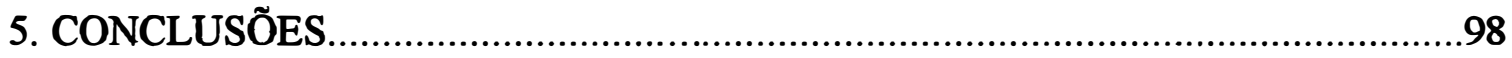

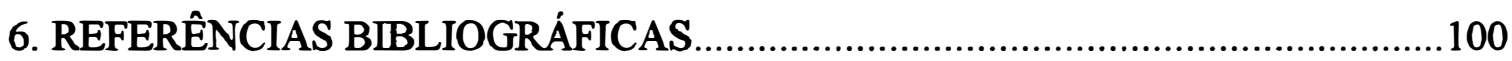

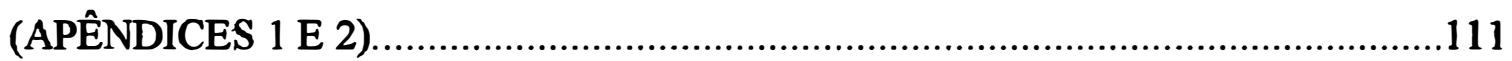




\section{LISTA DE FIGURAS}

1.a.Esquema frontal da colhedora SANTAL AMAZÓN.............................................37

1.b Esquema lateral da colhedora SANTAL AMAZÓN .............................................38

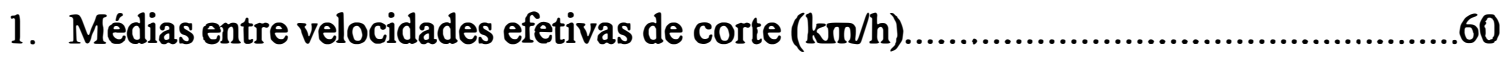

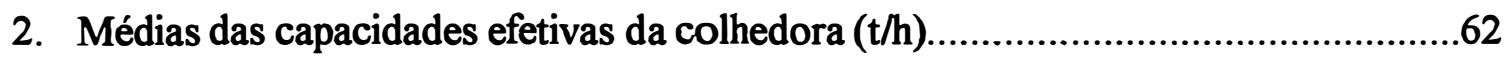

3. Percentagens médias obtidas de matéria estranha vegetal nos tratamentos...............67

4. Valores percentuais de matéria estranha vegetal e mineral....................................69

5. Valores percentuais de matéria estranha total.....................................................

6. Resultados médios de pol (\%) cana corrigido.......................................................

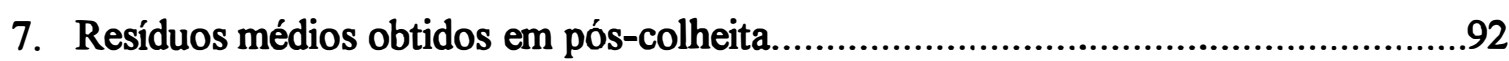

8. Energia contida no resíduo de pós-colheita nos tratamentos...................................95 


\section{LISTA DE TABELAS}

Página

1. Caracterizações ponderais e dimensionais do campo antes da colheita........................53

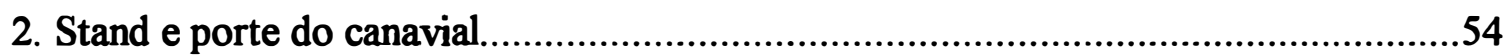

3. Média estimada em kg/ha de massa total em pré-colheita.........................................54

4. Resultados médios dimensionais e ponderais obtidos nos tratamentos. ......................56

5. Comparação de médias de densidade de matéria-prima através do teste $T$..................56

6. Comparação das médias de quantidade de massa colhida através do teste $T$..............57

7. Parâmetros médios de velocidade efetiva e capacidade efetiva da colhedora...............58

8. Comparação das médias de velocidade $(\mathrm{km} / \mathrm{h})$ através do teste $T$............................59

9. Comparação das médias de capacidade efetiva através do teste $T$...............................61

10. Valores percentuais médios dos componentes de massa colhida...............................63

11. Comparação das médias percentuais de colmos através do teste $T$...........................65

12. Comparação entre médias de matéria estranha vegetal através do teste T................66

13. Confronto entre as médias de matéria estranha mineral através do teste $T$................68

14. Comparação entre médias de matéria estranha total através do teste $T$......................70

15. Resultados médios das análises tecnológicas......................................................72

16. Comparação de médias de brix (\%) através do teste $T$..............................................73

17. Comparação de médias de pol (\%) através do teste T..............................................74

18. Comparação de médias de pureza (\%) através do teste T.......................................75

19. Comparação de médias de fibra (\%) através do teste T.............................................76

20. Confronto de pol (\%) de cana corrigido através do teste $\mathrm{T}$......................................78

21. Valores totais médios calculados de açúcar por unidade de área................................80

22. Quantificação das perdas no campo em pós-colheita.................................................81

23. Comparação de médias de perdas em pós-colheita através do teste $T$.......................82

24. Comparação de médias de perdas de toco em pós-colheita através do teste T...........83

25. Comparação das médias de perdas em frações de colmo em pós-colheita através do teste $\mathrm{T}$. 
26. Comparação de médias de rebolos em pós-colheita através do teste T...................86

27. Comparação de médias de perdas totais através do teste $\mathrm{T}$................................87

28. Componentes de perdas no campo, respectivas análises tecnológicas (PCC) e as perdas totais em açúcar no campo.............................................................89

29. Totais de açúcar entregues na usina e perdidos no campo..... . ...........................90

30. Comparação de médias de resíduos de pós-colheita através do teste T..................91

31. Resultados percentuais de umidade nos diferentes componentes dos resíduos .........93

32. Determinação de energia contida no resíduo pós-colheita (PCS) ...........................94 


\title{
COLHEDORA DE CANA-DE-AÇÚCAR(Saccharum spp) AVALIAÇÃo
}

\section{EM CANAVIAIS COM E SEM QUEIMA PRÉVIA}

\author{
Autor: Victório Laerte Furlani Neto \\ Orientador: Prof. Assoc. Nilson Augusto Villa Nova
}

\section{RESUMO}

A prática consagrada da queima de pré-colheita na cultura canavieira e a adoção de máquinas para realizar a operação de colheita, nessa cultura, vem sendo bastante incrementada, principalmente no Estado de São Paulo.

O objetivo do presente trabalho, desenvolvido na safra 93-94 na região de Ribeirão Preto - Estado de São Paulo, foi o de avaliar o desempenho operacional da colhedora de cana-de-açúcar Santal Amazón em cana crua e queimada, em duas variedades : SP71-1406 e SP71-6163 e suas interações com a qualidade da matéria-prima colhida, perdas de matérial industrializável no campo, determinações das massas e energia contida nos resíduos de pós colheita.

A análise e interpretação dos resultados obtidos permitiram as seguintes conclusões:

- O sistema de colheita mecânica da cana crua foi plenamente viável, pois embora resultem numa diminuição no rendimento de corte, apresentam como vantagens melhoria 
na qualidade tecnológica, diminuição nas impurezas minerais, conservação do resíduo pós colheita sobre o solo e evitando uma perda energética pela queima dos canaviais.

- O componente do colmo que teve sua massa, mais reduzida pela queima do canavial, foram as folhas, representando uma redução de $5.423 \mathrm{~kg} / \mathrm{ha}$ para a SP711406 e de $14.066 \mathrm{~kg} /$ ha para a SP71-6163.

- O aumento na velocidade da colhedora resultou em decréscimos significativos no pol( \%) cana corrigida ( PCC ).

- Os aumentos na densidade de matéria prima e fibra(\%) nas cargas foram inversamente significativos à velocidade de deslocamento da colhedora.

- A queima do canavial resultou aumentos significativos na velocidade de deslocamento $(+18,36 \%)$, e na capacidade efetiva da colheita $(+15,60 \%)$.

- A qualidade tecnológica do brix caldo, pol caldo e fibra foram significativamente superiores para a cana crua .

- Na SP71-1406 houve um acréscimo de 0,54\% na qualidade do PCC e de $601,4 \mathrm{~kg}$ de pol/ha para a cana crua, sendo na SP71-6163 reduzido de 0,53\% na PCC , resultando em $44 \mathrm{~kg}$ pol/ha para a cana crua.

- As perdas em cana crua após a colheita na SP71-1406 foram bem maiores que a cana queimada, ocasionadas por todos os componentes de perdas avaliados: ponta, tocos e rebolos. Para a SP71-6163 não houveram diferenças entre o total de cana.

- Na variedade SP71-6163, os acréscimos de resíduos em pós-colheita, propiciado pela cana crua foram bem superiores à SP71-1406, obtendo-se os seguintes 
valores percentuais de acréscimos em relação à cana-queimada: 67,01\% na SP71-1406 e de $137,27 \%$ na variedade SP71-6163.

- O potencial energético total de resíduo sobre o terreno é uma função varietal, obtendo sempre maiores valores para a variedade SP71-6163, independentemente do tipo de cana: crua ou queimada.

- A queima do canavial promoveu uma perda energética de $(39,2 \%)$ 23.143 Mcal/ha para a SP71-1406 e de $67.341 \mathrm{Mcal} / \mathrm{ha}(59,4 \%)$ para a SP71-6163 em (PCS) Poder Calorífico Superior. 


\title{
THE SUGAR CANE HARVEST (Saccharum spp) VALIATION \\ IN GREEN AND BURNING CANE CONDITIONS
}

\section{Author: Victório Laerte Furlani Neto}

\author{
Adviser: Prof. Assoc. Nilson Augusto Villa Nova
}

\section{SUMMARY}

The traditional practice to burn sugar cane fields before - harvest is being contested by Society and Officials organizations in Brazil. The damage to the environment is the reason of this mobilization.

By the other hands the adoption of modern equipment is remarkable in São Paulo State (Brazil).

Either the elimination of burning practices and the use of machinery in substitution of manual cut, will modify dramatically the sugar cane technology in field and industry.

The aim of this wok was to evaluate the operational performance of Santal Amazon sugar-cane harvester, in green and burning cane conditions. The work was developed in Ribeirão Preto region (São Paulo State), with SP71-1406 e SP71-6163 varieties, in 1993/1994 harvesting season. The follow parameters has sampled: 
technological quality of the raw material, losses in field (mass and quality) and residual energy remained in field (Mcal/ha).

Conclusions.

-The leaf reducing mass in the buming treatment resulted $5423 \mathrm{~kg} / \mathrm{ha}$ (SP71-1406 variety) and $14066 \mathrm{~kg} / \mathrm{ha}$ (SP71-6163variety).

- The bulk density and mass/ha of harvested material, in green cane, resulted higher then burned cane.

-In green cane treatment was detected significative reduction of operational velocity.

-The increase in velocity causes the decrease in pol\% cane (PPC), bulk density and fiber (\%) of the harvested material.

-The burning practice before harvest, causes a significative increase in harvest velocity $(+18.36 \%)$ and effective capacity $(+15.60 \%)$.

-The residual increments in green cane material was 67,01\% in SP71-1406 and in SP71-6163 variety, $137.27 \%$.

-Independent of green or burning treatment the potential energy of the residual material is function of the variety.

-The burning treatment promoted calorific energy losses of 39,2\% (23143 $\mathrm{Mcal} / \mathrm{ha}$ ) in SP71-1406 variety and in SP-71-6163 59.4\% (67341 Mcal/ha). 


\section{INTRODUÇÃO}

O Brasil se destaca como o maior produtor mundial de cana-de-açúcar, atingindo na safra 92/93 uma área de 4,2 milhões de hectares, produzindo 260 milhões de toneladas de cana-de-açúcar para a fabricação de álcool e de açúcar. No Estado de São Paulo, situa-se a maior parcela da área nacional canavieira, com área cultivada estimada em 2,0 milhões de hectares, com uma produção de 154 milhões de toneladas, com a produtividade média por hectare de 77,0 toneladas (AEB, 1992).

O processo de colheita mecanizada no Brasil ainda não atingiu níveis importantes em termos de área quando comparada com outros países. No Estado de São Paulo, conforme trabalho de VEIGA FILHO et al. (1994), estimando-se que no ano 2.000 , uma colheita mecanizada em $60 \%$ da área de produção total de 68,6 milhões de toneladas de cana-de-açúcar, haverá uma substituição gradual de mão de obra que iniciará com $18 \%$ na safra $94 / 95$ e terminaria na ordem de $55,1 \%$ para o ano 2.000 .

Embora não existam levantamentos sistematizados do total de área colhida mecanicamente no Brasil , para o estado de São Paulo, os levantamentos realizados sobre este índice de mecanização na região de Ribeirão Preto, indicam entre $20 \%$ e $30 \%$ (CANA, 1992) e para o estado índices em torno de 10 e 15\% para o ano de 1992.

Sabe-se também que algumas usinas já atingiram valores elevados no uso de colhedoras mecanizadas da cana-de-açúcar, como o caso da Usina da Barra, na safra 
92/93, com 50\% produção (JOHN, 1992), Usina São Martinho, com $85 \%$ da cana moída de um total de 5 milhões de toneladas (LIMA, 1994), Usina Santa Elisa com 35\%, Usina Santa Lydia com $41 \%$, Usina da Pedra, com 65\%, Usina Guarani e Cruz Alta com 35\% colhidos mecanicamente (CANA, 1992).

Verifica-se portanto, que a colheita mecânica de cana-de-açúcar nos dias atuais, é uma realidade dentro da agroindústria brasileira, assumindo então uma importância relevante os estudos e pesquisas realizadas com o tema proposto que consiste na interação entre máquina-planta-solo no processo produtivo da cana-deaçúcar, principalmente na colheita da cana sem a queima prévia.

Com toda esta exigência de matéria prima para a fabricação de açúcar e álcool, surge o corte mecânico da cana-crua, como um processo de aproveitamento energético de todo o material vegetal produzido pela cultura da cana-de-açúcar: ponteiros, folhas e palhas, praticamente destruídos pela queima prévia nos canaviais à serem cortados, que associados aos aspectos ligados ao meio ambiente citados por KIRCHHOFF (1991) e VEIGA FILHO et al.(1994), e aos problemas sócio-econômicos do corte manual da cana-crua surge no Brasil, apresentando os mais variados pontos de vista agrícola, mecânico, industrial, ambientalista, econômico e social, com os prós e contras a sua utilização.

O presente trabalho tem por objetivo geral de avaliar a validade desta hipótese do carte mecanizado de cana-crua e queimada e suas interações entre máquinaplanta-solo nos processos de colheita mecânica da cana-de-açúcar. Para todos os parâmetros avaliados, foram analisados pelo Teste $\mathrm{T}$, conforme as hipóteses: 
Como hipóteses para “ TIPO DE CAMPO”, foram testados:

Ho: Campo 1 = Campo 2

Ha: Campo 1 \# Campo 2

Para "TIPOS DE CANA", as hipóteses foram:

Ho: Cana Queimada $=$ Cana Crua

Ha: Cana Queimada \# Cana Crua

As interações possiveis entre os niveis de fatores, as hipóteses foram:

Ho: inexistência de interação

Ha: Existência de interação 


\section{REVISÃO BIBLIOGRÁFICA}

\subsection{Colheita da cana-de-açúcar \\ 2.1.1. Considerações Gerais}

A queima prévia do canavial, para facilitar o corte da cana-de-açúcar, constitui-se uma prática tradicional, visando a eliminação de folhas e palhas (AZZI-1967; FURLANI-1984; RIPOLI-1991), resultou em aumentos nos desempenhos dos sistemas semi-mecanizado e mecanizado de colheita.

Conforme levantamento realizado pelo Instituto de Economia Agrícola citado no ANUÁRIO ESTATÍSTICO DO ESTADO DE SÃO PAULO (1992), a área canavieira no Estado de São Paulo aumentou da safra 90 para 91 de $2.6 \%$ em área e de 4.0\% em produção, totalizando 2.165 .100 ha, com uma produção de 143.900 .000 toneladas e produtividade média de $77,2 \mathrm{t} / \mathrm{ha}$.

RIPOLI \& VILLA NOVA (1992) estimando nos 2.2 milhões de hectares de cana no Estado de São Paulo cortados sem a queima prévia, com uma produtividade média de 80 t/ha, nos 1,21 milhões de hectares agricultáveis que ocupam $55 \%$ da área em cana, haveria para a safra, uma necessidade de aproximadamente de 2.581 máquinas (com capacidades de $250 \mathrm{t} /$ cana/dia). Para o corte manual restariam $45 \%$ da área canavieira 
(990 mil hectares) demandando uma projeção de 264.000 homens/dia, com capacidade diária de corte de 2 à 3 toneladas.

A agroindústria sucro-alcooleira representa um índice de $3 \%$ do PIB nacional, dando suporte a mais de 500 empresas de insumos, que geram mais de um milhão de empregos diretos e mais de 300 mil indiretos (agrobusiness). Através da produção de álcool, um total de 12 bilhões de litros de gasolina/ano, movimentando 4,5 milhões de veículos à álcool, reduzindo em $75 \%$ a emissão de chumbo tetraetila, em $57 \%$ o CO e $64 \%$ dos hidrocarbonetos lançados por veículos para a atmosfera, além da vantagem de proporcionar cogeração de energia elétrica.

Segundo BERTELLI (1992) o complexo sucro-alcooleiro nacional é composto por 348 unidades industriais (168 usinas e 180 destilarias), das quais, 245 operam na região Centro - Sul e 103 na região Norte-Nordeste. Somente no Estado de São Paulo estão instaladas 206 unidades industriais (73 usinas e 133 destilarias).

\subsubsection{Colheita em condições diversas}

HUMBERT (1974) relata para o Hawaii o efeito de períodos chuvosos na colheita de cana e concluíu-se, que as chuvas conduzem a uma queima imperfeita dos canaviais resultando num aumento de matéria estranha levada à indústria o que reflem em redução na extração e diminuição na capacidade de moagem .

Conforme FURLANI (1984) os desempenhos obtidos para o corte manual da cana crua para plantio (sem amarração) tem variado de 2.5 à 3.5 t/homem-dia, 
enquanto que para cana queimada, o corte manual de cana disposta em montes tem variado de 5.0 à 7.0 t/ homem-dia e o corte manual em cana queimada, disposta no terreno em esteira contínua e despontada nas leiras, apresentam valores da ordem de 7.0 à $8.0 \mathrm{t} /$ homem-dia.

Em Porto Rico, SAMUELS (1969) observou que as variedades de despalha mais dificil, conduziram a valores mais elevados de matéria estranha vegetal. As percentagens de matéria estranha mineral e total foram maiores nas variedades mais tombadas que nas eretas e maiores ainda em variedades que apresentaram canas tortas, onde ocorre a formação de galerias nas cargas provenientes do carregamento mecânico.

Trabalhos realizados por AZZI (1967), FERNANDES \& OLIVEIRA (1977), FURLANI (1984) comparando o sistema semi-mecanizado (corte manual com carregamento mecânico) operando sob formas diferenciadas de deposição dos colmos sobre o terreno, permitiram concluir que a prática de colmos em montes sempre apresentou os menores índices de matéria estranha mineral em relação a deposição em leiras contínuas. Os autores concluiram também que a percentagem de presença de terra nas cargas em todas as opções de carregamento mecânico, foram diretamente proporcionais ao teor de umidade nos solos .

\subsubsection{Colheita de cana sem queima prévia}

\subsubsection{Colheita manual de cana crua}


A ocorrência de resíduos de colheita de cana crua no terreno traz dificuldades para a adequada localização do fertilizante, principalmente por requerer um cultivador-adubador que corte o palhiço residual. A adubação nitrogenada em subsuperficie, abaixo do resíduo de pós colheita é a operação mais dificultada (ORLANDO FILHO, 1994).

AYRES \& HAGIHARA (1963) verificaram que o aproveitamento do nitrogênio pela cana-de-açúcar é de aproximadamente $50 \%$ do total aplicado, sendo que PARISH (1965), atribui esta baixa eficácia à volatilização de amônia, lixiviação, desnitrificação e fixação biológica ou física, indicando a necessidade de estudos para melhor aproveitamento do $\mathrm{N}$ pelas plantas cultivadas.

TAKAHASHI (1970) observou que as perdas de $\mathrm{N}$ à partir do sulfato de amônio foram devidas principalmente à volatilização e desnitrificação. As perdas por volatilização são acentuadas quando não incorporadas ao solo.

$\mathrm{Na}$ África do Sul, THOMPSON (1969) determinou a seguinte quantidade de nutrientes no palhiço de 100 toneladas de cana:

$$
\begin{aligned}
& \mathrm{N}=31 \mathrm{~kg} ; \mathrm{P}_{2} \mathrm{O}_{5}=08 \mathrm{~kg} ; \mathrm{K}_{2} \mathrm{O}=42 \mathrm{~kg} ; \mathrm{CaO}=17 \mathrm{~kg} ; \mathrm{Mg} \mathrm{O}=43 \mathrm{~kg} . \\
& \mathrm{O} \text { autor conclui que do ponto de vista nutricional, não houve diferença }
\end{aligned}
$$
entre a queima da palha e a permanência da mesma como " mulch". A queima provocou perdas de nitrogênio, enquanto os demais nutrientes permaneceram quase que totalmente nas cinzas sobre o solo. Não foram observadas diferenças significativas na disponibilidade de $\mathrm{P}, \mathrm{K}, \mathrm{Ca}$ e $\mathrm{Mg}$ no solo onde a palha foi queimada e onde foi deixada na superficie, após 23 anos de cultivo de cana-de-açúcar. 0 teor de matéria orgânica em até $08 \mathrm{~cm}$ de 
profundidade, foi significativamente superior no tratamento que manteve a palha, enquanto a porosidade e densidade global não foram alteradas.

ARNAL (1976) descreve algumas mudanças ocorridas nos solo após as queimadas. Foi observado que em solos siltosos, até a profundidade de $2 \mathrm{~cm}$, a temperatura teve um aumento de até $5^{\circ} \mathrm{C}$ devido a queima do canavial, durante 20 minutos. A uma profundidade de $5 \mathrm{~cm}$ este acréscimo foi de $1,5^{\circ} \mathrm{C}$ durante 45 minutos, o que segundo o autor é insignificante.

DEGASPARI et al. (1983) determinaram, durante a queima do canavial, as temperaturas externas (normal), no interior do colmo (região do palmito) e no solo entre 3 e $5 \mathrm{~mm}$ de profundidade, através de pares termoelétricos, ligados a um registrador. Os valores médios obtidos em duas variedades de cana-de-açúcar, confimam os obtidos por ARNAL (1976).

Um dos trabalhos clássicos de relação $\mathrm{C} / \mathrm{N}$ em cana crua e queimada é o de WOOD (1966) na África do Sul, que observou que a presença de material não decomposto, com baixo teor de $\mathrm{N}$, sobre o solo cultivado com cana-de-açúcar ou incorporado ao mesmo. Resultou-se uma competição entre os microrganismos do solo e as plantas pelo nitrogênio, sendo mais acentuada no início de brotação do canavial, necessitando algumas complementações desse elemento para o solo manter o equilíbrio da relação $\mathbf{C} / \mathbf{N}$.

Segundo PEARSON (1960) com a conservação da matéria orgânica na superficie do solo, pode-se esperar aumentos de produtividades à partir da $2^{\mathrm{a}}$ soca da cultura, exceto onde ocorrer má drenagem ou excessos de matéria orgânica. Este 
aumento é causado pela decomposição do palhiço do $1^{\circ}$ corte mais o palhiço do $2^{\circ}$ corte sobre a produtividade do $3^{\circ}$ corte, principalmente, devido ao aumento da matéria orgânica nos solos. $\mathrm{O}$ autor também comenta $\mathrm{o}$ efeito do controle das ervas invasoras devido ao impedimento à fotossíntese pelas ervas, reduzindo o seu desenvolvimento. Tais afirmações são confirmadas por MUZIK (1970) CRAFTS (1975), e LORENZZI et al. (1989).

De acordo com SAMUELS (1969) em Porto Rico, a composição, em peso seco, da cana-de-açúcar, de 12 meses foi:

$$
\text { Cana }=49 \% ; \text { Pontas Verdes }=9 \% ; \text { Palhas }=25 \% ; \text { Tocos }=4 \% \text { e Raízes }=13 \%
$$

No Brasil, trabalhos com a variedade CB 41-76, citado pelo Ministério das Minas e Energia/Eletrobrás (1983) demonstraram que tanto para a cana-planta, como para cana-soca, as quantidades de nutrientes exportados por produção relativa e $100 \mathrm{t}$ de colmos e folhas, expressos em $\mathrm{kg} / 100 \mathrm{t}$ de peso verde, foram:

cana - planta cana - soca

kg de Elemento / $100 \mathrm{t}$ de colmos verdes

\begin{tabular}{lllll}
\hline macronutrientes & colmos & folhas & colmos & folhas \\
\hline Nitrogênio & 92 & 62 & 73 & 58 \\
Fósforo & 10 & 08 & 13 & 08 \\
Potássio & 64 & 89 & 71 & 102 \\
Cálcio & 59 & 48 & 35 & 32 \\
Magnésio & 34 & 17 & 31 & 14 \\
Enxofre & 28 & 19 & 23 & 16 \\
\hline
\end{tabular}


Uma comparação entre os sistemas de cana crua e queimada, foi realizada por BODDEY et al. (1993) na Usina Cruangi, no Estado de Pemambuco no período de 1986 à 1992, com a variedade CB35-3. O efeito prejudicial da queima foi detectado na produtividade agrícola à partir da $2^{\mathrm{a}}$ soca até $6^{\mathrm{a}}$ soca, onde concluiu-se que, à partir da segunda soca (1988) até o final do trabalho (1992), com a exceção de 1990, o corte da cana crua apresentou resultado significativo $(p=0.05)$ em cada colheita subsequente em relação à cana queimada, onde apresentou os seguintes percentuais comparativos por ano:

$1986=-5,3 ; 1987=+12,8 ; 1988=+23,5 ; 1989=+13,6 ; 1990=+11,3 ; 1991=+25,4$ e $1992=+57,2 \%$.

Com relação a fertilidade nos solos devido à incorporação do palhiço, para todos os elementos nutricionais, foram realizadas análises de 0-20, 20-40 e 40 à 60 $\mathrm{cm}$ de profundidade de solo. $\mathrm{O}$ único elemento que apresentou incremento na área de cana crua comparada com a queimada, foi o nitrogênio (abaixo da palhada), nos 8 cortes com, um acréscimo de $43,3 \mathrm{~g} / \mathrm{m}^{3}$ no horizonte de $0-20 \mathrm{~cm}$. Os autores concluem que a prática de queima da cana antes da colheita, prejudica a produtividade da cana-de-açúcar, o nível de matéria orgânica e o nitrogênio do solo, a longo prazo. A colheita manual da cana sem queima prévia já está sendo realizado a mais de 30 anos na totalidade das áreas canavieiras da Usina Cruangi, onde a precipitação pluviométrica anual é de $1.000 \mathrm{~mm}$, e a produtividade média dos canaviais é de cerca de $70 \mathrm{t} / \mathrm{ha}$, bem acima da média de outras unidades sujeitas ao mesmo regime hídrico. 
De acordo com TILLMANN (1994) durante a safra de 91/92 o Brasil se destacou mundialmente como um dos maiores produtores mundiais de cana-de-açúcar, com 4,2 milhões de hectares, produzindo 260 milhões de toneladas de cana-de-açúcar para a fabricação de álcool e açúcar. Em estudo realizado em corte manual de cana crua e queimada, em duas variedades (SP70-6163 e SP71-1406), o autor conclui que tanto o desempenho operacional como o econômico da colheita sem queima prévia, foram significativamente inferiores aos verificados para a cana queimada, sendo que, em termos energéticos e conservacionistas, a prática de colheita em cana crua, aumentou significativamente a quantidade de resíduos sobre o solo. $\mathrm{O}$ carregamento na condição de cana crua proporcionou elevados índices de matéria estranha mineral e vegetal junto à matéria prima industrializável.

\begin{tabular}{|c|c|c|c|c|}
\hline \multirow[t]{2}{*}{ Áreas } & \multicolumn{2}{|c|}{ Imp.Vegetais (\%) } & \multicolumn{2}{|c|}{ Imp. minerais (\%) } \\
\hline & $\mathrm{CC}$ & $\mathrm{CQ}$ & $\mathrm{CC}$ & $\mathrm{CQ}$ \\
\hline A & 15,00 & 7,97 & 0,61 & 0,33 \\
\hline B & 15,40 & 6,90 & 1,13 & 0,24 \\
\hline
\end{tabular}

Fonte: TILLMANN,1994 (DISS.MESTRADO-ESALQ/USP)

$C C=$ cana-crua $; C Q=$ cana queimada

As conclusões foram:

- O sistema semi-mecanizado em cana queimada apresentou os melhores desempenhos no corte, no carregamento e no transporte . 
- O corte manual de cana crua, apresentou maiores índices de perdas de matéria-prima industrializável, em relação à cana queimada.

- O corte manual da cana crua aumentou a quantidade de resíduos sobre o solo em $140 \%$, quando comparado ao sistema de colheita em cana queimada.

- A cana crua, acarretou na matéria-prima maiores índices minerais de $232 \%$ e de $40 \%$ na impureza vegetal, quando comparados ao sistema de cana queimada.

- O sistema de colheita semi-mecanizado em cana queimada apresentou um desempenho econômico aproximado de $20 \%$ superior ao verificado em cana-crua.

FERRARI et al. (1980) recomenda que para diminuir-se a matéria estranha vegetal nas cargas, deve-se ter o cuidado, no corte manual da cana crua, em limpar a superficie do terreno onde será depositado os montes para posterior carregamento, obrigando o cortador a realizar o desponte dos colmos fora do alinhamento da deposição dos colmos no eito.

\subsubsection{Colheita mecânica de cana crua}

As cortadoras de cana inteira existentes no mercado mundial não separam adequadamente, as folhas verdes e secas, em face a esse aspecto recomenda-se a utilização dessas máquinas somente em canaviais queimados. $\mathrm{O}$ corte mecânico de cana inteira e crua pode ser recomendado apenas para obtenção de cana-planta. Na Louisiana, a totalidade dos canaviais é cortado no sistema de cana crua, constituindo uma exceção 
em relação ao que ocorre no Brasil. Os colmos após o corte pela cortadora, ficam dispostos em esteiras contínuas e a queima de folhas e palhas é então realizada. Dessa forma as linhas de cana estando em camaleões, permitem uma melhor ventilação e conseqüente melhor queima das folhas e palhas (FURLANI NETO, 1984). As colhedoras recolhem o material cortado pelo despontador e corte de base para dentro da máquina onde os colmos são picados em rebolos, sendo a matéria estranha vegetal eliminada parcialmente através de ventilação ou exaustão, enquanto os colmos picados são conduzidos, através de taliscas e correntes ou rotores-lançadores, sobre veículos de transporte com carrocerias teladas ou fechadas.

FURLANI NETO et al. (1989) com o objetivo de avaliar o desempenho operacional da colheita mecânica em canaviais com e sem a queima e com e sem a utilização de dessecante PARAQUAT (2,0 litros em 40 litros de calda/ha em aplicação aérea), na variedade SP71-1406 de $2^{\circ}$ corte, demonstraram que os melhores desempenhos da colhedora SANTAL - Rotor IV, foram em cana queimada, independente do uso ou não de dessecante. A capacidade efetiva da colhedora em cana crua, foi de $57,16 \mathrm{t} / \mathrm{h}$ o que representa $95.6 \%$ do resultado obtido em cana queimada $(59,82 \mathrm{t} / \mathrm{h})$. Não foi observado, ainda, influência do dessecante ou da queima na qualidade tecnológica da matéria prima, bem como para as perdas de matéria prima no campo. A colheita da cana crua deixou sobre o terreno resíduos (massa verde) da ordem de 10,39 e 11,96 t/ha, respectivamente para com ou sem a aplicação do dessecante. A umidade dos resíduos foram de 17,3 (com dessecante) e $36,7 \%$ (sem dessecante). 
De acordo com LIMA (1994), os custos finais dos sistemas de corte manual e mecânico, na safra 93/94 para a cana queimada na Usina S.Martinho Pradópolis -S.P. foram:

a) colheita semi-mecanizada..(corte manual carregamento mecânico) $\mathrm{R} \$ 3,00 / \mathrm{t}$.

b) colheita mecanizada. $R \$ 1,65 / t$.

O autor apresenta, ainda, as planilhas finais da safra 1993/1994, onde comparam-se as capacidades operacionais, consumos, caracterização da matéria prima colhida e perdas de matéria prima no campo entre a cana queimada e a cana crua, colhidas com a colhedora ENGEAGRO:

\section{CANA QUEIMADA - ENGEAGRO E-6.000}

desempenho operacional

toneladas/máquina./safra.......95.000

toneladas/maquina/ dia .550 15

tonelagem/viagem. consumo (litros/t ) diesel............. .......... 0.731

óleo hidráulico... .0 .0101 
parâmetros/matéria prima

perdas de cana/campo ( $\mathrm{t} / \mathrm{ha})$

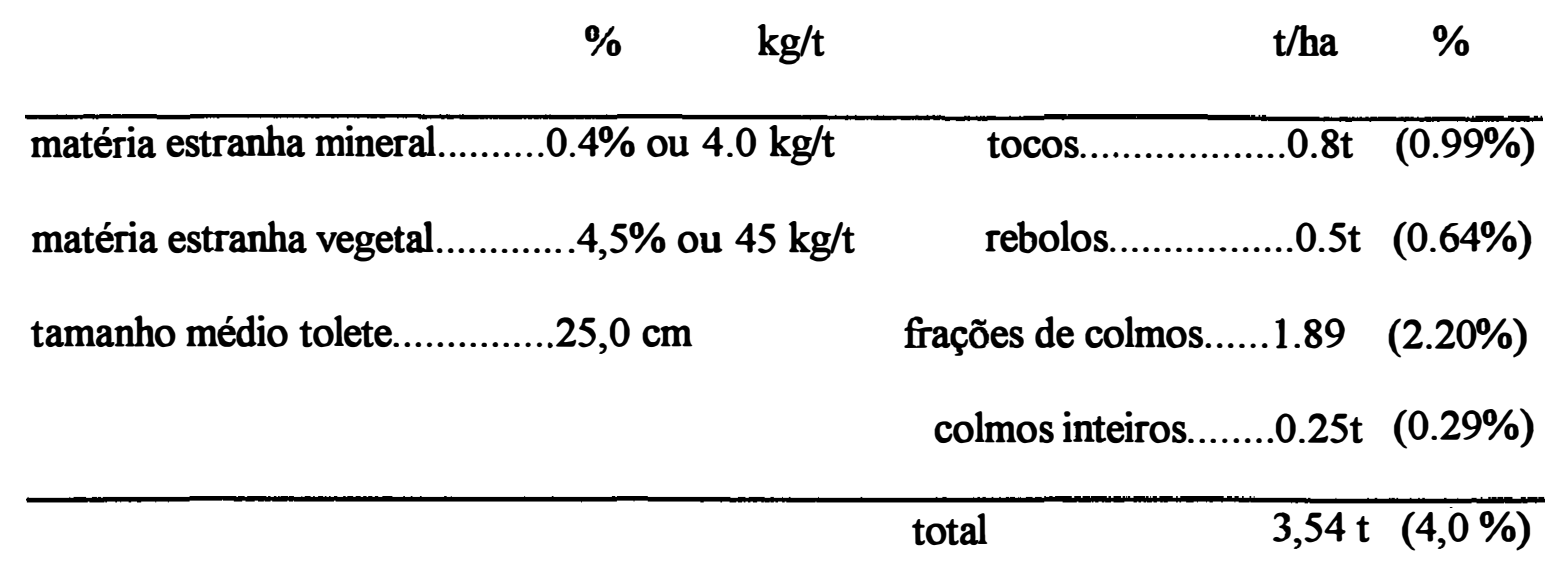

CANA CRUA - ENGEAGRO - E-8.000

\begin{tabular}{|c|c|}
\hline Desempenho & Consumo (litros/t ) \\
\hline tonelagem/maquina/dia $\ldots \ldots \ldots \ldots \ldots \ldots \ldots \ldots . . .500 .0$ & diesel................. \\
\hline tonelagem/viagem..... & óleo hidráulico...0,0151 \\
\hline
\end{tabular}

\begin{tabular}{lcc}
\hline matéria estranha & $\%$ & $\mathrm{~kg} / \mathrm{t}$ \\
\hline minerais.. & 0,2 & 2. \\
impurezas vegetais & 5,5 & 55 \\
\hline
\end{tabular}




\begin{tabular}{|c|c|c|}
\hline \multicolumn{3}{|c|}{ Perdas de matéria prima no campo } \\
\hline componente & $\mathrm{t} / \mathrm{ha}$ & $\%$ \\
\hline tocos........................ & $\ldots \ldots \ldots . .0, .67$ & 0,82 \\
\hline rebolos...................... & ..........1,22 & 1,49 \\
\hline frações de colmos & $.1,77$ & 2,16 \\
\hline colmos inteiros & $.0,20$ & 0.24 \\
\hline TOTAL & 3,86 & 4,71 \\
\hline
\end{tabular}

Conforme citado por JOHN (1992) na safra 93/94 foram colhidas na Usina São Francisco cerca de 25.000 t de cana sem queima com a colhedora Santal Rotor, protótipo do atual modelo AMAZÓN, motivo da presente pesquisa. $\mathrm{O}$ autor afirma que a colhedora apresentou um índice médio de matéria estranha mineral, nas cargas, de 0.3 a $2.0 \mathrm{~kg}$ por tonelada de cana, bem abaixo do encontrado, em média, para o corte semimecanizado, que variou de 7,0 à $10 \mathrm{~kg}$ por tonelada de cana. Os índices de matéria estranha vegetal foram 1,0 à $2,0 \%$ maior que os encontrados no sistema semimecanizado. $\mathrm{O}$ autor afirma que a cana chegou mais limpa à indústria, o que permite a eliminação da lavagem industrial, o que resulta em uma economia de 20 à $25 \%$ nos custos industriais. No sistema de colheita mecânica da cana crua, as folhas e palhas eliminadas pela colhedora, permanecem no campo, formando uma camada de $20 \mathrm{~cm}$ de altura, através das quais as canas rebrotam e as ervas daninhas não conseguem desenvolver-se. 
Informa, por fim que a Usina está tendo uma economia final em redor de $10 \%$ em relação à cana queimada devido a não utilização de herbicidas nas soqueiras.

RIPOLI \& VILLA NOVA (1992), relatam que a colheita em cana crua evita desperdício da energia contida no palhiço (pontas, folhas verdes e palhas), o qual representa, em média, $32.5 \%$ da biomassa total do canavial. Os autores citam algumas vantagens e desvantagens do sistema de cana crua:

a) do ponto de vista agronômico, quando o palhiço decorrente deste processo permanece sobre o terreno, há os seguintes beneficios:

-diminuição ou até eliminação do uso de herbicidas;

-aumento e manutenção do grau de umidade do solo;

-eficiente mecanismo de controle da erosão;

-aumento da quantidade de matéria orgânica no solo;

-redução da população de nematoides nocivos e

-não destrói os inimigos naturais da broca.

b) sob o ponto de vista industrial, serão obtidos reflexos positivos em termos de menores perdas de sacarose, diminuição dos problemas de tratamento de águas de lavagem e no aproveitamento parcial do palhiço, que associado ao bagaço poderá ser utilizado na cogeração de energia elétrica pelas unidades industriais sucro-alcooleiras.

As desvantagens da colheita em cana crua são:

-aumento do esforço fisico dos cortadores ;

-aumento dos riscos de acidentes ocupacionais;

-redução no desempenho operacional de corte manual diário; 
-aumento nos custos da tonelada cortada;

-aumento de matéria estranha vegetal;

-aumento nas perdas de matéria prima no campo;

-aumento de focos de doenças e pragas no canavial;

-exigência de modificações nos implementos e máquinas de cultivo e adubação e

-grandes riscos de incêndios acidentais ou propositais durante todo o ano.

ABRAMO FILHO et al. (1993) estudando os resíduos da colheita mecanizada em cana crua, para a variedade SP71-6163, determinaram que o resíduo pós colheita caracterizado pelos ponteiros e palhas foi de $21,3 \mathrm{t} / \mathrm{ha}$ (peso úmido) e15.1 t/ha (peso seco), e que, os efeitos da palha deixada como cobertura promovem:

- menor temperatura do solo sob a palha, em comparação com o solo desnudo;

- maior manutenção da umidade do solo;

- retardamento da brotação da soqueira que, todavia, pode ser uma questão varietal;

- controle de uma grande parte das ervas invasoras;

- possível aumento de pragas e

- maior teor de matéria orgânica nos solos. 


\subsection{Compactação dos solos}

Segundo BALBO (1994) um problema que está prestes a ser solucionado na colheita mecanizada é a compactação causada pelas colhedoras e por caminhões de transporte. As colhedoras pesam cerca de $13 \mathrm{t} \mathrm{e} \mathrm{o} \mathrm{veículo} 23 \mathrm{t}$. $\mathrm{O}$ ideal para a atenuação da compactação nos solos agrícolas, seria o uso de pneus de alta flutuação, tanto nos veículos de transporte, como nas colhedoras, semelhante aos utilizados na Austrália e Estados Unidos com $220 \mathrm{~kg} / \mathrm{m}^{2}$. O mercado brasileiro fornece pneus com pressão nos solos de $450 \mathrm{~kg} / \mathrm{m}^{2}$.

Como vantagens do sistema de colheita em cana crua, o autor cita:

- a palhada deixada após a colheita melhora a estrutura física do solo,

- acumula nutrientes e melhora a retenção de água no solo;

- a população quantidade de anelídeos aumenta-se de três a quatro vezes;

- o risco de erosão é nulo, permitindo a sulcação reta;

- diminui a insolação sobre o solo descoberto;

- aumenta-se a atividade microbiana do solo e

- elimina-se o uso de herbicidas nas soqueiras.

A compactação dos solos agrícolas pode ocorrer, principalmente, pelo tráfego de máquinas, que exercem pressão ou desfazem seus agregados estruturais, conforme citam os autores: VOMICIL \& FLOCKER (1965), VOORHEES et al. (1978). A compactação do solo modifica a densidade do solo, parâmetro muito usado para caracterizá-la, segundo ROSENBERG \& WILLITS (1962), GROHMANN \& QUEIROZ 
NETO (1966), ou reduzindo a quantidade de macroporos, segundo LAWTON (1945), ou reduzindo a condutividade hidráulica saturada, conforme ROSEMBERG \& WILLETS (1962), SILVA et al. (1977) e. BELTRAMI et al. (1981), observaram que os efeitos da compactação são maiores em solos argilosos que em arenosos.

Usando-se um penetrógrafo conforme os trabalhos de PRIMAVESI et al. (1984) pode-se detectar variações na densidade de um mesmo solo, sendo que segundo os autores, o ideal para a determinação da compactação dos solos, seria o uso da percentagem de poros de aeração ou macroporos efetivos.

STOLF (1991) definiu para o Penetrômetro de Impacto, uma nova forma de apresentação da compactação dos solos agrícolas, transformando os dados de "impactos por decímetro para $\mathrm{kg} / \mathrm{cm}^{2}$ ", permitindo comparar os dados do penetrômetro com os utilizados em outros métodos para determinação de densidade aparente ( global) de um perfil de solo, sem a necessidade de uso de trincheiras, tornando-o num método mais rápido, prático e menos oneroso .

\subsection{Tipo de colheita e implicações industriais}

STUPIELLO (1989), destacando alguns aspectos importantes ligados à qualidade da matéria-prima, comparou diferentes horários de queima, denominados: "à quente" quando é feita das 12 às 16 horas e "à frio" das 19 às 7 horas. 0 autor verificou que a queima "à frio", proporciona uma vantagem em termos de qualidade da matéria 
prima, de deterioração após a queirna, devido menor atividade microbiológica nas rachaduras provocadas nas casca dos colmos.

NOA (1992) relata a importância da biomassa associada às folhas e palhas, obtida à partir da colheita de cana crua em Cuba. 0 autor informa que já está em $90 \%$ o total das áreas cultivadas, sendo $74 \%$ em colheita mecanizada. Uma quantidade do palhiço é mantida sobre o terreno para o controle de ervas invasoras e manutenção da umidade do solo. Outra parte do palhiço é recolhida do campo e utilizada como combustível em caldeiras, na produção de bio-fertilizantes ou ainda como alimento para 0 . gado.

Os valores percentuais das pontas e folhas são os seguintes:

matéria seca $=26,00$; açúcares totais $=2,18$; sacarose $=0$; fibras $=19,80$; cinzas $=2,31$; água $=74,00$; outros componentes $=2,43$.

CHURCHWARD \& POULSEN (1988) citam as vantagens da cana crua, principalmente as voltadas para a área agrícola : controle do mato; conservação da umidade; economia no cultivo; melhor perfilhamento e brotação da socas, além de permitir o tráfico de veículos sem prejuízos acentuados ao solo.

Com o objetivo de analisar o efeito da matéria estranha mineral sobre o comportamento das características tecnológicas da cana-de-açúcar quando se utiliza o sistema de pagamento pela qualidade, MUTTON et al. (1992) estudaram os parâmetros industriais: brix e pol \% caldo, peso do bagaço, fibra, pol \% cana, pol \% cana corrigido e valorização da matéria-prima em ágio e ou deságio. Os autores concluíram que para valores elevados de matéria estranha mineral, maiores que $4 \%$, ocorre a depreciação do 
preço da matéria-prima. $\mathbf{O}$ mesmo deságio ocorre quando eleva-se a matéria estranha vegetal, principalmente para fibra na matéria prima, reduzindo significativamente os valores de pol \% cana corrigido.

Segundo STUPIELO (1982) a qualidade da matéria prima industrial é comprometida pela quantidade de matéria estranha carreadas com os colmos da cana-deaçúcar em conseqüência das etapas de colheita. A quantidade delas, minerais e vegetais são afetadas pelas condições climáticas reinantes, prejudicando a queima ou a limpeza pelos extratores das colhedoras. Esse material estranho, além de afetar a qualidade da matéria prima, ocasiona desgastes industriais, obrigando as usinas a lavarem os colmos inteiros, antes da moagem. Com isto ocorre maior contaminação, por microrganismos, dos colmos através da água de lavagem. Outro problema que decorre do corte da cana picada é a necessidade de moagem imediata ao corte, sem o seu armazenamento na indústria, devido ao aceleramento de deterioração da cana picada pelo microrganismo Leuconostoc dextranicum e mesenteriodes. $\mathrm{O}$ autor, com relação à queima do canavial para o corte, conclui que a queima do canavial não elimina os microrganismos, mas sim provocam rachaduras na casca dos colmos, facilitando a entrada de microrganismos através da terra aderente ao material exudado do colmo durante as fases da colheita. 


\subsection{Poluição ambiental pela queima}

No Estado de São Paulo existe o Decreto Estadual nº 28.895 de 20/09/88, onde no Parágrafo V do Artigo I lê-se: "vedação da queima em uma faixa de um quilômetro do perímetro urbano das cidades".

Preocupadas com o problema, várias instituições tem procurado colher dados sobre o assunto em pauta, dos quais se destacam os levantados pelo INPE com a colaboração da UNESP/Jaboticabal; os estudos realizados pela ESALQ-USP, COPERSUCAR e UFSCar sobre os sistemas de colheita queimada e crua, seus desempenhos, influências da queima na qualidade da matéria prima e poder energético do palhiço residual e seu aproveitamento.

O trabalho do Instituto Nacional de Pesquisas Espaciais iniciou-se na área ambiental em 1978, com VOLKER W.J.H. KIRCHHOFF e sua equipe, efetuando levantamentos de índices de concentração de ozônio em vários ecossistemas naturais no Brasil. Foram usadas técnicas de medida à bordo de balões e foguetes. Foi após a realização de vários trabalhos na Amazônia que amadureceu o interesse pelas queimadas de canaviais.

A principal camada da atmosfera que apresenta interesse ao estudo das queimadas é a denominada troposfera, estando localizada até 15 quilometros de altitude. Os gases denominados de monóxido de carbono $(\mathrm{CO})$, ozônio $\left(\mathrm{O}_{3}\right)$ e óxido nitroso $\left(\mathrm{N}_{2} \mathrm{O}\right)$ são constituintes naturais da atmosfera, que foram produzidos através de reações 
fotoquímicas ou de emissões do solo, vegetação e oceanos, sendo também produzidas por emissões industriais, queimadas, combustão de combustíveis fósseis ,etc.

O ozônio troposférico $\left(\mathrm{O}_{3}\right)$, citado por $\mathrm{KIRCHHOFF} \mathrm{(1991)} \mathrm{é} \mathrm{o} \mathrm{que}$ possue um papel diferente daquele que exerce na estratosfera onde absorve a radiação ultra-violeta proveniente do sol . Na troposfera, o ozônio, em altas concentrações tornase tóxico tanto para o ser humano quanto para a vegetação e animais, sendo também um dos gazes do efeito estufa. As concentrações naturais de ozônio de superficie são de 20 a 40 ppbv (partes por bilhão por volume) e segundo a legislação este limite não poderá ultrapassar 80 ppbv.

Segundo o autor, o monóxido de carbono (CO), através de reação fotoquímica constitue um dos precursores do ozônio troposférico, podendo-se afirmar que "onde houver altas concentrações de $\mathrm{CO}$, na presença de luz solar e óxidos de nitrogênio, haverá produção de ozônio". Os níveis de $\mathrm{CO}$ em ambientes naturais variam de 50 à $150 \mathrm{ppbv}$, enquanto que em regiões poluídas, podem chegar a $1.000 \mathrm{ppbv}$.

Em trabalho realizado por KIRCHHOFF et al. (1991) denominado Projeto Fogo, com o objetivo de estudar o efeito das queimadas da palha da cana-de-açúcar sobre os gases atmosféricos; $\mathrm{O}_{3}, \mathrm{CO}$ e $\mathrm{CO}_{2}$,. onde a coleta dos gases foi realizada a bordo de um avião Bandeirantes, fabricação da EMBRAER, adaptado pelo INPE, que sobrevoando a região canavieira encontrou-se aumentos expressivos nas concentrações de $\mathrm{CO}$ e $\mathrm{O}_{3}$. As coletas foram tomadas em dois períodos distintos: 
a) época seca -( período das queimadas ) atingiu-se 80 ppbv para $\mathrm{O}_{3}$ e 600 ppbv para o CO. b) época chuvosa- onde não havia o fenômeno de queima, os índices foram de $\mathbf{3 0}$ para o 03 e 100 para o CO.

No trabalho coordenado pelo INPE, estima-se que somente no Estado de São Paulo, as queimadas de cana injetam na atmosfera cerca de 350.000 toneladas/safra de carbono na forma de CO. Variações semelhantes para épocas chuvosas e secas foram encontrados por WARNER (1968) em cana -de-açúcar..

Segundo LAURE (1991) os principais gases produzidos nas queimadas são: $\mathrm{CO}, \mathrm{CO}_{2}, \mathrm{O}_{3}$ e $\mathrm{SO}_{2}$, os quais quando encontrados em concentrações elevadas, produzem riscos à vida humana, destacando-se principalmente o $\mathrm{CO}$ e $\mathrm{O}_{3}$, sendo que o primeiro tem uma afinidade para com a hemoglobina 200 vezes maior do que o $\mathrm{O}_{2}$ e para a mioglobina, com afinidade 37 vezes maior que o $\mathrm{O}_{2}$. Quanto ao Ozônio $\left(\mathrm{O}_{3}\right)$, é um dos oxidantes mais poderosos e que pode se tornar um verdadeiro pesadelo, pondo em risco toda a vida sobre o planeta, ao nível do solo.

Em relação às plantas, VOLPI (1991) verificou que a produtividade das plantas diminui com o aumento da concentração do $\mathrm{O}_{3}$, ocasionando os seguintes efeitos: redução da capacidade fotossintética, redução da habilidade dos cloroplastos diminuindo a eficiência fotossintética e indução à clorose e à necrose.

Dentre os gases produzidos, o autor cita que nas queimadas destaca-se $o$ $\mathrm{CO}_{2}$, que é o responsável pelo metabolismo das plantas. Segundo LAURE (1991), a concentração de $\mathrm{CO}_{2}$ aumentou em $26 \%$ num período de 200 anos, passando de 272 ppm 
para $346 \mathrm{ppm}$. A queima dos combustíveis fósseis é a maior fonte de $\mathrm{CO}_{2}$ para a atmosfera .

Os desmatamentos e as queimadas também contribuem para a emissão de $\mathrm{CO}_{2}$ para a atmosfera. $\mathrm{O}$ aumento da concentração de $\mathrm{CO}_{2}$ atmosférico é de grande importância, pois é o principal gás do "EFEITO ESTUFA", do ponto de vista de sua concentração e as interações com as plantas, sabe-se que o dobro de sua concentração acarretam aumentos nas produtividades das plantas.

Nos aspectos da saúde pública ,citado por JOHN (1994), trabalho que contou com o apoio do Núcleo de Monitoramento Ambiental (NMA EMBRAPA) e das faculdades de Medicina e de Saúde Pública da USP, levantamentos de 1990 à 1992, de mais de 170.00 prontuários médicos nos municípios de Campinas, Atibaia, Ribeirão Preto e São José dos Campos no interior do Estado de São Paulo, foram analisados também os dados meteorológicos dos municípios estudados. As baixas temperaturas, umidade elevada e ventos, são causas naturais determinantes de doenças respiratórias. Dentre as quatro municípios estudados, Campinas foi a que apresentou os piores resultados, com doenças respiratórias representando $6,31 \%$ do total de atendimentos, sendo seguido por São José dos Campos com 4,27\%, posteriormente por Atibaia com $1,80 \%$ e por último Ribeirão Preto com $1,58 \%$.Estes resultados contradizem os resultados de FRANCO (1992).

Conforme JOHN (1994) num estudo anterior, no Estado de São Paulo as doenças respiratórias correspondiam à $12,0 \%$ do total de atendimento, graças a inclusão da capital, onde o nível de poluição é considerado como primário pelos padrões da 
CETESB; primário implica risco à saúde. $\mathrm{O}$ autor cita também as palavras do Dr. Paulo Saldiva, médico e sanitarista do Laboratório de Poluição Ambiental da Faculdade de Medicina da USP: “A grande surpresa foi a condição de Ribeirão Preto, que esperava-se estar bem pior devido a queima dos canaviais junto à cidade”.

Conforme citado por FRANCO (1992), em levantamento realizado das cinco principais causas de altas hospitalares de trinta e cinco hospitais, em vinte e uma cidades da região canavieira de Ribeirão Preto realizados pelo Departamento de Medicina Social da FMRP/USP-(Convênio Secretaria de Estado da Saúde do Estado de São Paulo), concluem que as doenças do sistema respiratório nos meses iniciados coincidentes com o início da safra canavieira, apresentam diferenças nítidas de elevação das internações por problemas respiratórios nos anos de 1988 (15\%), 1989 (13\%), e agravando em 1990 (18\%), chegando à casa de 2.290 internações em julho/1990 (meio da safra), sendo em janeiro, quando não há safra este número atingiu a 1.274 pessoas.

O autor apresenta um mapa geral das doenças respiratórias na região de Ribeirão Preto tabuladas pelo Centro de Processamento de Dados/USP em 1990, a saber:

NUMERO DE INTERNAÇÕES

NÚMERO DE ALTAS

NÚMERO DE ÓBITOS

PERCENTUAL DE ÓBITOS
20.672

19.589

1.083

$5,23 \%$

Em seu trabalho o autor conclui que:

- Não há dúvidas que durante a época das queimadas dos canaviais há uma piora na qualidade do ar da região; 
- A queimada dos canaviais não é o único fator de agravamento da qualidade do ar, mas trás consequências em virtude da extensão das áreas plantadas e do período das queimadas: abril a novembro;

- A população de risco, que tem sua qualidade de vida e de saúde agravada no período é bastante significativa.

\subsection{Conservação dos solos}

Conforme trabalhos de LOMBARDI (1994), somente no Estado de São Paulo, a erosão tem provocado, por ano, o deslocamento de mais de 180 milhões de toneladas de terra das camadas superficiais do solo. $\mathrm{O}$ principal problema ambiental do Brasil é a degradação do solo, onde grande parte deste material arrastado vai parar nos rios, represas e cursos de água, assoreando-os, poluindo-os, dificultando o abastecimento de água nas cidades, reduzindo a vida útil das hidroelétricas, que representam o principal componente da matriz energética do pais.

O autor comparando o preparo convencional dos solos com arado de aiveca, onde perdeu-se de 14,6 à $8.6 \mathrm{t}$ de solo, com o plantio direto onde a cobertura morta permanece sobre o terreno, conclui que a cobertura morta impede o impacto direto das gotas de chuva sobre os solos agrícolas, favorece a infiltração, incorpora matéria orgânica aos solos e dificulta o escoamento das enxurradas e contribui para a conservação da água no solo. Conclui dizendo que "a utilização da cobertura morta sobre 
o terreno é uma técnica simples que ajuda o agricultor a melhorar o aproveitamento da camada fértil, sem degradá-la".

\subsection{Potencial energético da cana-de-açúcar}

Conforme STUPIELLO (1989) com a criação do PROALCOOL em 1975, os objetivos principais da matéria prima eram voltados para a fabricação de álcool e açúcar, restando somente como principais resíduos de fabricação: o bagaço e a vinhaça.

Trabalho de MATSUOKA \& ARIZONO (1987) propunham que novas finalidades para o aproveitamento da matéria prima seriam inevitáveis, então realizaram o seu trabalho de seleção de variedades, voltados para o potencial de biomassa dos clones pelo então IAA/PLANALSUCAR. Das nove variedades testadas em cana-planta e canasoca, três delas superaram o padrão - NA 5679, na produção de biomassa total (após queima e desponte) e de 15 à 25\% em PCI.(poder calorífico inferior).

Os resultados de cana-soca foram:

\begin{tabular}{lccc}
\hline VARIEDADES & $\begin{array}{r}\text { ÁLCOOL } \\
\mathrm{m3} / \mathrm{ha}\end{array}$ & $\begin{array}{c}\text { BAGAÇO } \\
\mathrm{t} / \mathrm{ha}\end{array}$ & $\begin{array}{c}\text { PODER CALORÍFICO } \\
\text { Gcal/ha }\end{array}$ \\
\hline RB795479 & 6,02 & 29,4 & 82,6 \\
RB735275 & 6,44 & 20,9 & 69,4 \\
RB745429 & 6,22 & 19,1 & 65,1 \\
NA 5679 & 5,96 & 18,2 & 62,2 \\
RB805035 & 5,09 & 19,1 & 59,5 \\
RB715479 & 4,83 & 18,2 & 56,7 \\
RB735036 & 5,22 & 16,6 & 55,7 \\
RB745228 & 3,83 & 19,2 & 53,5 \\
RB735200 & 4,78 & 15,9 & 52,2 \\
RB795349 & 3,36 & 14,1 & 42,0 \\
\hline
\end{tabular}


Os autores concluem que o valor das variedades é substancialmente alterado quando se considera a produção de biomassa ou seu teor energético, e que poderão serem aceitas futuramente, se a exigência atual de açúcar e álcool (pol \% cana , produtividade e longevidade) for alterada para a biomassa.

Comparando o balanço energético em Mcal / ha / ano para as culturas de: cana-de-açúcar, mandioca e sorgo, GOMES et al. (1976) transformaram em álcool toda a energia produzida e a consumida em produção agrícola e industrial, apresentou $o$ seguinte balanço energético:

\begin{tabular}{lcccccc}
\hline & \multicolumn{2}{c}{ PRODUZIDA } & \multicolumn{2}{c}{ Mcal/ha/ano } & \multicolumn{3}{c}{ CONSUMIDA Mcal/ha/ano } \\
Cultura & Álcool & Residual & Total & Agrícola & Industrial & Total \\
\hline CANA & 18747 & 17550 & 36297 & 4226 & 10814 & 15040 \\
MANDIOCA & 13271 & -- & 13271 & 2753 & 8883 & 11636 \\
SORGO & 19856 & 11830 & 31686 & 4667 & 11883 & 16550 \\
\hline
\end{tabular}

Os autores concluem que para as condições do trabalho as culturas apresentaram os saldos positivos de balanço energético :

$\begin{array}{ll}\text { cana } & +21.257 \mathrm{Mcal} / \mathrm{ha} / \mathrm{ano} \\ \text { mandioca } & +1.635 \text { “ } \\ \text { sorgo } & +15.136 \text { “ }\end{array}$

RIPOLI et al. (1991) avaliando o potencial energético de resíduos provenientes da colheita em cana-de-açúcar sem queima prévia, nas variedades SP701284; SP70-1143; SP70-6163; SP71-1406 e NA5679, determinaram os seguintes valores médios correspondentes a energia contida no palhiço, em Mcal/ha: 


\begin{tabular}{ll}
\hline VARIEDADES & Mcal/ha \\
\hline SP 70 1284 & $29.245,00$ \\
SP 70 6163 & $45.721,10$ \\
SP 70 1143 & $42.615,10$ \\
SP 71 1406 & $58.711,70$ \\
NA 5679 & $52.623,60$ \\
\hline Os autores citam a importância da biomassa vegetal queimada nos
\end{tabular}
processos convencionais e tradicinais de colheita, representam grandes desperdícios de energia em um país que terá fatalmente uma crise energética.

Para as avaliações dos poderes caloríficos, BRITO \& BARRICHELLO (1982) comentam que poder calorífico de massas vegetais pode ser considerado tanto o superiòr (PCS), como o inferior(PCI), determinados através de bomba calorimétrica, e que somente dependerá se o calor liberado pela condensação da água de constituição do material (umidade\%) for ou não considerado. Para conhecer a relação entre os poderes caloríficos superior e inferior, é necessário saber-se a quantidade de hidrogênio contida no material, tendo-se descontado o valor consumido para a vaporização da água envolvido no processo conforme a equação de DOAT (1977):

$P C I=P C S-600 \times 9 \mathrm{H} / 100$

onde:

PCI $(\mathrm{kcal} / \mathrm{kg})=$ Poder Calorífico Inferior

PCS $(\mathrm{kcal} / \mathrm{kg})=$ Poder Calorífico Superior

H (\%) = Teor de Hidrogênio do Material 


$$
\begin{aligned}
600= & \text { Constante correspondente ao valor médio }(\mathrm{kcal} / \mathrm{kg}) \\
& \text { de energia absorvida por kg de água para se atingir a } \\
& \text { temperatura de evaporação } \\
9= & \text { Constante, múltiplo de peso de hidrogênio contido no } \\
& \text { combustivel que fornece o peso da água para atingir a } \\
& \text { temperatura de combustão. }
\end{aligned}
$$

Trabalho conduzido por ZALAUF et al. ( 1985) avaliou a energia contida na palha de canaviais das principais regiões canavieiras do Estado de São Paulo, em précolheita, conforme é apresentado a seguir:

P ALHAS

\begin{tabular}{llccc}
\hline REGIÃO & VARIEDADES & $\begin{array}{c}\text { UMIDADE } \\
(\%)\end{array}$ & $\begin{array}{c}\text { PCS } \\
(\mathrm{kcal} / \mathrm{kg})\end{array}$ \\
\hline Baurú & SP70-1143 & 21.3 & 4.315 & 3.073 \\
Piracicaba & NA 5679 & 18.6 & 3.979 & 2.992 \\
Araraquara & NA 5679 & 9.1 & 4.181 & 3.563 \\
Ribeirão Preto & SP70-1143 & 8.0 & 4.096 & 3.534 \\
Campinas & CP 5122 & 11.3 & 4.098 & 3.389 \\
\hline
\end{tabular}

PCS $=$ poder calorifico superior $; \mathrm{PCI}=$ poder calorífico inferior

RIPOLI (1991) estudando duas variedades de cana-de açúcar( NA 5679 e SP71-1406), colhidas mecanicamente e sem a queima prévia, obteve os seguintes resultados em t/ha : 
massa de colmos $=73,54$ e 67,20 ; de ponteiros $=9,91$ e 4,84; folhas verdes $=8,23$ e 5,26; palha $=11,52$ e 9,43; palhiço $=29,67$ e 19,53 e índice de palhiço $=$ 0,40 e 0,29 respectivamente para as variedades NA e SP. $O$ autor determinou para o hidrogênio $(\mathrm{H})$ o valor médio de $6,34 \%$ e os poderes caloríficos superior , inferior e útil para os componentes: Ponteiros (PO), Folhas Verdes(PV) e Palhas (PA), obtendo os seguintes valores médios:

\begin{tabular}{llrcr}
\hline Variedades & Variáveis & \multicolumn{1}{l}{ P O } & F V & P A \\
& & & & \\
SP71-1143 & PCS & 4334,10 & 4406,00 & 4508,80 \\
& PCI & 3998,30 & 4057,90 & 4179,30 \\
& PCU & 759,40 & 1177,90 & 3602,30 \\
& & & & \\
NA 5679 & PCI & 4367,70 & 4418,20 & 4330,80 \\
& PCU & 1003,30 & 1457,80 & 3613,10 \\
& & & & \\
\hline
\end{tabular}

$(\mathrm{PO}=$ ponteiros $; \mathrm{FV}=$ folhas verdes $\mathrm{e} \mathrm{PA}=$ palha $)$

O autor conclui em seu trabalho que uma tonelada de material remanescente de colheita substitui $1,08 \mathrm{t}$ de bagaço em termos de poder calorífico, se considerado como combustivel para fomalhas de caldeiras em usinas e ou destilarias.

Por levantamentos de SANCHES (1976) a biomassa total de uma floresta tropical varia entre 100 a 400 toneladas de massa sêca . A constituição é a seguinte: troncos e galhos $=75 \%$; raizes $=15$ à $20 \%$; folhas $=4$ à $6 \%$ e serrapilheira $=1$ à $2 \%$. 
DEMATTÊ (1988) afirma que no manejo da fertilidade dos solos tropicais brasileiros, durante a queima desta biomassa, o $\mathrm{N}$ e o $\mathrm{S}$ são volatilizados para atmosfera, mas os outros nutrientes são introduzidos no solo e estão prontamente disponíveis às plantas.

RIPOLI et al. (1991) estimam a energia contida no aproveitamento do canavial com produtividade de $70 \mathrm{t} / \mathrm{ha}$, rendimento de fabricação em álcool de $75 \mathrm{l} / \mathrm{t}$, em colheita sem a queima prévia, obtiveram os seguintes valores expressos em Mcal/ha:

\begin{tabular}{ccc}
\hline álcool & 5.250 l álcool & $20.877 \mathrm{Mcal} / \mathrm{ha}$ \\
bagaço & $17,5 \mathrm{t} / \mathrm{ha}$ & $31.325 \mathrm{Mcal} / \mathrm{ha}$ \\
palhiço & $9,7 \mathrm{t} / \mathrm{ha}$ & $22.166 \mathrm{Mcal} / \mathrm{ha}$ \\
\hline
\end{tabular}

Os autores citam também algumas desvantagens do sistema de recolhimento do palhiço :

- material com baixa densidade ( $25 \mathrm{~kg} / \mathrm{m}^{3}$ );

- teores elevados de terra $=7 \%$ );

- teores elevados de umidade (ponteiros $=76 \%$, folhas verdes $=65 \%$ e palhas secas $=7 \%$ ). 


\section{MATERIAL E MÉTODOS}

\subsection{Material}

O material utilizado no presente trabalho abrangeu áreas pertencentes à Usina Santa Lydia, localizada no município de Ribeirão Preto, Estado de São Paulo. Os ensaios de campo ocorreram durante a safra agrícola de 1993/1994, em as áreas denominadas neste trabalho de 01 e 02 respectivamente, identificadas pela carta cartográfica. Nos materiais utilizados estão a colhedora de cana-de-açúcar, os veículos de transporte com as carrocerias teladas, os equipamentos requeridos nas determinações das cargas no pátio de recepção da cana, laboratório tecnológicos da usina e do Departamento Florestal , da ESALQ-USP, são descritos a seguir:

\subsubsection{Colhedora SANTAL AMAZóN}

A máquina para o corte da cana crua e queimada foi a mesma para todos os campos, sendo revisada para o início de cada campo, com um mesmo operador em todos os ensaios. É uma colhedora totalmente nacional, que foi lançada no mercado em 1994, após cinco anos de pesquisa e desenvolvimento de protótipos pelo fabricante: 
Santal Equipamentos S/A, da cidade de Ribeirão Preto, no Estado de São Paulo, apresentando as seguintes características:

Características da Colhedora utilizada nos 02 campos

Marca

Modelo

Procedência

Peso

Rodados

dianteira

trazeira

motor

potência

rotação máxima
SANTAL

$A M A Z O ́ N$

Nacional

$12.750 \mathrm{~kg}$

4 apoios com pneus

$10.00 \times 16 / 10$ lonas

$21 \mathrm{~L}$ 30- 12 lonas

Scania - DS11-54

$268 \mathrm{cv}(\max$.

$2.100 \mathrm{rpm}$

\subsubsection{Características dimensionais -( $\mathrm{mm})$}

Bitola Frontal

Bitola Traseira

Largura Máxima

Comprimento

Altura Para Transporte
2.000

2.700

3.300

8.300

4.700 


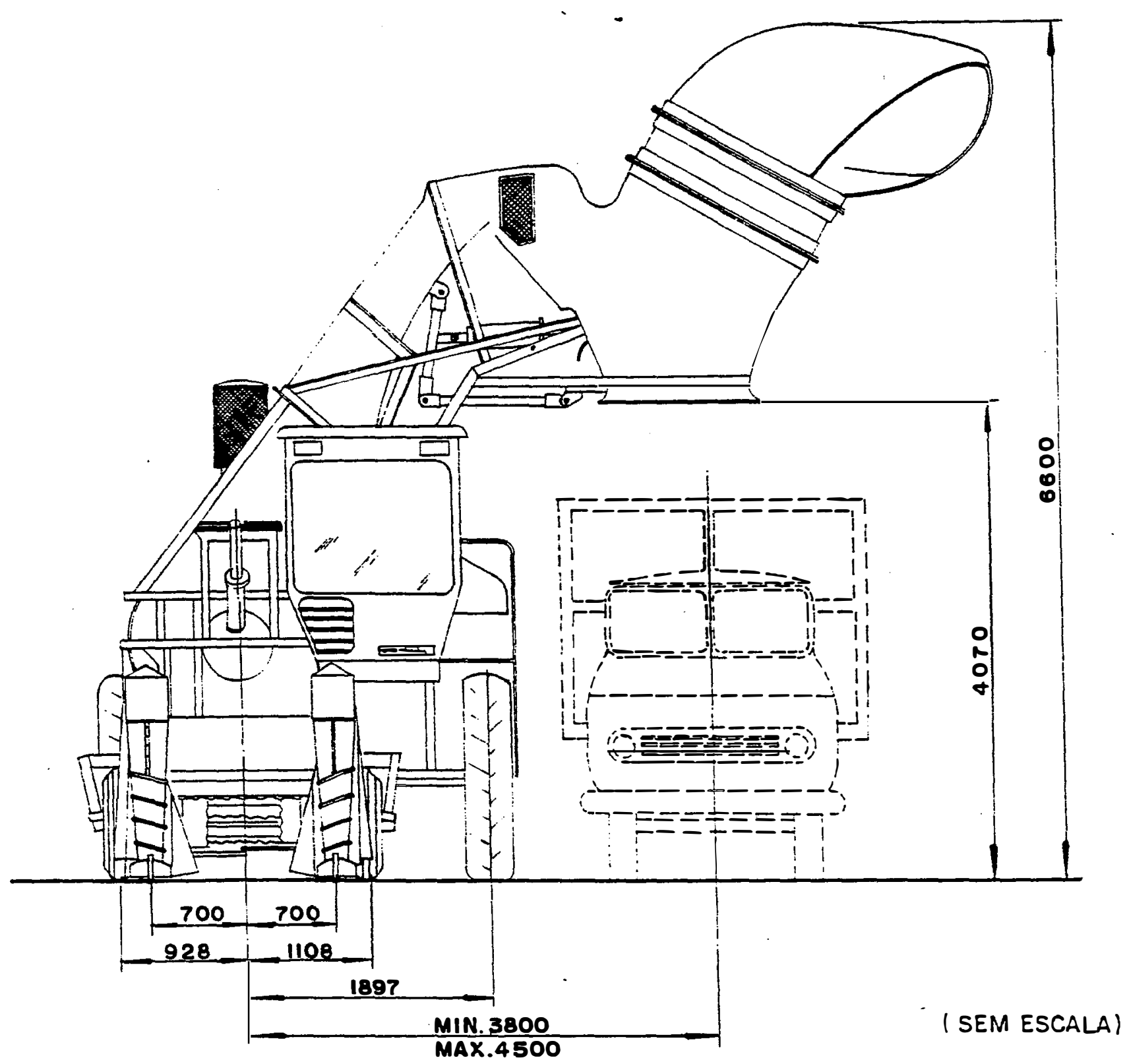

Figura 01a. Esquema frontal da Colhedora SANTAL AMAZÓN e suas dimensões principais. 


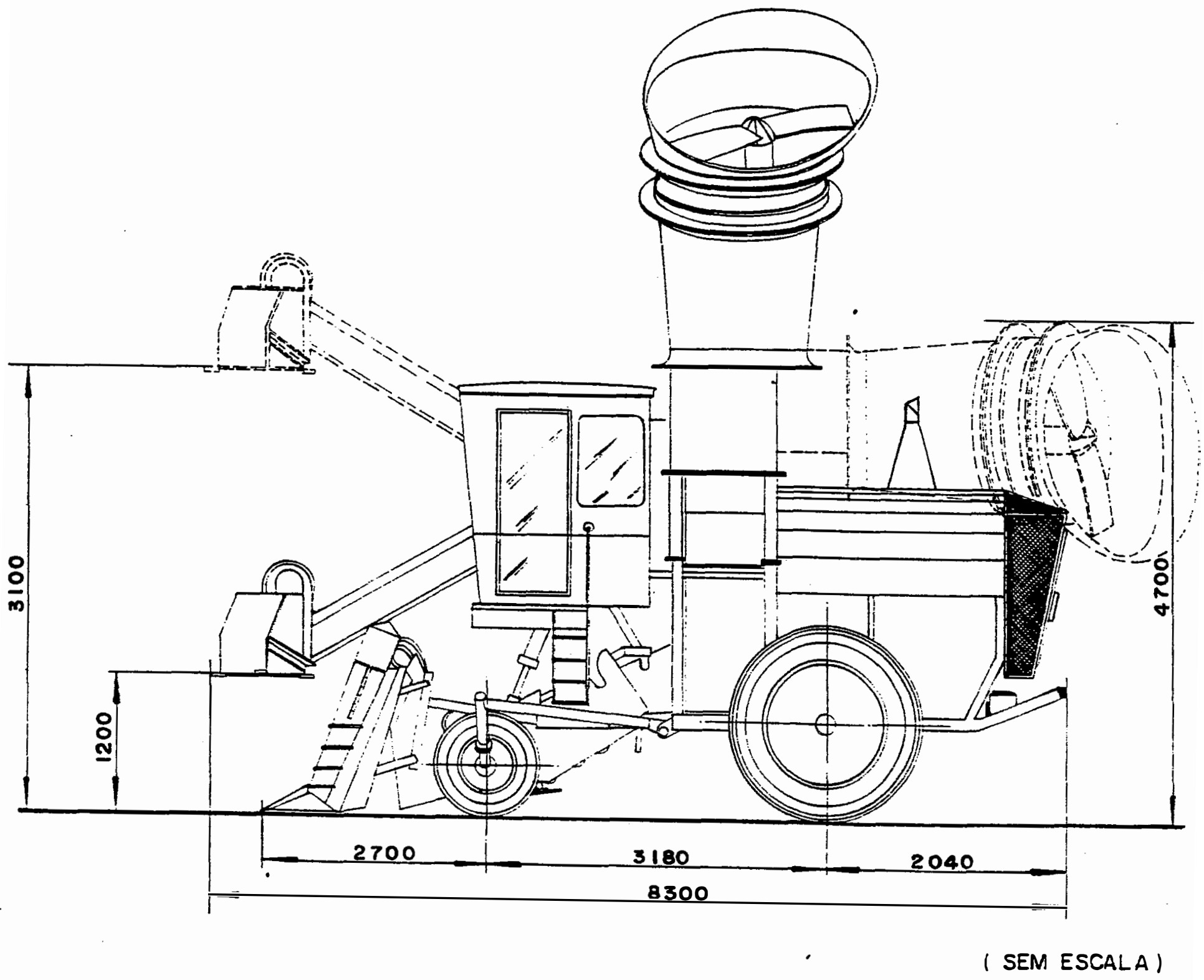

Figura 01b. Esquema dimensional lateral da colhedora SANTAL AMAZÓN 
Altura Para Colheita (útil....4.070) $\quad 6.600$

Altura Corte Base

-Acima do solo $\quad 400$

$\begin{array}{ll}\text {-Abaixo do solo } & 100\end{array}$

Raio de Giro:

-à Direita $\quad 6.000$

-à Esquerda $\quad 6.100$

Corte de Pontas:

-Mínimo $\quad 1.200$

-Máximo $\quad 3.500$

3.1.1.2. Características técnicas de funcionamento dos órgãos ativos da colhedora

\section{DESPONTADOR}

Constituído de um cilindro hidráulico para ajustes de altura de corte, faca de corte acoplada a um motor hidráulico de engrenagem. Sistema defletor que lança os ponteiros dos colmos para a esquerda, fora da frente da máquina, de maneira à formar no solo uma esteira de pontas, para o transito dos pneus dianteiros da colhedora. 


\section{LEVANTADOR DE COLMOS}

Dotado de cilindros (pirulitos) levantadores cônicos, com a frente prolongada e lâmina flutuante sob a sapata esquerda. A finalidade deste levantador é com relação ao recolhimento dos colmos acamados e deitados, para serem despontados.

\section{CORTADOR BASAL}

É efetuado através de dois discos com seis facas cada, e um sistema de segurança para evitar sobrecarga. Existe também no painel do operador um indicador da pressão do corte de base para munitorar o operador qual é o pressão ideal e a profundidade exata do disco de corte no solo.

\section{SISTEMA DE ALIMENTAÇÃO}

É constituído de rolos horizontais, acionados por motores hidráulicos, que tem a finalidade de conduzir os colmos inteiros até o picador. É composto por:

- 01 rolo tombador frontal superior - tombam os colmos para frente, antes de haver o corte de base;

-01 rolo levantador inferior - conduz os colmos já picados para os rolos condutores alimentadores.

-05 rolos alimentadores - conduzem os colmos já cortados para o picadorpor entre os rolos condutores parte da matéria estranha mineral cai ao solo. 


\section{PICADOR}

Está montado em um eixo que é sincronizado com o lançador por intermédio de uma caixa de redução de $3: 1$, girando portanto 3 vezes mais que o lançador, tendo afixada uma faca plana, com corte duplo para facilitar a troca, fixada por sistema de cunha, para troca rápida do facão no campo.

Através de duas alavancas posicionadas atrás da cabine da colhedora, consegue-se alterar os toletes em 4 tamanhos médios: $220,260,310$ e $370 \mathrm{~mm}$.

\section{LANÇADOR}

A matéria prima cortada é lançada por 3 aletas defasadas em $120^{\circ}$, denominado rotor, não necessitando de taliscas ou correntes transportadoras para conduzir os colmos já cortados até o veículo.

\section{DUTO CONDUTOR}

É o conjunto que é composto pelo duto metálico, pelo exaustor, defletor e biruta giratória.

DUTO CONDUTOR - O duto é metálico e articulável para transporte, leva o material vegetal já cortado, lançado pelo rotor, até o veículo, permitindo que durante o trajeto, parte da impureza vegetal seja retirada pelo exaustor.

EXAUSTOR - retira parte da matéria estranha contida na massa vegetal colhida mecanicamente, constituídas de folhas e palhas que são encaminhadas a biruta giratória para a área já cortada pela máquina. 
DEFLETOR - Direcionam os rebolos para dentro dos veículos de transporte.

\subsubsection{Caracterização da cultura da cana-de-açúcar}

As variedades de cana-de-açúcar utilizadas foram:

$$
\begin{array}{ll}
\text { Campo 1 } & \text { SP71-1406 } \\
\text { Campo 2 } & \text { SP71-6163, }
\end{array}
$$

Atualmente sendo das mais plantadas em toda a região Centro-Sul do Brasil, conforme MATSUOKA et al. (1993).

\subsubsection{Material do primeiro experimento (área 1)}

a) Local: Fazenda Santo Antônio do Pau Alto, pertencente a Usina Santa Lydia, com área de 14,30 ha, codificado com o $\mathrm{n}^{\circ}$ 1488.e situado segundo carta cartográfica em latitude: $21^{\circ} 11^{\prime} 27^{\prime}$ 'S e longitude Gr. $48^{\circ} 07^{\prime} 03^{\prime}$ 'W e altitude de 610 metros.

b) Cultura: variedade SP71-1406, estágio de $4^{\circ}$ corte ou $3^{\mathrm{a}}$ soca com espaçamento médio de plantio com 1,42m, com 12 meses de idade (corte anterior em 19/8/92). 
c) Solo: Classificado por FRANÇA \& FREIRE (1976) como Latossolo Vermelho Escuro- eutrófico $\left(\mathrm{LE}_{\mathrm{e}}\right)$, classe "A" de Capacidade de Uso (0-5\% declividade), sendo o solo sistematizado e cultivado para a melhor eficácia do corte mecanizado.

A análise granulométrica, à partir de método proposto por STEEL \& BRADFIELD (1934), em amostras compostas resultaram os seguintes valores:

\begin{tabular}{cccc}
\hline profundidade & areia total & silte & argila \\
\hline $\mathrm{cm}$ & $\%$ & $\%$ & $\%$ \\
$0-10$ & 36,5 & 12,3 & 51,2 \\
\hline
\end{tabular}

d) Clima: Durante a realização do ensaio não houve precipitações nos dias precedentes e nem durante a realização dos trabalhos de campo, sendo registradas temperaturas médias, com a máxima em $34,0^{\circ} \mathrm{C}$ e a mínima de $19,0^{\circ} \mathrm{C}$.

\subsubsection{Material do segundo experimento (área 2)}

a) Local: Fazenda da Serra, área própria da USINA SANTA LYDIA, com área total de 10,90 ha, talhão codificado na empresa com $n^{\circ} 819$, conforme carta cartográfica em latitude: $21^{\circ} 12^{\prime}-15^{\prime} \mathrm{S}$; longitude Gr.: $48^{\circ} 12^{\prime} 24^{\prime \prime} \mathrm{W}$ e altitude de 690 metros.

b) Cultura: Variedade SP71-6163, em estágio de $3^{\circ}$ corte ou $2^{a}$ soca, com idade de 12 meses (corte anterior em 10/09/92), sendo cortada em 14 e 15 de setembro de 1993 . O espaçamento médio das linhas de plantio foi de 1,42 metros. 
c) Solo: Classificado por FRANÇA \& FREIRE (1976) como Latossolo Roxo (LR), (Eutorthox), classe " $\mathrm{A}$ " de capacidade de uso ( 0 à $5 \%$ declividade), textura argilosa. $\mathrm{O}$ solo foi previamente preparado e sistematizado para o corte mecanizado, isto nos aspectos de cultivo no ano anterior e nivelamento de terreno.

O resultado médio da análise granulométrica, de amostras compostas resultaram nos seguintes valores:

\begin{tabular}{cccc}
\hline profundidade & areia total & silte & argila \\
\hline $\mathrm{cm}$ & $\%$ & $\%$ & $\%$ \\
$0-10-$ & 30,4 & 15,0 & 59,6 \\
\hline
\end{tabular}

d) Clima: Durante os dias que precederam ao corte houveram precipitações (17 mm no dia pré-precedente e $21 \mathrm{~mm}$ no precedente), sendo que no dia da realização das colheitas da cana crua como da queimada não houve precipitação. A temperatura máxima registrada nos dias do ensaio foi de $33,5^{\circ} \mathrm{C}$ e a mínima de $17,0^{\circ} \mathrm{C}$.

\subsubsection{Caracterização dos veículos de transporte}

Foram utilizados caminhões convencionais de transporte de cana picada, com capacidade de carga líquida de $16.000 \mathrm{~kg}$, apresentando um engate traseiro para o acoplamento de uma carreta para $14.000 \mathrm{~kg}$. Nessas unidades de transporte a matéria prima é depositada em carrocerias fechadas e teladas para evitar perdas durante o transporte do campo até a indústria. Nas carrocerias existem 03 furos com tampas 
removíveis para as tomadas de amostragens pela sonda no sistema de pagamento de cana-de-açúcar pela qualidade, adotado no Brasil.

\subsubsection{Equipamentos para determinações no campo}

Os equipamentos utilizados nas determinações de campo foram os seguintes:

- balança de plataforma, marca TOLEDO, com capacidade máxima para $100 \mathrm{~kg}$ e precisão de $100 \mathrm{~g}$.

- balança tipo bandeja, marca FILIZOLLA, com capacidade máxima de $5 \mathrm{~kg}$ e precisão de $10 \mathrm{~g}$.

- trena de fibra marca ESLON, com comprimento total de $50 \mathrm{~m}$ e precisão $1 \mathrm{~cm}$.

- cronômetro digital marca CASIO, com precisão de centésimo de segundo.

- triângulo de madeira para leitura de inclinação dos colmos $\left(45^{\circ}\right.$ e $\left.22,5^{\circ}\right)$.

- estacas de madeira, barbantes, sacos plásticos, sacos para amostras de solo e plantas.

- trena metálica STARRET, com comprimento de $5 \mathrm{~m}$ e precisão de $1 \mathrm{~mm}$.

- paquímetro marca MYTUTOYO, com precisão de $0.1 \mathrm{~mm}$.

- estacas, sacos plásticos, lonas plástica, barbantes, pranchetas, fita adesiva, etc. 


\subsubsection{Equipamentos de laboratório}

No presente trabalho foram utilizados: as instalações e equipamentos de balança e do laboratório de análise tecnológica da Usina Santa Lydia, compreendendo as operações de pesagem dos veículos ou as julietas (peso total, tara e peso líquido), as amostragens com as sondas nas cargas, visando as análises tecnológicas (brix, pol, pureza, açúcar redutor, fibra, açúcar corrigido e ágio/deságio) e a análise de impurezas nas cargas (impurezas vegetais e minerais).

Os equipamentos do laboratório da Engenharia Florestal/ESALQ-USP foram utilizados para as determinações do poder calorífico superior e teor de água nas frações dos componentes da biomassa, envolvendo:

-Estufa para peso seco (até $220^{\circ} \mathrm{C}$ )

-Balança analítica (precisão $10^{-3} \mathrm{~g}$ )

$-\operatorname{Mufla}\left(1.200^{\circ} \mathrm{C}\right)$

- Bomba calorimétrica INCOMAP- mod D-217.

-Cápsulas taradas de porcelana.

\subsection{Métodos}

\subsubsection{Determinação das condições de campo}

Nas duas séries de ensaios realizados, utilizou-se os critérios propostos por RIPOLI et al. (1987), que preconizam as determinações de: 
- comprimento médio dos colmos cortados;

- porte do canavial (\% de colmos eretos, acamados ou/e deitados);

- qualidade da queima;

- teor de umidade atual do solo;

- granulometria do solo;

- idade e grau de maturação da cultura

\subsubsection{Caracterização do canavial}

$\mathrm{Na}$ caracterização do canavial e suas porções adotou-se método proposto por RIPOLI (1991) onde tomou-se 10 parcelas ao acaso no canavial em cana crua e queimada, em uma área de $2,82 \mathrm{~m}^{2}$, correspondendo a 2 sulcos de $1,0 \mathrm{~m}$ de comprimento e com $1,42 \mathrm{~m}$ de espaçamento.

Cortou-se, manualmente, os colmos rente ao solo, recolhendo toda a biomassa. Posteriormente realizou-se a separação, sobre uma lona plástica, dos componentes do palhiço: palhas, folhas verdes e ponteiros. Para os colmos, determinouse seus comprimentos, número de internódios e o peso total dos colmos da amostra. $\mathbf{O}$ ponto de separação dos ponteiros e colmo, foi utilizado o método proposto por FURLANI NETO (1984) para determinação das perdas de ponteiros no campo, denominado "método do ponto de quebra". 
De cada fração dos componentes do colmo e do palhiço da cana queimada e crua, retirou-se sub-amostras que foram acondicionadas e encaminhadas ao laboratório para a determinação do teor de água e poder calorífico superior.

Dos colmos, após as avaliações ponderais, retirou-se sub-amostras para o encaminhamento do laboratório de análise tecnológica, para as análises de Brix \% caldo, pol $\%$ caldo, pureza, fibra e pol \% cana corrigido.

\subsubsection{Avaliações de desempenho da colhedora}

As avaliações de desempenho operacional da colhedora foram realizadas segundo métodos preconizados por MIALHE \& RIPOLI (1976) e FURLANI NETO (1984):

- Capacidade efetiva - $t / h$;

- Índice de matéria estranha total \%;

- Índice de matéria estranha vegetal \%;

- Índice de matéria estranha mineral \%;

- Comprimento médio dos toletes.

\subsubsection{Análise granulométrica e teor de umidade $\%$ no solo}

O teor de umidade no perfil foi obtido nos dois perfis de $0-20 \mathrm{~cm}$ de profundidade, retirando-se uma amostra composta originária de 5 amostragens coletadas 
no centro das entrefileiras da cana, sendo acondicionadas inicialmente em sacos plásticos, homogeneizadas e transferidos para vasilhas de alumínio, as quais, após vedadas e identificadas, foram encaminhadas ao laboratório de tecnologia da Usina.

\subsubsection{Potencial residual de pós-colheita.}

Em cada campo, após a colheita nos dois tratamentos, foram amostrados o palhiço residual em 64 áreas de $28,40 \mathrm{~m}^{2}$, para cada tipo de cana, originadas de áreas de amostragem referentes à 02 linhas de $1,42 \mathrm{~m}$ de espaçamento, por 10 metros de comprimento, onde segundo método de perdas adotado por FURLANI NETO (1984), separou-se os componentes de "catação manual", identificando como:

frações de colmos inteiros = parte da matéria prima industrializável.

tocos $=$ pedaços de colmos deixados agregados à soqueira devido a altura do corte basal pela colhedora.

rebolos $=$ pedaços de colmos picados pela colhedora, mas caídos no campo.

fração de colmo agregado $=$ fração de matéria- prima agregado ao ponteiro devido ao desponte baixo pela colhedora.

ponteiro $=$ parte superior da planta, não industrializável.

folhas $=$ Parte da planta constituídas de folhas verdes ou secas, agregadas ao colmo ou já caídas sobre o terreno. 
Após as determinações das massas das frações, foram retiradas amostras compostas, ensacadas, vedadas em plásticos, identificadas e em caminhadas para os laboratórios de sacarose da Usina Santa Lydia e da ESALQ, para determinações do poder calorífico superior das frações das plantas. As variáveis caracterizadas por cana inteira, pedaços, ponteiros (colmos agregados ao ponteiro), tocos e folhas verdes, secas e ponteiros, foram submetidas à análise estatística, onde seus valores confrontados para os tratamentos estudados.

\subsubsection{Capacidade operacional da colhedora}

A capacidade operacional da colhedora foi determinada em toneladas por hora (t/h), conforme proposto por RIPOLI \& MIALHE (1987).

Para cada repetição, foi demarcado uma distância de $50 \mathrm{~m}$ de comprimento, onde o. tempo em corte foi cronometrado, sendo, posteriormente os valores transformados em velocidade $(\mathrm{km} / \mathrm{h})$. Para todas as repetições, utilizou-se o mesmo operador, sendo um dos mais experientes escolhido pela Usina.

No carregamento de cada repetição, foi utilizado um veículo de transporte, sendo tomados todos os devidos cuidados de limpeza prévia das carrocerias e devidamente identificados para as avaliações na usina. No campo, o comprimento dos sulcos cortados para cada (repetição) carga, foi determinado com o emprego de trena, sendo suas massas líquidas, levantados junto ao setor balança da Usina Santa Lydia, através da diferença de massa bruta (entrada) e tara do veículo (saída). 
As variáveis obtidas no desempenho operacional do corte em cana crua e queimada foram submetidas à análise estatística, onde foram confrontados pelo Teste Tukey (teste T), contido em CAMPOS (1984).

\subsubsection{Determinações no Laboratório de Sacarose}

Cada caminhão de transporte após a determinação das massas na balança, foi encaminhada para o amostrador de sonda, onde amostrou-se pelos 3 furos da carroceria, 3 amostragens, que após homogeneizadas, foram subdivididas em 02 partes compostas que serviram de material básico para:

a) Análise de Cana pela Qualidade, padronizado pelo Ato $n^{\circ} 32 / 89$ de 28 de agosto de 1989, do Ministério da Indústria e Comércio, dotado na região Centro-Sul do Brasil, determinando os parâmetros de: brix , pol \% caldo, pureza, fibra, pol \% cana corrigido, sendo realizado o confronto estatístico dos parâmetros tecnológicos da matéria prima pelo teste $\mathrm{T}$.

b) Determinação das impurezas minerais, vegetais e totais-

Em cada amostra realizou-se a separação manual da matéria estranha vegetal ,tomando-se as suas massas, posteriormente o material foi carbonizado a $900^{\circ} \mathrm{C}$ para a obtenção das matérias estranhas minerais. Nas determinações da matéria estranha mineral foram descontadas as massas das cinzas originárias da prova em branco somente com cana limpa. 
Os valores obtidos foram submetidos à análise estatística, através do método do Teste Tukey (T) conforme contidos em sua íntegra no Apêndice 1. 


\section{RESULTADOS E DISCUSSÃO}

\subsection{Potencial do canavial em pré-colheita.}

A avaliação prévia do canavial antes da colheita mecânica realizada nos tratamentos estudados, permitiu obter os valores médios que constam da Tabela 01 .

TABELA 01 - Caracterizações ponderais e dimensionais do campo antes da colheita

\begin{tabular}{cccccccc}
\hline CAMPO & TIPO & $\mathrm{N}^{0}$ & massa & & \multicolumn{3}{c}{ MASSA PONTEIROS (kg) } \\
& CANA & internódias & \begin{tabular}{c} 
(kg)/colmo \\
\cline { 6 - 8 }
\end{tabular} & Ponteiros & Palha+Folha & Total \\
\hline 1 & CC & 18,1 & 0,974 & 0,212 & 0,152 & 1,338 \\
& CQ & 18,3 & 1,058 & 0,202 & 0,062 & 1,322 \\
& & & & & & & \\
\hline 2 & CC & 20,1 & 0,952 & 0,242 & 0,133 & 1,327 \\
& CQ & 22,1 & 0,917 & 0,083 & 0,152 & 1,153
\end{tabular}

Campo 1 = SP71-1406; Campo $2=$ SP71-6163; CC = Cana crua; $C Q=$ Cana queimada.

Foram determinados também em pré-colheita os valores médios do "stand" do canavial e o porte do canavial, conforme tabelas 29 e 30 do apêndice (2).

Os resultados médios para o porte do canavial e "stand" do canavial, seguindo o método proposto por RIPOLI \& MIALHE (1987) estão contidos na Tabela 2. 
TABELA 2 - Número de plantas"Stand" e porte do canavial.

\begin{tabular}{ccccc}
\hline CAMPO & Erecto & $\begin{array}{c}\text { Porte \% Canavial } \\
\text { Acamado }\end{array}$ & Deitado & $\begin{array}{c}\text { Stand } \\
\text { Colmos } / \mathrm{m}\end{array}$ \\
\hline 1 & $93,8 \%$ & 6,1 & 1,1 & 10,1 \\
\hline 2 & $100 \%$ & - & - & 12,3 \\
\hline Campo 1 = SP71-1406; Campo 2 $=$ SP71-6163. & &
\end{tabular}

Com os valores médios obtidos nas Tabelas 1 e 2, estimou-se o potencial do hectare para cana crua e queimada antes do corte mecânico. Estes valores totais de colmos, palmitos, ponteiros e folhas estão contidos na Tabela 3.

TABELA 3 - Média estimada em kg/ha de massa total em pré-colheita.

\begin{tabular}{|c|c|c|c|c|c|}
\hline CAMPO & $\begin{array}{c}\text { TIPO } \\
\text { CANA }\end{array}$ & $\begin{array}{c}\text { Colmos } \\
\mathrm{kg} / \mathrm{ha} \quad(\%)\end{array}$ & $\begin{array}{c}\text { Palmito } \\
\mathrm{kg} / \mathrm{ha} \quad(\%)\end{array}$ & $\begin{array}{c}\text { Folhas+Palhas } \\
\text { kg/ha (\%) }\end{array}$ & $\begin{array}{c}\text { Total } \\
\mathrm{kg} / \mathrm{ha} \quad(\%)\end{array}$ \\
\hline \multirow[t]{2}{*}{1} & $\mathrm{CC}$ & $68,589(100)$ & $14,929(100)$ & $10,703(100)$ & $94,221(100)$ \\
\hline & CQ & $74,504(108,62)$ & $14,224(95,28)$ & $4,366(40,79)$ & $93,095(98,80)$ \\
\hline \multirow[t]{2}{*}{2} & $\mathrm{CC}$ & $82,459(100)$ & $11,520(100)$ & $20,961(100)$ & $114,940(100)$ \\
\hline & CQ & $79,427(96,32)$ & $13,165(114,28)$ & $7,275(34,71)$ & $99,868(86,89)$ \\
\hline
\end{tabular}

* os valores (\%) estão considerando para cada variedade de cana-crua $=100 \%$.

Campo 1 = SP71-1406; Campo 2 = SP71-6163; CC = Cana crua; $C Q=$ Cana queimada. 
Observa-se que no campo 1 o efeito da queima sobre a variável palhas e folhas foi de 59,21\% na redução na massa do palhiço e para a variedade SP71-6163 esta redução foi de $65,29 \%$.

Observa-se que o potencial estimado da variedade SP71-6163 em cana crua, é bem maior que a SP71-1406, devido ao excesso de folhas na cana crua (mais de $10 \mathrm{t} / \mathrm{ha}$ ). Na variável ponteiro, as diferenças encontradas entre a cana crua e queimada (maior na SP71-6163 e menor na SP71-1406) podem ser devidos à densidade do ponteiro das variedades.

\subsection{Resultados médios das determinações dimensionais e ponderais.}

De acordo com a metodologia adotada e descrita por MIALHE \& RIPOLI (1976), FERRARI et al. (1980), FURLANI NETO (1984), RIPOLI (1993) e MOLINA JUNIOR (1994), apresenta-se na tabela 4, os resultados obtidos nas séries de ensaio denominados de CAMPO 1 (SP71-1406) e CAMPO 2 (SP71-6163), apresentadas na íntegra nas tabelas do Apêndice (2).

Observa-se pela Tabela 4, os valores médios obtidos nas determinações dos parâmetros dimensionais e ponderais nos tratamentos. As Tabelas 5 e 6 apresentam o detalhamento dos parâmetros ponderais da Tabela 4, a saber: densidade colheita, que constitui numa interação das distâncias e respectivas massas e do componẹte massa colheita, que é dependente da densidade e do espaçamento das fileiras, que foi determinado, registrando uma média de $1,42 \mathrm{~m}$. 
TABELA 4 Resultados médios dimensionais e ponderais obtidos nos tratamentos

\begin{tabular}{cccccc}
\hline CAMPO & Tipo Cana & $\begin{array}{c}\text { Distância } \\
(\mathrm{m})\end{array}$ & $\begin{array}{c}\text { Massa Cargas } \\
(\mathrm{kg})\end{array}$ & $\begin{array}{c}\text { Densidade } \\
\text { Colheita }(\mathrm{kg} / \mathrm{m})\end{array}$ & $\begin{array}{c}\text { Massa Colheita } \\
(\mathrm{tha})\end{array}$ \\
\hline 1 & $\mathrm{CC}$ & $1.099,38$ & $12.176,25$ & 12,05 & 84,88 \\
& $\mathrm{CQ}$ & 980,75 & $11.677,50$ & 11,93 & 84,03 \\
\hline 2 & $\mathrm{CC}$ & 808,50 & $10.360,00$ & 12,84 & 90,42 \\
\cline { 2 - 6 } & $\mathrm{CQ}$ & 852,25 & $10.533,75$ & 12,37 & 87,10 \\
$\begin{array}{l}\text { Campo 1 } \\
\text { Queimada }\end{array}$ & & & & & \\
\hline
\end{tabular}

\subsubsection{Densidade de matéria-prima.}

Para a densidade de matéria-prima não houve interação entre as variedades e tipo de cana, sendo obtidos os seguintes resultados pelas médias dos dois fatores conforme mostrados na Tabela 5 .

TABELA 5 - Comparação de médias de densidade $(\mathrm{kg} / \mathrm{m})$ de matéria-prima nos diferentes campos e tipos de cana, através do teste $\mathrm{T}$.

\begin{tabular}{lcccc}
\hline & \multicolumn{2}{c}{ CAMPO ** } & \multicolumn{2}{c}{ TIPO DE CANA * } \\
\hline \multicolumn{1}{c}{ VARIAVEL } & SP71-1406 & SP71-6163 & CRUA & QUEIMADA \\
\hline $\begin{array}{l}\text { DENSIDADE } \\
\text { MATÉRIA- } \\
\text { PRIMA }\end{array}$ & 11,9919 & 12,6044 & 12,4469 & 12,1494 \\
\hline$*$ diferença significativa ao nível de 5\% de significância. & & \\
$* *$ diferença significativa ao nível de 1\% de significância. &
\end{tabular}


Pelos resultados da Tabela 5 pode-se afirmar que a densidade da variedade SP71-1406 foi inferior à densidade do canavial da variedade SP71-6163 e que a cana colhida pelo processo de cana crua é maior que o de cana queimada para as 2 variedades testadas, confimando os resultados de MATSUOKA \& ARIZONO (1987), FURLANI NETO et al. (1989), RIPOLI (1991), MOLINA JUNIOR (1991) e TILLMANN (1994).

\subsubsection{Quantidade de massa colhida.}

Para a quantidade de massa colhida ( $t / h a)$ a interação entre campo e tipo de cana não foi estatisticamente significativa, sendo obtidos para as médias dos 2 fatores, conforme Tabela 6.

TABELA 6 - Comparação das médias de quantidade de massa colhida (t/ha) nos diferentes campos e tipos de cana, através do teste $\mathrm{T}$.

\begin{tabular}{lcccc}
\hline & \multicolumn{2}{c}{ CAMPO ** } & \multicolumn{2}{c}{ TIPO DE CANA * } \\
\hline \multicolumn{1}{c}{ VARIÁVEL } & SP71-1406 & SP71-6163 & CRUA & QUEIMADA \\
& & & \\
\hline QUANTIDADE & 84,4537 & 88,7556 & $\mathbf{8 7 , 6 4 5 6}$ & 85,5636 \\
DE MASSA & & & & \\
COLHIDA (t/ha) & & & \\
\hline$* \quad$ diferença significativa ao nível de 5\% de significância. \\
$* *$ diferença significativa ao nivel de 1\% de significância.
\end{tabular}

Conforme os resultados contidos na Tabela 6 , observa-se que a quantidade de massa da variedade SP71-1406 foi inferior à da SP71-6163 e as quantidades colhidas por hectare no sistema mecânico de cana crua apresentou uma 
quantidade de massa maior que o sistema de cana queimada, confirmando os resultados de MATSUOKA \& ARIZONO (1987) e TILLMANN (1994).

\subsubsection{Desempenho efetivo de colheita.}

A Tabela 7 contém os parâmetros médios de velocidade efetiva da colhedora em quilômetros por hora $(\mathrm{km} / \mathrm{h})$ em toneladas por hora $(\mathrm{t} / \mathrm{h})$ nas diferentes condições de colheita.

TABELA 7 - Parâmetros médios de velocidade efetiva e capacidade efetiva da colhedora

\begin{tabular}{cccc}
\hline CAMPO & Tipo de cana & $\begin{array}{c}\text { Velocidade efetiva } \\
\mathbf{k m} / \text { hora }\end{array}$ & $\begin{array}{c}\text { Capacidade efetiva } \\
\text { t/hora }\end{array}$ \\
\hline 1 & CC & 4,91 & 59,11 \\
\cline { 2 - 4 } & CQ & 5,78 & 68,95 \\
\hline 2 & CC & 4,39 & 56,36 \\
\hline & CQ & 5,18 & 64,02
\end{tabular}

Campo 1 = SP71-1406; Campo $2=$ SP71-6163; CC = Cana Crua; CQ = Cana Queimada

Observa-se na Tabela 7 os valores de velocidade efetiva da colhedora, que é um parâmetro ponderal com tempo, conforme metodologia de RIPOLI \& MIALHE (1987) e de capacidade efetiva de colheita, que é função da densidade de colheita e da velocidade. As observações individualizadas para os parâmetros: velocidade e capacidade efetiva de colheita estão contidas respectivamente nas Tabelas 8 e 9 . 


\subsubsection{Velocidade efetiva de colheita.}

Pela interação realizada entre campo e tipo de cana para os fatores: velocidade efetiva e capacidade, não se obteve resultado significativo tanto para velocidade efetiva como para capacidade efetiva. A análise das médias é mostrada nas Tabelas 8 e 9 .

TABELA 8 - Comparação das médias de velocidade $(\mathrm{km} / \mathrm{h})$ nos diferentes campos e tipos de cana, através do teste $\mathrm{T}$.

\begin{tabular}{ccccc}
\hline & \multicolumn{2}{c}{ CAMPO ** $^{* *}$} & \multicolumn{2}{c}{ TIPO DE CANA ** } \\
\hline VARIAVEL & SP71-1406 & SP71-6163 & CRUA & QUEIMADA \\
\hline VELOCIDADE & 5,3450 & 4,8087 & 4,6500 & 5,5037 \\
EFETIVA $(\mathrm{km} / \mathrm{h})$ & & & & \\
\hline
\end{tabular}

** diferença estatística ao nível de $1 \%$ de probabilidade.

Pela Tabela 8 observa-se altas significâncias entre as variedades, apresentando um melhor desempenho de velocidade na variedade SP71-1406 do que na SP71-6163.

Com relação ao tipo de cana, a queima prévia, apresentou a melhor velocidade efetiva que a cana queimada, confirmando os trabalhos desenvolvidos por FURLANI NETO (1989); RIPOLI (1991); RIPOLI et al. (1992) e LIMA (1994). 
A Figura 1 contém as médias obtidas nos dois campos e nos tipos de cana.

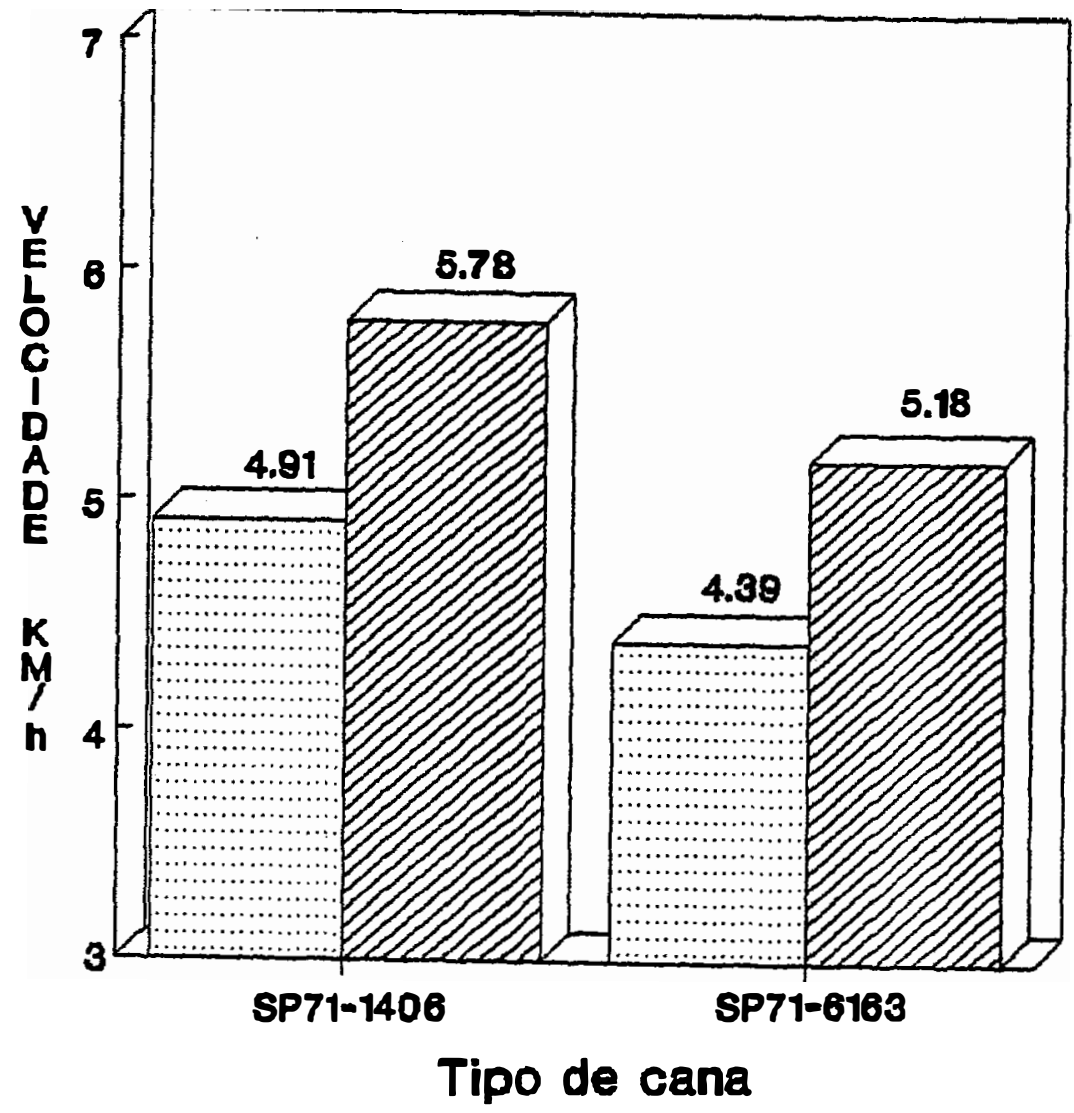

…… Cana Grua Ra Cana Queimada

FIGURA 1 - Médias entre velocidades efetivas de corte. 


\subsubsection{Capacidade efetiva.}

TABELA 9 - Comparação das médias de capacidade efetiva $(t / h)$ nos diferentes campos e tipos de cana, através do teste $\mathrm{T}$.

\begin{tabular}{lcccc}
\hline & \multicolumn{2}{c}{ CAMPO $^{* *}$} & \multicolumn{2}{c}{ TIPO DE CANA ** } \\
\hline \multicolumn{1}{c}{ VARIAVEL } & SP71-1406 & SP71-6163 & CRUA & QUEIMADA \\
\hline CAPACIDADE & 64,0600 & 60,5125 & 57,7800 & 66,7925 \\
EFETIVA $(\mathrm{t} / \mathrm{h}$ ) & & & & \\
\hline ** diferença com nivel de significância a $1 \%$. &
\end{tabular}

Pela Tabela 9 observa-se alta significância para a capacidade efetiva da colhedora, sendo que o melhor desempenho ocorreu na variedade SP71-1406 .

Para o parâmetro capacidade efetiva, conforme mostrado na Tabela 9, a queima prévia do canavial auxiliou o desempenho da máquina, obtendo um acréscimo médio de $15,60 \%$ (57,78 t/ha para 66,79 t/h) em relação ao canavial sem queima prévia, sendo esta diferença significativa ao nível de $1 \%$ de probabilidade. A figura 2 contém as diferenças obtidas entre as variedades e os tipos de colheita.

Estas reduções nas capacidades de colheita também foram observadas na colheita manual por HUMBERT et al. (1960), SAMUELS (1969), TILLMANN (1994), e confirmadas para colheita mecânica por FURLANI et al. (1989), RIPOLI (1991), RIPOLI et al. (1992), LIMA (1994). 


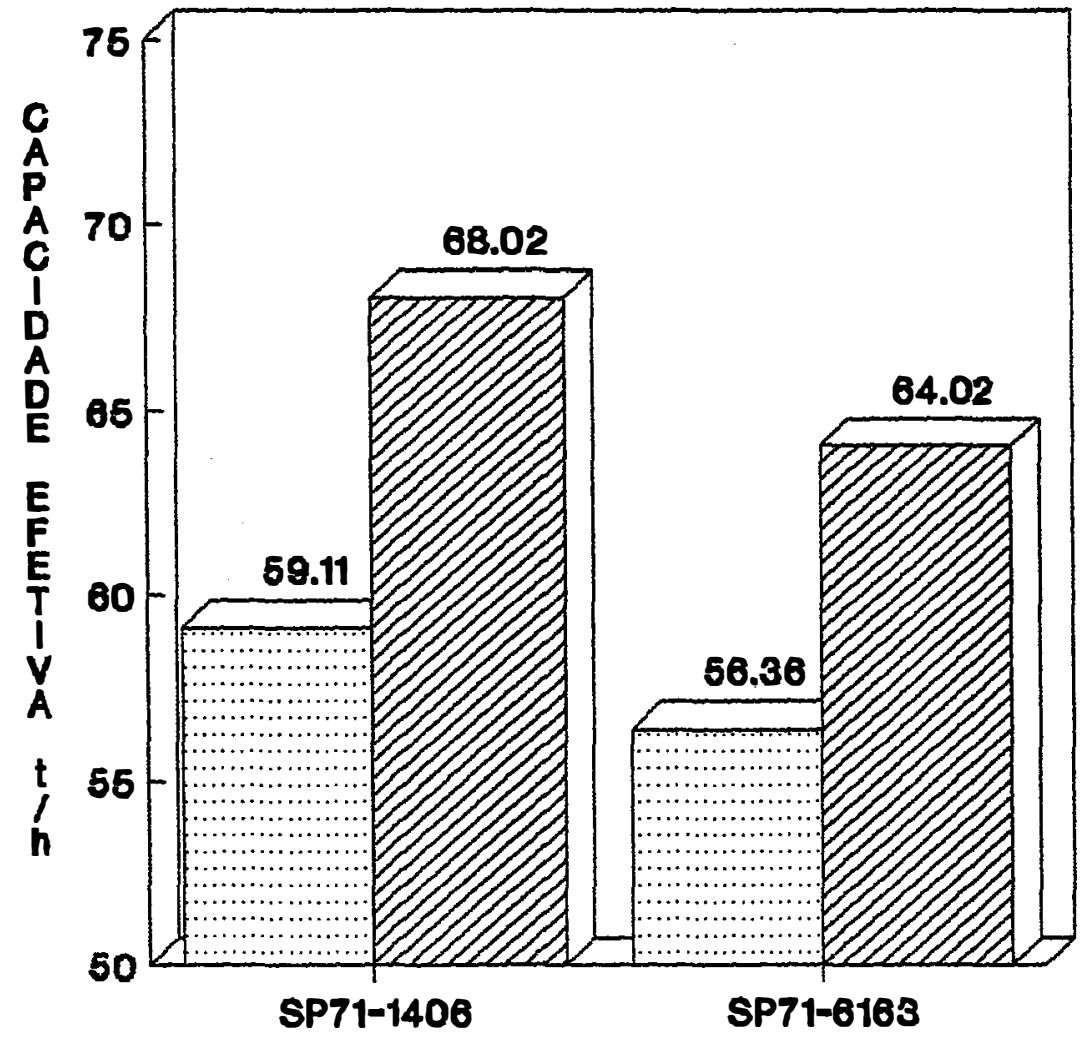

Tipo de cana

…... Cana Crua Q Cana Queimada

FIGURA 2 - Médias das capacidades efetivas da colhedora $(\mathrm{t} / \mathrm{h})$. 


\subsection{Avaliações quantitativas.}

Após a amostragem dos veículos de transporte, pela sonda do pagamento de cana pelo teor de sacarose, de cada repetição chegada à Usina, retirou-se uma amostra para as determinações quantitativas nos componentes da massa colhida, separando-os em 2 componentes: colmos e massa de matéria estranha, sendo que a massa de matéria estranha foi também separada em 2 componentes: massa vegetal, massa mineral e a somatória de ambas, denominado de massa total, conforme Tabelas 13, 14, 15 e 16 do apêndice 2.

Estes dados obtidos foram transformados em valores percentuais, cujos valores médios estão contidos na Tabela 10, sendo conferido a massa total amostrada o índice 100, para facilitar o confronto entre os tratamentos.

TABELA 10 - Valores percentuais médios dos componentes de massa colhida .

\begin{tabular}{|c|c|c|c|c|c|}
\hline \multirow[t]{2}{*}{ CAMPO } & \multirow{2}{*}{$\begin{array}{c}\text { TIPO DE } \\
\text { CANA }\end{array}$} & \multirow[t]{2}{*}{ COLMOS } & \multicolumn{3}{|c|}{ MATÉRIA ESTRANHA } \\
\hline & & & Vegetal & Mineral & Total \\
\hline \multirow[t]{2}{*}{1} & $\mathrm{CC}$ & 93,95 & 5,59 & 0,46 & 6,05 \\
\hline & CQ & 94,03 & 5,30 & 0,67 & 5,97 \\
\hline \multirow[t]{2}{*}{2} & $\mathbf{C C}$ & 88,40 & 10,70 & 0,90 & 11,60 \\
\hline & $\mathbf{C Q}$ & 94,98 & 4,01 & 1,01 & $\overline{5,02}$ \\
\hline
\end{tabular}


Os valores médios percentuais de cada componente isolado serão analisados pelo teste $\mathrm{T}$, conforme as tabelas $11,12,13$ e 14 e as Figuras 3,4 e 5 .

\subsubsection{Percentagem de Colmos contidos na matéria-prima.}

Para a variável colmos, obteve-se a interação significativa entre campo e tipo de cana, o que vale dizer que as variedades se comportaram diferentemente para os 2 tipos de condição de cana: crua e queimada.

Observa-se pelos dados contidos na Tabela 11, que para a variedade SP71-1406 (campo 1) não houve diferenças significativas para a variável colmos, quando se compara a cana crua com a queimada. Estas diferenças não são observadas na variedade SP71-6163, onde a percentagens de colmos colhidos na cana crua foi bem menor que na cana queimada. Isto é devido ao excesso de palhiço presente no material colhido sem a queima prévia do canavial na variedade SP71-6163 e a massa excessiva da variável ponteiro, elevando, a quantidade de matéria estranha vegetal, confirmando resultados de RIPOLI et al. (1991) e MOLINA JUNIOR (1991) e ABRAMO et al. (1993).

Observa-se também pelos dados percentuais de colmos, da tabela 11, que na variedade SP71-6163, os valores obtidos contradizem ao que foi obtido para densidade de matéria prima, apresentados na Tabela 5 . Uma outra variável, poderá ter causado esta diminuição no percentual de colmos na carga na SP71-6163, provavelmente os ponteiros, contidos na matéria estranha vegetal. 
TABELA 11 Comparação das médias percentuais de colmos nos tratamentos, através do teste $\mathrm{T}$ aplicado sobre a variável transformada.

\begin{tabular}{|c|c|c|c|c|c|c|}
\hline \multirow{2}{*}{\multicolumn{3}{|c|}{$\begin{array}{l}\text { Variáveis } \\
\text { Colmos \% }\end{array}$}} & \multicolumn{4}{|c|}{ Campos } \\
\hline & & & \multicolumn{2}{|c|}{1} & \multicolumn{2}{|c|}{2} \\
\hline \multirow[t]{2}{*}{ Campos } & Tipos & & Crua & Queimada & Crua & Queimada \\
\hline & & Médias & 93,9475 & 94,0550 & 88,4000 & 94,9787 \\
\hline \multirow[t]{2}{*}{1} & Crua & 93,9475 & - & NS & ** & NS \\
\hline & Queimada & 94,0550 & NS & - & ** & NS \\
\hline \multirow[t]{2}{*}{2} & Crua & 88,4000 & ** & $* *$ & - & ** \\
\hline & Queimada & 94,9787 & NS & NS & ** & - \\
\hline
\end{tabular}

\subsubsection{Matéria estranha vegetal.}

Para interpretar os resultados obtidos no componente matéria estranha vegetal, a interação entre "campo" e "tipo de cana" foi significativa, para tanto, analisouse as combinações pelo teste $\mathrm{T}$, aplicado na variável transformada, constantes na tabela 12. 
TABELA 12 - Comparação entre médias de matéria estranha vegetal, através do teste $T$, aplicado sobre a variável transformada.

\begin{tabular}{|c|c|c|c|c|c|}
\hline \multirow[b]{2}{*}{ Variedade } & & \multicolumn{2}{|c|}{ SP71-1406 } & \multicolumn{2}{|c|}{ SP71-6163 } \\
\hline & & $\overline{C C}$ & $\overline{C Q}$ & $\overline{C C}$ & CQ \\
\hline \multirow{5}{*}{ SP71-1406 } & & & & & \\
\hline & $\overline{C C}$ & - & NS & * & $*$ \\
\hline & 5,5913 & & & & \\
\hline & $\mathrm{CQ}$ & NS & - & ** & NS \\
\hline & 5,2950 & & & & \\
\hline \multirow[t]{4}{*}{ SP71-6163 } & $\mathrm{CC}$ & * & $* *$ & - & $* *$ \\
\hline & 10,6250 & & & & \\
\hline & $\mathrm{CQ}$ & * & NS & ** & - \\
\hline & 4,0113 & & & & \\
\hline
\end{tabular}

Observa-se pela Tabela 12, que na variedade SP71-1406, não houve diferenças significativas para a variável matéria estranha vegetal entre os tratamentos.

Não houve diferenças para matéria estranha vegetal entre as duas variedades, quando queimou-se previamente o canavial. Foi encontrado um acréscimo significativo quando comparamos o desempenho da cana crua na SP71-6163 com a SP71-1406 (figura 3), o que confirma os resultados obtidos para a diminuição do percentual de colmos na SP71-6163, foram causados pelo excesso de matéria estranha vegetal nas cargas. 
A variedade SP71-6163 apresentou um significativo acréscimo de matéria estranha vegetal, quando colhida sem queima com um acréscimo médio de $165,08 \%$ à maior que a cana queimada, conforme mostrado na Figura 3. Tem-se que levar em conta que o período as condições climáticas reinantes, em dias anteriores ao do corte, houveram precipitações, que podem ter influenciado nestes altos valores obtidos.

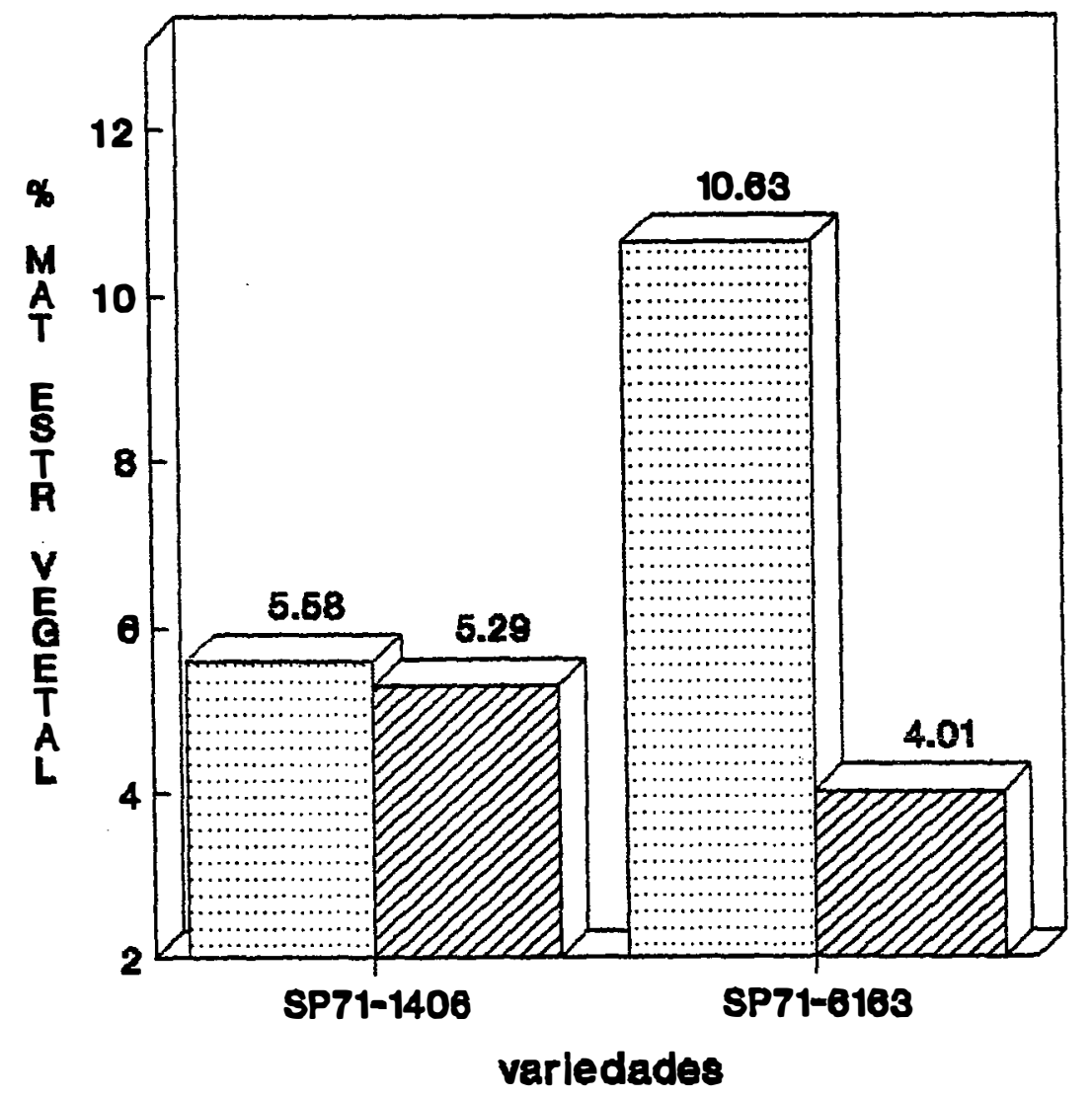

Cana Grua Cana Queimada

FIGURA 3 - Percentagens médias obtidas de matéria estranha vegetal nos tratamentos. 
Estes valores de matéria estranha vegetal obtidos nos campo 2, estão acima dos encontrados por LIMA (1994), RIPOLI (1991) em colhedoras e abaixo dos valores percentuais obtidos por TILLMANN (1994), para estas mesmas variedades, em sistema semi-mecanizado.

\subsubsection{Matéria estranha mineral.}

Para a variável matéria estranha mineral não houve uma interação significativa entre campo e tipo de cana. A Tabela 13 contém o confronto entre médias de matéria estranha mineral.

TABELA 13 - Confronto entre as médias de matéria estranha mineral, através do teste $\mathrm{T}$.

\begin{tabular}{lcccc}
\hline & \multicolumn{2}{c}{ CAMPO ** } & \multicolumn{2}{c}{ TIPO DE CANA * } \\
\hline \multicolumn{1}{c}{ VARIAVEL } & SP71-1406 & SP71-6163 & CRUA & QUEIMADA \\
\hline $\begin{array}{l}\text { MATÉRIA } \\
\text { ESTRANHA } \\
\text { MINERAL }\end{array}$ & 0,5525 & 0,9550 & 0,6800 & 0,8275 \\
\hline $\begin{array}{l}* \text { diferença de significância a } 5 \% . \\
\text { ** diferença de significância a } 1 \% .\end{array}$ & & & \\
\end{tabular}

Observa-se que houve um acréscimo altamente significativo para a variedade SP71-6163 em relação à SP71-1406 para a variável matéria estranha mineral.

Uma das prováveis causas desse excesso de terra nas cargas é que a maior quantidade de folhas e palhas encontradas na variedade SP71-6163, citados por 
MATSUOKA \& ARIZONO (87), TILLMAN (1994) pode ter dificultado a visualização do corte de base, provocando uma penetração maior dos discos de corte basal no solo.

A variável matéria estranha mineral na colheita da cana crua foi, significativamente reduzido, conforme os dados contidos na tabela 13.

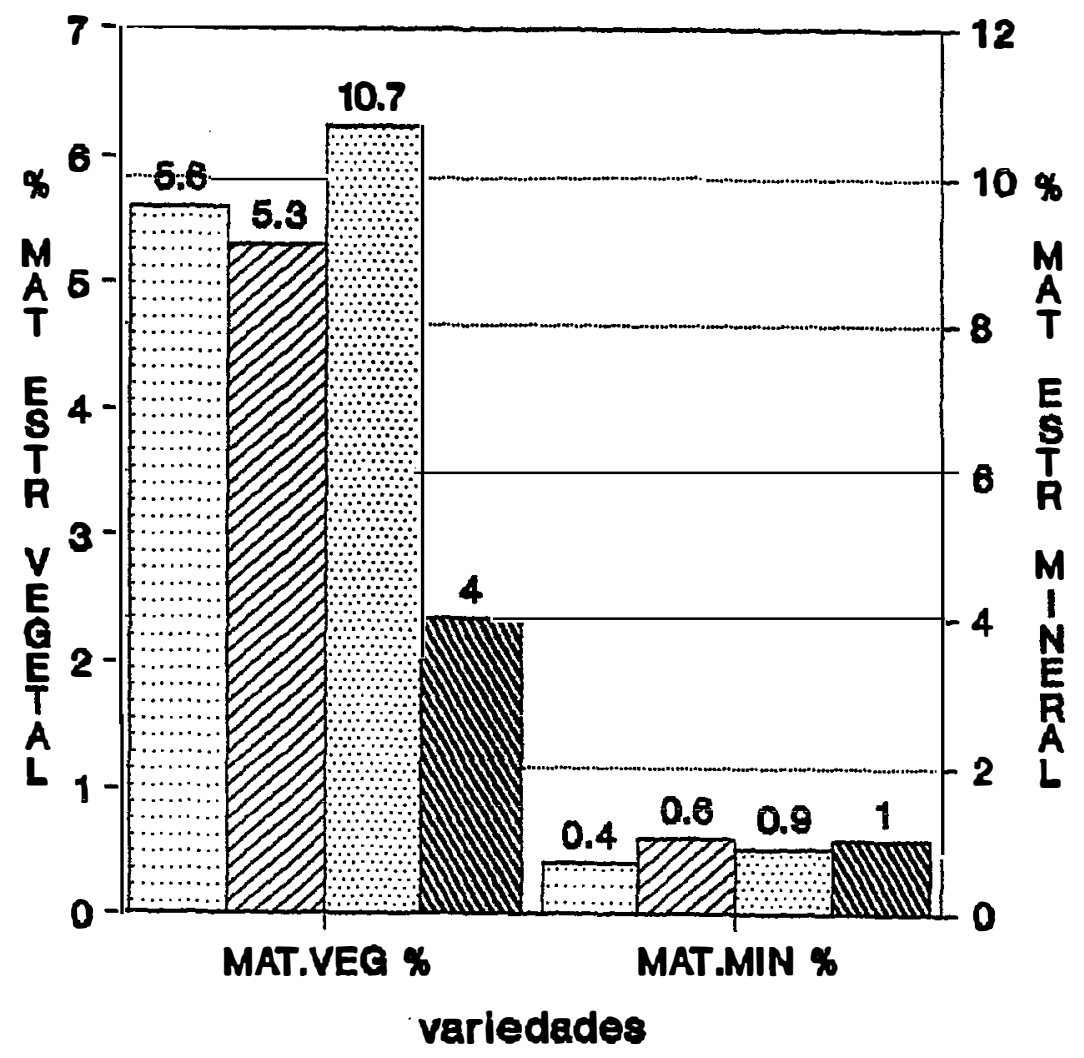

CC-SP71-140B DCD CQ-SP71-1406

CC-SP71-6168 AllW CQ-SP71-6168

FIGURA 4 - Valores percentuais de matéria estranha vegetal e mineral. 
Esses valores confirmam os resultados apresentados por FURLANI et al. (1989), RIPOLI (1991) e LIMA (1994).

Os resultados percentuais médios de matéria estranha mineral em cana queimada apresentaram um acréscimo de $21,69 \%$ na matéria-prima colhida.

\subsubsection{Matéria estranha total.}

Para o componente matéria estranha total, que se constitui na somatória das matérias estranhas vegetal e mineral, a interação entre campo e tipo de cana foi significativa conforme Tabela 10 (apêndice 1), portanto desdobrou-se a análise estatística nas 4 combinações de níveis dos fatores, cujos resultados estão contidos na Tabela 14.

TABELA 14 - Comparação entre Médias de Matéria Estranha Total, através do teste T, aplicado sobre a variável transformada.

\begin{tabular}{|c|c|c|c|c|c|}
\hline \multirow[b]{2}{*}{ Variedade } & & \multicolumn{2}{|c|}{ SP71-1406 } & \multicolumn{2}{|c|}{ SP71-6163 } \\
\hline & & $\overline{C C}$ & $\overline{C Q}$ & $\overline{C C}$ & $\mathrm{CQ}$ \\
\hline \multirow[t]{2}{*}{ SP71-1406 } & $\mathrm{CC}$ & - & NS & ** & $\mathbf{N S}$ \\
\hline & $\overline{C Q}$ & NS & - & ** & NS \\
\hline \multirow[t]{2}{*}{ SP71-6163 } & $\overline{C C}$ & ** & ** & - & $* *$ \\
\hline & $\overline{C Q}$ & NS & $\overline{\mathrm{NS}}$ & ** & - \\
\hline
\end{tabular}


Observa-se pela Tabela 14 que, à semelhança da matéria estranha vegetal, a matéria estranha total não apresentou diferenças significativas entre a cana crua ou queimada dentro da variedade SP71-1406. Na variedade SP71-6163 o acréscimo de matéria estranha foi altamente significativo para o corte da cana crua, com um acréscimo médio da ordem de $129,68 \%$ em relação a cana queimada.

A figura 5 contém os percentuais de matéria estranha total obtidos nas cargas amostradas, pela sonda, e separados manualmente em laboratório.

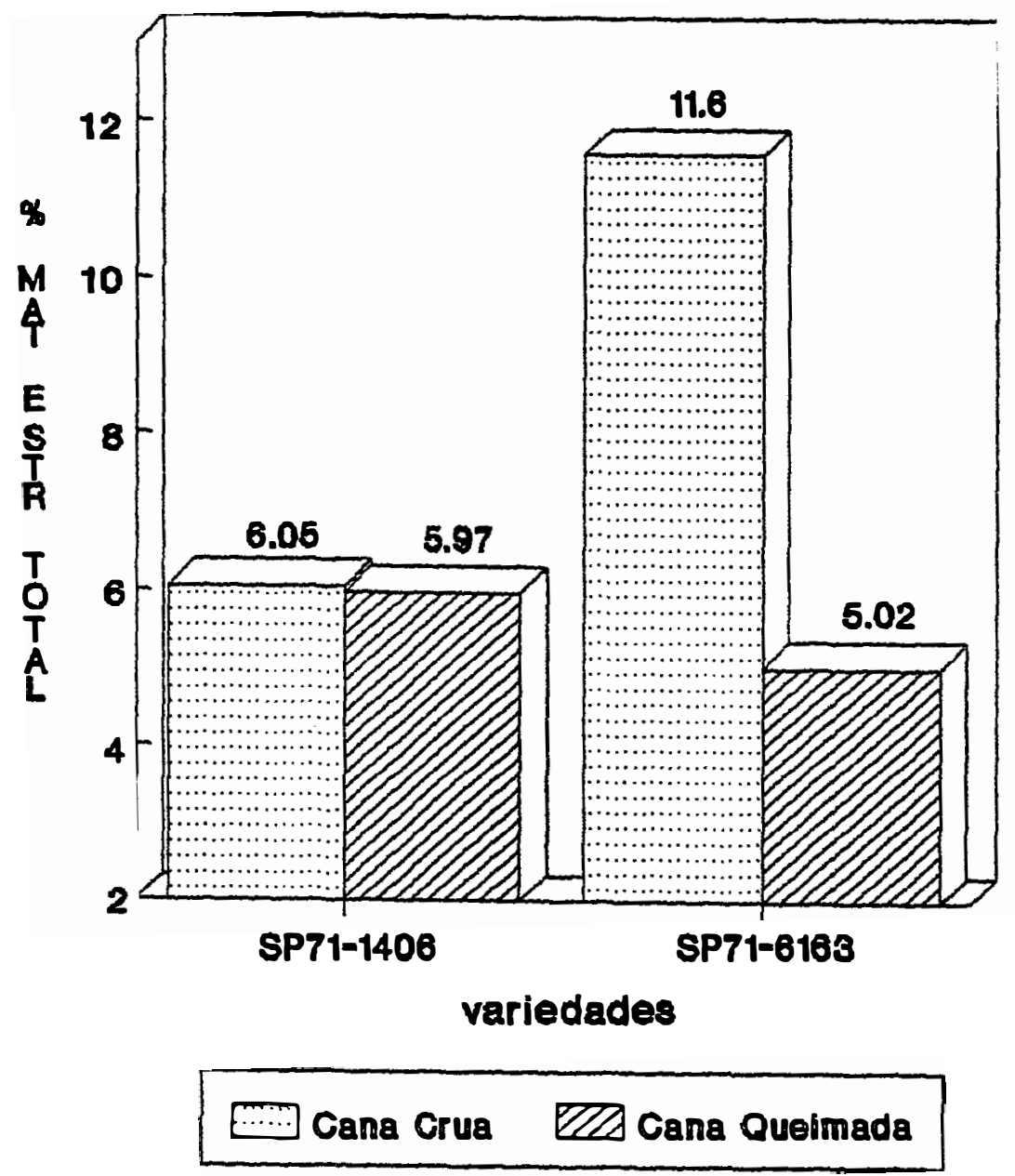

FIGURA 5- Valores percentuais de matéria estranha total. 


\subsection{Análises tecnológicas nas massas colhidas mecanicamente.}

Foram realizadas análises tecnológicas nas amostras retiradas de cada veículo, contemplando os parâmetros de: brix \%, pol. \% caldo, pureza \%, fibra \% e pol. $\%$ cana corrigido (PCC) cujos resultados se encontram constantes nas tabelas 9, 10, 11 e 12 do anexo (2).

As análises tecnológicas da matéria prima colhida forneceram os resultados apresentados na tabela 15 .

TABELA 15 - Resultados médios das análises tecnológicas nas massas do material colhido.

\begin{tabular}{|c|c|c|c|c|c|c|}
\hline CAMPO & TIPO CANA & BRIX \% & Pol \% & PUREZA & FIBRA \% & $\begin{array}{c}\text { Pol \% Cana } \\
\text { Corrigido }\end{array}$ \\
\hline \multirow[t]{2}{*}{1} & $\overline{\mathrm{CC}}$ & 21,50 & 18,56 & 86,28 & 14,83 & 14,54 \\
\hline & CQ & 20,42 & 17,71 & 86,72 & 14,03 & 14,00 \\
\hline \multirow[t]{2}{*}{2} & $\overline{\mathrm{CC}}$ & 21,96 & 20,30 & 92,44 & 18,77 & 15,23 \\
\hline & CQ & 21,32 & 19,99 & 93,76 & 16,03 & 15,76 \\
\hline
\end{tabular}

Para cada componente da análise tecnológica foi feita uma análise pelo teste $\mathrm{T}$, cujos parâmetros se seguem: 


\subsubsection{Brix \% caldo.}

A determinação dos sólidos solúveis no caldo, denominado Brix \%, apresentou os dados médios contidos na Tabela 15 onde pode-se observar pela análise de variança entre campo e tipo de cana a não ocorrencia de diferenças significativas. A Tabela 16 apresenta o confronto entre as médias através do teste $\mathrm{T}$, obtendo-se uma diferença significativa ao nível de $5 \%$ para as duas variedades testadas, com maior Brix $\%$ no caldo, para a SP71-6163.

TABELA 16 Comparação de Médias Brix \% nos tratamentos, através do teste T.

\begin{tabular}{ccccc}
\hline & \multicolumn{2}{c}{ CAMPO* } & \multicolumn{2}{c}{ TIPO DE CANA** } \\
\cline { 2 - 4 } VARIÁVEL & SP71-1406 & SP71-6163 & CRUA & QUEIMADA \\
\cline { 2 - 4 } BRIX \% & 20,9687 & 21,6394 & 21,7363 & 20,8719 \\
\hline
\end{tabular}

* diferença estatística significativa à $5 \%$ de probabilidade.

** diferença estatística significativa à $1 \%$ de probabilidade.

$\mathrm{Na}$ comparação estatística entre a cana crua e queimada, para o componente Brix \%, houve um acréscimo significativo em favor do sistema de cana crua, nas duas variedades estudadas, comprovando os resultados obtidos por ELIAS (1976), FURLANI et al. (1989), STUPIELLO (1989), STUPIELLO (1992), MUTTON et al. (1992),ana crua. 


\subsubsection{POL \% caldo.}

Os açúcares contidos no caldo analisado estão representados pelo Pol \% caldo, sendo constatado não haver interação significativa entre campo e tipo de cana na análise de variança (Tabela 10 - anexo 1).

Efetuou-se a comparação de médias de Pol \% caldo nos tratamentos, conforme mostrados na Tabela 17.

TABELA 17 Confronto de médias de pol $\%$ caldo nos tratamentos, através do teste T.

\begin{tabular}{lcccc}
\hline & \multicolumn{2}{c}{ CAMPO** $^{*}$ TIPO DE CANA* } \\
\cline { 2 - 4 } VARIÁVEL & SP71-1406 & SP71-6163 & CRUA & QUEIMADA \\
\cline { 2 - 4 } POL \% CALDO & 18,1406 & 20,1425 & 19,4331 & 18,8500 \\
\hline & & & \\
* diferença significativa ao nível de 5\% de probabilidade. & \\
**diferença significativa ao nivel de 1\% de probabilidade.
\end{tabular}

Observa-se, que, para as 2 variedades, a SP71-6163 foi que apresentou o melhor índice de Pol \% caldo nas cargas, confirmando os resultados de JOHN (1994) e LIMA (1994) .

Com relação ao tipo de colheita de cana, o sistema de cana sem a queima prévia, proporcionou índices médios maiores para Pol \% caldo em relação à cana queimada, elevando em aproximadamente em $0,58 \%$, sendo significativamente superior ao nível de $5 \%$ de probabilidade, para as duas variedades testadas. 


\subsubsection{Pureza \% caldo.}

Os totais de açúcar contidos nos sólidos solúveis do caldo, representado pela pureza \% caldo, não apresentaram resultados estatisticamente significativos para a interação entre campo e tipo de cana, resultando para sua melhor compreensão uma comparação das médias dos dois fatores pelo teste $\mathrm{T}$, conforme a Tabela 18.

TABELA 18 Comparação das médias de Pureza \% através do teste T.

\begin{tabular}{lcccc}
\hline & \multicolumn{2}{c}{ CAMPO** $^{*}$} & \multicolumn{2}{c}{ TIPO DE CANA } \\
\cline { 2 - 5 } VARIÁVEL & SP71-1406 & SP71-6163 & CRUA & QUEIMADA \\
\cline { 2 - 5 } PUREZA \% & $\mathbf{8 6 , 5 2 0 6}$ & $\mathbf{9 2 , 9 7 5 0}$ & $\mathbf{8 9 , 3 8 3 1}$ & $\mathbf{9 0 , 1 1 2 5}$ \\
\hline & & & & \\
\hline
\end{tabular}

** significativo a 1\% de probabilidade.

Para o componente Pureza \% não houve diferença significativa ao nível de $5 \%$ de probabilidade entre cana crua e queimada. Os resultados obtidos confirmam os de BIRKETT (1967), FURLANI NETO et al. (1989), BUREAU OF SUGAR EXPER.STATIONS (1987) e STUPIELLO(1989).

As únicas diferenças significativas observadas foram entre as variedades, com vantagem para a SP71-6163. 


\subsubsection{Fibra \%}

O componente fibra \% contida no material colhido foi submetido a uma análise de variança, sendo significativa a interação entre campo e tipo de cana.

A tabela 19 contém a comparação das médias nas 4 combinações possíveis, realizado sobre a variável transformada.

TABELA 19 - Comparação de Médias de Fibra \%, através do teste T.

\begin{tabular}{|c|c|c|c|c|c|}
\hline \multirow[b]{2}{*}{ Variedade } & & \multicolumn{2}{|c|}{ SP71-1406 } & \multicolumn{2}{|c|}{ SP71-6163 } \\
\hline & & $\overline{C C}$ & $\overline{C Q}$ & $\overline{\mathrm{CC}}$ & CQ \\
\hline \multirow[t]{4}{*}{ SP71-1406 } & CC & - & * & ** & $* *$ \\
\hline & $(14,83)$ & & & & \\
\hline & $\overline{C Q}$ & * & - & $* *$ & $* *$ \\
\hline & $(14,03)$ & & & & \\
\hline \multirow[t]{4}{*}{ SP71-6163 } & $\mathrm{CC}$ & $* *$ & $* *$ & - & $* *$ \\
\hline & $(18,77)$ & & & & \\
\hline & $\overline{C Q}$ & $* *$ & $* *$ & ** & - \\
\hline & $(16,03)$ & & & & \\
\hline
\end{tabular}

* diferença significativa à $5 \%$ de probabilidade.

* diferença significativa à $1 \%$ de probabilidade

Pela tabela 19 observa-se que a colheita da cana crua, elevaram significativamente os teores de fibra \% em relação à queimada, independentemente da 
variedade, dando um maior diferencial na variedade SP71-6163, onde os acréscimos das impurezas vegetais nas cargas, contribuíram para estes diferenciais elevados.

Os acréscimos de fibra \% na carga de cana crua para a variedade SP716163 foram bem maiores que para cana queimada, acrescendo $2,74 \%$ na matéria prima. Para a variedade SP71-1406 estes índices também foram significativamente superiores para a cana crua, atingindo acréscimo de $0,8 \%$.

Estes acréscimos nos valores de fibra \% na colheita de cana sem queima prévia, são também confirmados por trabalhos de AYALA et al. (1975), CERRIZUELA (1977), STUPIELLO (1989), MOLINA JUNIOR (1991), RIPOLI et al. (1991) e TILLMANN (1994).

\subsubsection{Pol \% cana corrigido.}

De todos os parâmetros tecnológicos, o pol \% cana corrigido é o mais importante, porque engloba, indiretamente, todos os demais e é um dos principais índices avaliados na fabricação industrial de açúcar e álcool, através de amostragens da matériaprima entregues na recepção industrial.

Analisando os dados obtidos de Pol \% cana corrigido através de uma análise de variança, foi constatada uma interação entre campo e tipo de cana.

A comparação de médias, através do teste $T$ aplicado sobre a variável transformada estão contidos na tabela 20 . 
TABELA 20 - Confronto de médias de Pol \% Cana Corrigido (PCC).

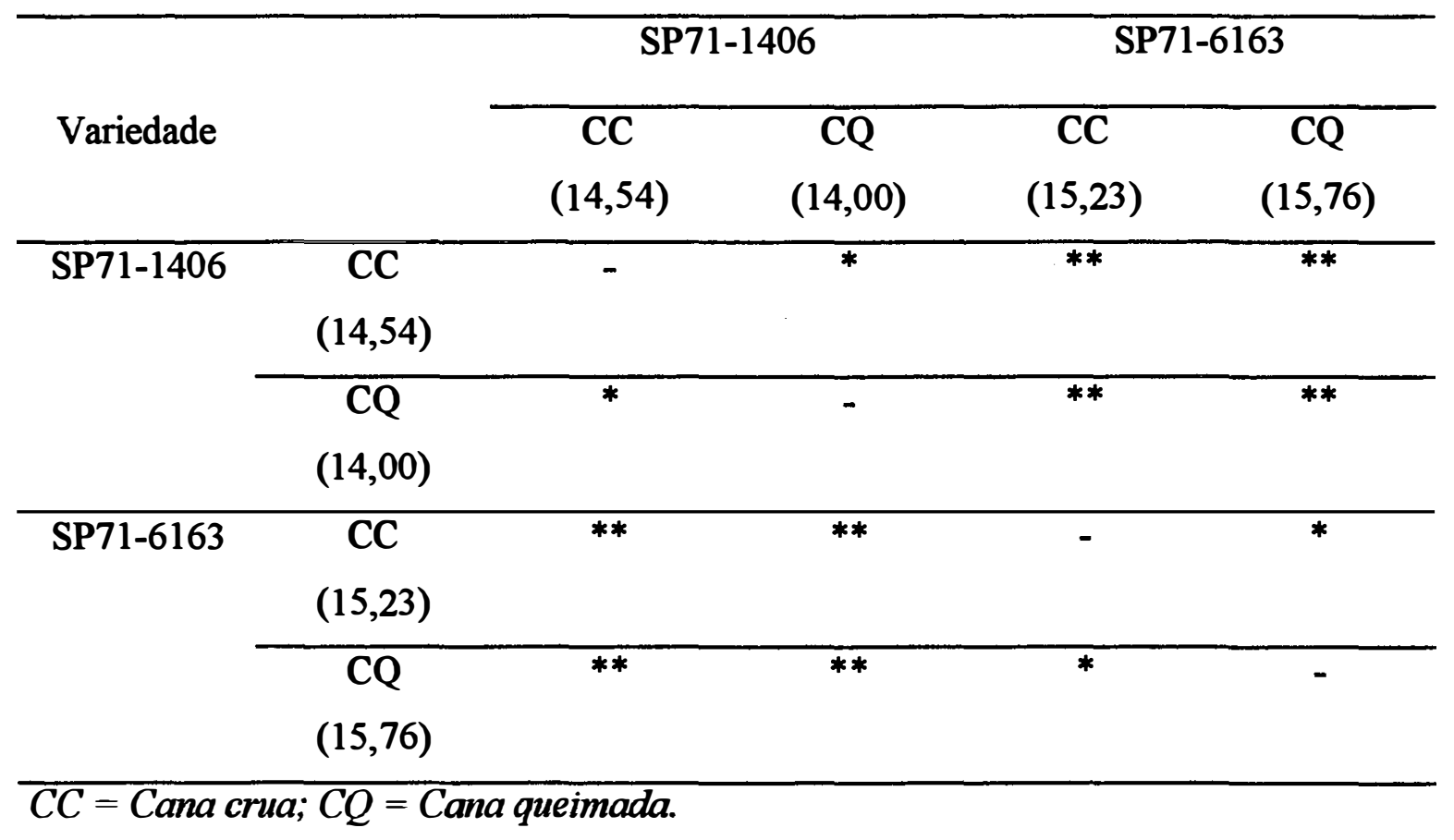

Observa-se pela tabela 20 que na variedade SP71-1406 houve uma diferença significativa com melhor comportamento em relação a qualidade industrial para a cana crua, ao passo que, para uma variedade com excesso de folhas e palhas, como é a SP71-6163, o excesso de matéria estranha vegetal contida das cargas, ocasionou um excesso de fibra $\%$, resultando um decréscimo significativo no teor de pol $\%$ cana corrigido (PCC) da cana crua em relação à queimada.

Observa-se pela tabela 15 , que apesar dos resultados tecnológicos nas variedades SP71-1406 (campo 1) e SP71-6163 (campo 2) apresentarem teores de brix \% e pol \% caldo significativamente superiores para a cana crua em relação à queimada, o valor final de PCC da matéria prima para a SP71-6163, beneficiou a cana queimada, 
elevando os teores finais de pol \% cana corrigido em $0,53 \%$, sendo que para a variedade SP71-1406 esta diferença já beneficiou a cana crua, elevando os valores de pol \% cana corrigido em $0,54 \%$.

Todas estas diferenças são melhor visualizadas na figura 6 , onde são apresentado os resultados médios de PCC no material colhido em ambas variedades.

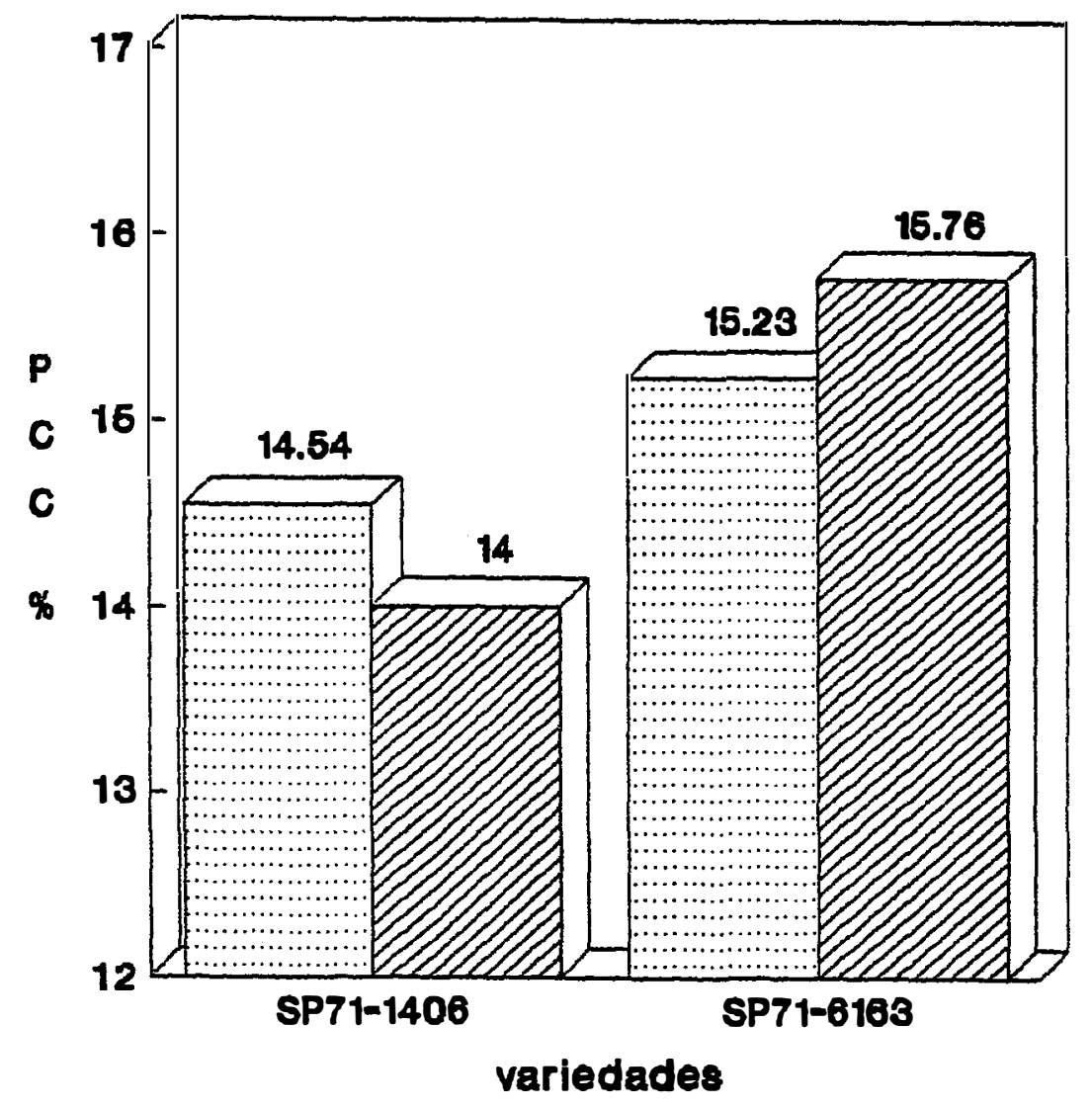

FIGURA 6 - Resultados médios de pol \% cana corrigido (PCC) nas massas do material colhido mecanicamente. 


\subsubsection{Totais de açúcar nos processos de colheita.}

Com os resultados médios obtidos de total de massa colhida/ha e na qualidade tecnológica do material colhido, expresso em pol \% cana corrigido, foram estimados os totais de açúcar entregue na Usina pelos processos de colheita, cujos resultados estão contidos na tabela 21 .

TABELA 21 - Valores totais médios calculados de açúcar por unidade de área.

\begin{tabular}{ccccc}
\hline VARIEDADE & TIPO/CANA & t/ha & PCC & $\mathrm{kg} \mathrm{pol} / \mathrm{ha}$ \\
\hline SP71-1406 & $\mathrm{CC}$ & 84,87 & 14,54 & $12.365,60$ \\
& $\mathrm{CQ}$ & 84,03 & 14,00 & $11.764,20$ \\
\cline { 2 - 5 } & & & & \\
\hline SP71-6163 & $\mathrm{CC}$ & 90,42 & 15,23 & $13.770,96$ \\
\cline { 2 - 5 } & $\mathrm{CQ}$ & 87,10 & 15,76 & $13.726,96$ \\
\hline CC = Cana crua; $C Q=$ Cana queimada. & & \\
\end{tabular}

Pelos valores contidos na tabela 21, permite-se afirmar que para a variedade SP71-1406 a colheita da cana crua, resultou num acréscimo de 601,4 kg de pol por ha e para a variedade SP71-6163 praticamente não houve diferenças acentuadas em açúcar/ha, diferindo de $44 \mathrm{~kg}$ de pol/ha entre os sistemas de colheita.

Considerando o total de açúcar entregue na usina, entre as hipóteses do trabalho, observa-se sempre haver uma ligeira vantagem para o corte mecânico da cana 
crua, confirmando os trabalhos de BIRKETT (1967), FURLANI NETO et al. (1989), BUREAU OF SUGAR EXPER STATIONS (1987) e STUPIELLO (1989).

\subsection{Perdas de material industrializável no campo após a colheita.}

Os resultados médios obtidos pela quantificação das perdas no campo nas parcelas em pós-colheita, são apresentados na Tabela 22.

Esses valores correspondem ao potencial das perdas de matéria prima que ficam após a colheita, sobre o terreno, resultante de inúmeros fatores, sendo constituídos de: pontas(frações de colmos agregados à ponteiro), tocos, frações de colmos, e rebolos . A perda total foi calculada com a somatória das perdas parciais.

TABELA 22 - Quantificação das perdas no campo em pós-colheita .

$(\mathrm{kg} /$ parcela)

\begin{tabular}{ccccccc}
\hline CAMPO & TIPO CANA & PONTA & TOCOS & $\begin{array}{c}\text { FRAÇÕES/ } \\
\text { COLMOS }\end{array}$ & REBOLOS & TOTAL \\
\hline 1 & CC & 2,69 & 1,70 & 0,86 & 4,09 & 9,34 \\
& CQ & 0,41 & 0,45 & 0,33 & 1,33 & 2,92 \\
\hline 2 & CC & 0,41 & 1,30 & 0,77 & 2,05 & 4,53 \\
\cline { 2 - 7 } & CQ & 0,45 & 1,13 & 0,81 & 1,81 & 4,20
\end{tabular}

Campo $1=$ SP71-1406; Campo $2=S P 71-6163 ; C C=$ Cana crua; $C Q=$ Cana queimada.

Foi realizada uma análise estatística individual, por componente de perda, comparando as médias, através do teste $\mathrm{T}$, conforme segue-se: 


\subsubsection{Perda de frações de colmos agregados ao ponteiro.}

Analisando estatisticamente as diferenças para cada componente de perda pós-colheita, obteve-se para o componente fração de colmo agregasdo a ponteiro uma interação entre campo e tipo de cana, portanto pela análise das médias pelo teste $T$, contidas na tabela 23 , realizada sobre a variável transformada, observa-se:

TABELA 23 - Comparação de médias de perdas de colmo agregado através do teste T.

( $\mathrm{kg} /$ parcela )

\begin{tabular}{|c|c|c|c|c|c|}
\hline \multirow[b]{2}{*}{ Variedade } & & \multicolumn{2}{|c|}{ SP71-1406 } & \multicolumn{2}{|c|}{ SP71-6163 } \\
\hline & & $\mathrm{CC}$ & CQ & $\overline{C C}$ & CQ \\
\hline \multirow[t]{4}{*}{ SP71-1406 } & $\mathrm{CC}$ & - & ** & ** & ** \\
\hline & $(2,69)$ & & & & \\
\hline & $\mathrm{CQ}$ & ** & - & NS & NS \\
\hline & $(0,40)$ & & & & \\
\hline \multirow[t]{4}{*}{ SP71-6163 } & $\mathbf{C C}$ & ** & NS & - & NS \\
\hline & $(0,41)$ & & & & \\
\hline & $\mathbf{C Q}$ & ** & NS & NS & - \\
\hline & $(0,45)$ & & & & \\
\hline
\end{tabular}

Pela análise deste componente de perda pós-colheita denominado fração de colmo agregado a ponteiro, observam-se pelas tabelas 22 e 23 , que o desponte pela colhedora na variedade SP71-1406 em cana crua, foi o mais alto que os demais tratamentos, diferindo estatisticamente de todos, independente da variedade e do tipo de cana, sendo que os demais tratamentos não diferiram entre si. 


\subsubsection{Perda de tocos em pós-colheita.}

Para a variável tocos, foi observada pela análise de variança, uma interação entre campo e tipo de cana.

Para visualizar melhor estas diferenças, realizou-se uma comparação entre médias, pelo teste $T$, sobre a variável transformada, cujos resultados estão contidos na tabela 24.

TABELA 24 - Comparação de médias de perdas tocos na parcela em pós-colheita , através do teste $T$.

( $\mathrm{kg} /$ parcela )

\begin{tabular}{|c|c|c|c|c|c|}
\hline \multirow[b]{2}{*}{ CAMPO } & & \multicolumn{2}{|c|}{ SP71-1406 } & \multicolumn{2}{|c|}{ SP71-6163 } \\
\hline & & $\overline{\mathrm{CC}}$ & CQ & $\mathrm{CC}$ & CQ \\
\hline \multirow[t]{4}{*}{1} & $\mathrm{CC}$ & $\overline{-}$ & ** & NS & NS \\
\hline & $(1,70)$ & & & & \\
\hline & CQ & $* *$ & - & $* *$ & $* *$ \\
\hline & $(0,45)$ & & & & \\
\hline \multirow[t]{3}{*}{2} & $\overline{\mathrm{CC}}$ & NS & ** & - & NS \\
\hline & $(1,30)$ & & & & \\
\hline & $\overline{\mathrm{CQ}}$ & NS & ** & NS & - \\
\hline
\end{tabular}

Campo 1 = SP71-1406; Campo $2=$ SP71-6163; CC = Cana crua; CQ = Cana queimada.

** = indica diferença significativa a $1 \%$ de probabilidade entre as médias.

Na variedade SP71-1406 obteve-se significancia entre os tratamentos.

Para a SP71-6163 não houve diferenças entre a cana crua e queimada. Estes acréscimos 
nas perdas em toco no campo 2 podem ser devidos a vários fatores que interagem : desníveis acentuados no terreno ocasionados pelo cultivo, o que pode-se descartar, pois estava com a SP71-1406 em $4^{0}$ corte, praticamente nivelada em relação à entrelinha. Outro fator que poderia ter influenciado nestas diferenças é a falta de visão ocasionada pela variedade, influindo positivamente para que, pequenas oscilações no deslocamento da máquina, associado com velocidade, propiciem acréscimos de perdas no campo em tocos, de acordo com LIMA (1994). Verificou-se que no caso específico da SP71-1406 houve uma abaixamento maior do disco de corte basal da colhedora, quando trabalhou-se em cana queimada, resultando também como consequência um aumento nos valores de terra \% na carga observados pela tabela 13 e gráfico 4 , que foram significativamente diferentes maiores de terra \% para a cana queimada em relação à crua. Estes valores diferem dos valores médios obtidos por LIMA (1994), onde o corte mecânico da cana crua reduziu-se de 0,8 para $0,67 \mathrm{t} / \mathrm{ha}$, da cana queimada para crua.

\subsubsection{Perda de frações de colmo em pós-colheita.}

Para o componente frações de colmo em pós-colheita a análise de variança não apresentou diferença significativa entre campo e tipo de cana.

A tabela 25 contém a comparação das médias das perdas em pedaços industrializáveis. 
TABELA 25 - Comparação das médias de perdas em frações de colmo em pós-colheita ( $\mathrm{kg} /$ parcela )

\begin{tabular}{lcccc} 
& \multicolumn{2}{c}{ CAMPO } & \multicolumn{2}{c}{ TIPO DE CANA } \\
\cline { 2 - 5 } VARIÁVEL & 1 & 2 & CRUA & QUEIMADA \\
\cline { 2 - 5 } $\begin{array}{c}\text { Perdas em frações } \\
\text { de colmos }(\mathrm{kg})\end{array}$ & 0,7731 & 0,7037 & 0,8206 & 0,7463 \\
\hline
\end{tabular}

Observa-se pelos dados da tabela 25 não haver diferenças significativas para perdas de fração de colmo entre as variedades e para os tipos de colheita mecânica em crua e queimada, conforme trabalho de FURLANI NETO et al.(1989) e BALBO (1994), mas diferindo dos resultados de LIMA (1994).

\subsubsection{Perda de rebolos em pós-colheita.}

Houve uma interação significativa para a análise de variança entre campo e tipo de cana, portanto foi realizada para o componente rebolos, uma comparação de médias pelo teste $\mathrm{T}$, sobre a variável transformada, obtendo-se os resultados mostrados na tabela 26.

Observa-se que para as perdas de rebolos, na cana crua da SP71-1406, aumentou-se as perdas de rebolos em relação a todos os outros tipos de colheita, independendo do tipo de colheita ou variedade, que se igualaram entre si. 
TABELA 26 - Comparação de médias de rebolos em pós-colheita, através do teste T, em valores transformados.

(kg/parcela)

\begin{tabular}{|c|c|c|c|c|c|}
\hline \multirow[b]{2}{*}{ CAMPO } & & \multicolumn{2}{|c|}{ SP71-1406 } & \multicolumn{2}{|c|}{ SP71-6163 } \\
\hline & & $\mathrm{CC}$ & CQ & $\mathrm{CC}$ & $\overline{C Q}$ \\
\hline \multirow[t]{4}{*}{1} & $\mathrm{CC}$ & - & $* *$ & ** & ** \\
\hline & $(4,09)$ & & & & \\
\hline & CQ & $* *$ & - & NS & NS \\
\hline & $(1,73)$ & & & & \\
\hline \multirow[t]{4}{*}{2} & $\overline{\mathrm{CC}}$ & $* *$ & $\mathrm{NS}$ & - & NS \\
\hline & $(2,05)$ & & & & \\
\hline & $\mathrm{CQ}$ & $* *$ & NS & NS & - \\
\hline & $(1,81)$ & & & & \\
\hline
\end{tabular}

Observa-se também um ligeiro acréscimo, embora não significativo, na variedade SP71-6163 para o componente de perda de rebolos. Para a variedade SP711406 estas diferenças foram significativas e bem maiores entre cana crua e queimada, chegando ao índice de $236 \%$ de acréscimo de perdas na cana-crua em relação à queimada.

Os resultados obtidos para o campo 1, variedade SP71-1406, confirmam os resultados médios da Usina São Martinho, durante a safra de 93/94 apresentados por LIMA (1994), onde as perdas por rebolos na cana crua foram $244 \%$ maiores que às obtidas com cana queimada (de 0,5 t/ha cana queimada para 1,22 t/ha na cana crua). 


\subsubsection{Perdas totais em pós-colheita.}

Obteve-se uma análise significativa para a variância para o componente perdas totais quando comparou-se campo com tipo de cana. Foi realizada uma comparação de médias, através do teste $\mathrm{T}$ sobre a variável transformada, obtendo-se a tabela 27.

Observa-se pelos dados da Tabela 27 que as perdas totais de cana no campo, foram maiores para a SP71-1406 em cana crua, diferindo significativamente de todos outros tratamentos de campo e tipo de cana, os quais não diferiram entre si. Estas diferenças foram devidas ao acréscimo dos principais componentes de perdas que foram pontas (frações de colmos agregados a ponteiro) e rebolos.

TABELA 27 - Comparação de médias de perdas totais nos diferentes campos e tipos de cana, através do teste $\mathrm{T}$ aplicado em valores transformados.

$(\mathrm{kg} /$ parcela $)$

\begin{tabular}{|c|c|c|c|c|c|}
\hline \multirow[b]{2}{*}{ CAMPO } & & \multicolumn{2}{|c|}{ SP71-1406 } & \multicolumn{2}{|c|}{ SP71-6163 } \\
\hline & & $\overline{C C}$ & CQ & $\overline{\mathrm{CC}}$ & $\overline{C Q}$ \\
\hline \multirow[t]{2}{*}{1} & $\begin{array}{c}\mathrm{CC} \\
(13,72)\end{array}$ & - & ** & ** & ** \\
\hline & $\begin{array}{c}\text { CQ } \\
(7,64)\end{array}$ & ** & - & $\mathrm{NS}$ & $\mathrm{NS}$ \\
\hline \multirow[t]{2}{*}{2} & $\begin{array}{c}\text { CC } \\
(8,91)\end{array}$ & ** & NS & - & NS \\
\hline & $\begin{array}{c}\text { CQ } \\
(8,58)\end{array}$ & ** & $\overline{\mathrm{NS}}$ & NS & - \\
\hline
\end{tabular}


Isto quer dizer que a colhedora na variedade SP71-1406 perdeu pelo desponte, pelo toco e pelo componente rebolo, que resultou em uma perda total na canacrua, bem superior aos demais tratamentos.

Para a variedade SP71-6163 não houve diferença entre as perdas totais no campo entre a cana-crua e a queimada, confirmando os resultados obtidos por FURLANI NETO et. al. (1989) para as variedades NA 5679 e na SP71-1406 e RIPOLI (1991) na variedade NA 5679 e SP70-1143, não observaram diferenças significativas nas perdas totais entre a cana crua e a queimada, sendo que LIMA (1994) obteve os valores médios para a safra 93/94 de 3,86 t/ha para a cana crua e 3,54 t/ha para a queimada

\subsection{Potencial das perdas no campo em pós-colheita.}

A tabela 28 contém as transformações das perdas no campo em $\mathrm{kg}$ de pol por área, baseadas nas análises tecnológicas dos componentes de perdas.

Observa-se pela tabela 28 que no campo 1 as perdas em açúcar por área na cana crua em relação à queimada foram superiores ao campo 2 onde quase não houve diferenças acentuadas para as perdas no campo, em $\mathrm{kg}$ de pol/ha. 
TABELA 28 - Componentes de perdas no campo, respectivas análises tecnológicas (PCC) e as perdas totais em açúcar no campo.

\begin{tabular}{|c|c|c|c|c|c|c|}
\hline$\overline{\text { CAMPO }}$ & $\begin{array}{l}\text { TIPO } \\
\text { CANA }\end{array}$ & $\begin{array}{c}\text { Componente } \\
\text { de Perda }\end{array}$ & $\mathrm{kg} / \mathrm{ha}$ & PCC & $\begin{array}{l}\text { Sub-totais } \\
\mathrm{kg} \mathrm{Pol} / \mathrm{ha}\end{array}$ & Total \\
\hline \multirow{8}{*}{1} & $\overline{\mathrm{CC}}$ & Ponta & 947 & 8,95 & 84,75 & \\
\hline & & Toco & 598 & 15,70 & 93,88 & \\
\hline & & Pedaço & 303 & 15,84 & 48,09 & \\
\hline & & Rebolos & 1.440 & 16,0 & 230,4 & 457,12 \\
\hline & CQ & Ponta & 143 & 7,91 & 11,31 & \\
\hline & & Toco & 158 & 11,65 & 18,40 & \\
\hline & & Pedaço & 116 & 13,18 & 15,28 & \\
\hline & & Rebolo & 609 & 13,63 & 83,00 & 127,99 \\
\hline \multirow{8}{*}{2} & $\mathrm{CC}$ & Ponta & 144 & 11,06 & 15,92 & \\
\hline & & Toco & 457 & 19,60 & 89,57 & \\
\hline & & Pedaço & 271 & 20,17 & 54,66 & \\
\hline & & Rebolo & 722 & 19,30 & 139,34 & 299,49 \\
\hline & $\overline{\mathrm{CQ}}$ & Ponta & 158 & 10,93 & 17,27 & \\
\hline & & Toco & 397 & 19,52 & 77,49 & \\
\hline & & Pedaço & 285 & 20,34 & 57,97 & \\
\hline & & Rebolo & 637 & 19,50 & 124,21 & 276,94 \\
\hline
\end{tabular}

Campo $1=$ SP71-1406; Campo $2=$ SP71-6163; CC = Cana crua; CQ = Cana queimada. $P C C=$ Pol \% cana corrigido. 
4.7. Totais de açúcar obtidos na usina e perdidos no campo nos tratamentos.

Partindo dos resultados obtidos no material entregue na usina (total de massa) e o PCC das análises tecnológicas pode-se determinar o potencial geral colhido e total perdido no campo, através da colheita mecânica, cujos valores estão contidos na tabela 29.

TABELA 29 - Totais de açúcar expressos em $\mathrm{kg}$ de pol por ha entregues na usina e perdidos no campo.

\begin{tabular}{ccccc}
\hline CAMPO & Tipo Cana & $\begin{array}{c}\text { Entregues/usina } \\
\mathrm{kg} \mathrm{de} \mathrm{pol/ha}\end{array}$ & $\begin{array}{c}\text { Perdas/campo } \\
\mathrm{kg} \mathrm{de} \mathrm{pol/ha}\end{array}$ & $\begin{array}{c}\text { Total } \\
\mathrm{kg} \mathrm{de} \mathrm{pol} / \mathrm{ha}\end{array}$ \\
\hline 1 & CC & 12.365 & 457 & 12.822 \\
& $\mathrm{CQ}$ & 11.764 & 128 & 11.892 \\
\hline 2 & $\mathrm{CC}$ & 13.770 & 299 & 14.069 \\
& $\mathrm{CQ}$ & 13.726 & 277 & 14.003 \\
\hline
\end{tabular}

\subsection{Resíduos de pós-colheita}

A análise de variância das médias dos dados originais podem ser observadas na tabela 30 as significâncias obtidas para resíduos de pós-colheita. 
TABELA 30 - Comparação de médias de resíduos de pós-colheita em kg/parcela, através do teste $\mathrm{T}$.

\begin{tabular}{|c|c|c|c|c|c|}
\hline \multirow[b]{2}{*}{ CAMPO } & & \multicolumn{2}{|c|}{ SP71-1406 } & \multicolumn{2}{|c|}{ SP71-6163 } \\
\hline & & $\mathrm{CC}$ & $\overline{C Q}$ & CC & CQ \\
\hline & $\begin{array}{c}\mathrm{CC} \\
(38,3766)\end{array}$ & - & $* *$ & *** & ** \\
\hline 1 & $\begin{array}{c}\text { CQ } \\
(22,9828)\end{array}$ & $* *$ & - & ** & $* *$ \\
\hline & $\begin{array}{c}\mathrm{CC} \\
(69,0656)\end{array}$ & $* *$ & $* *$ & - & $* *$ \\
\hline 2 & $\begin{array}{c}\text { CQ } \\
(29,1078)\end{array}$ & ** & $* *$ & $* *$ & - \\
\hline
\end{tabular}

Campo 1 = SP71-1406; Campo $2=$ SP71-6163; CC = Cana crua; $C Q=$ Cana queimada.

** = diferença significativa à $1 \%$ de probabilidade.

Estes valores médios obtidos, estão contidos na Tabela 30 e na figura 7, onde pode-se verificar que os resíduos da cana crua na SP71-1406 foram de 67,01\% superiores a queimada e na SP71-6163 estes acréscimos foram de $137,27 \%$. Estes acréscimos nos resíduos pós colheita e diferenças varietais também foram encontradas por ZALAUF et al. (1985) MOLINA JUNIOR (1991), RIPOLI et al. (1991); TILLMANN (1994); e para diferentes idades e variedades de cana, mas, com valores sempre superiores em massa vegetal de pos-colheita para a cana crua.

Observa-se pela tabela 30 que houveram diferenças significativas entre todas as comparações de médias, sempre com maiores acréscimos para a cana crua em 


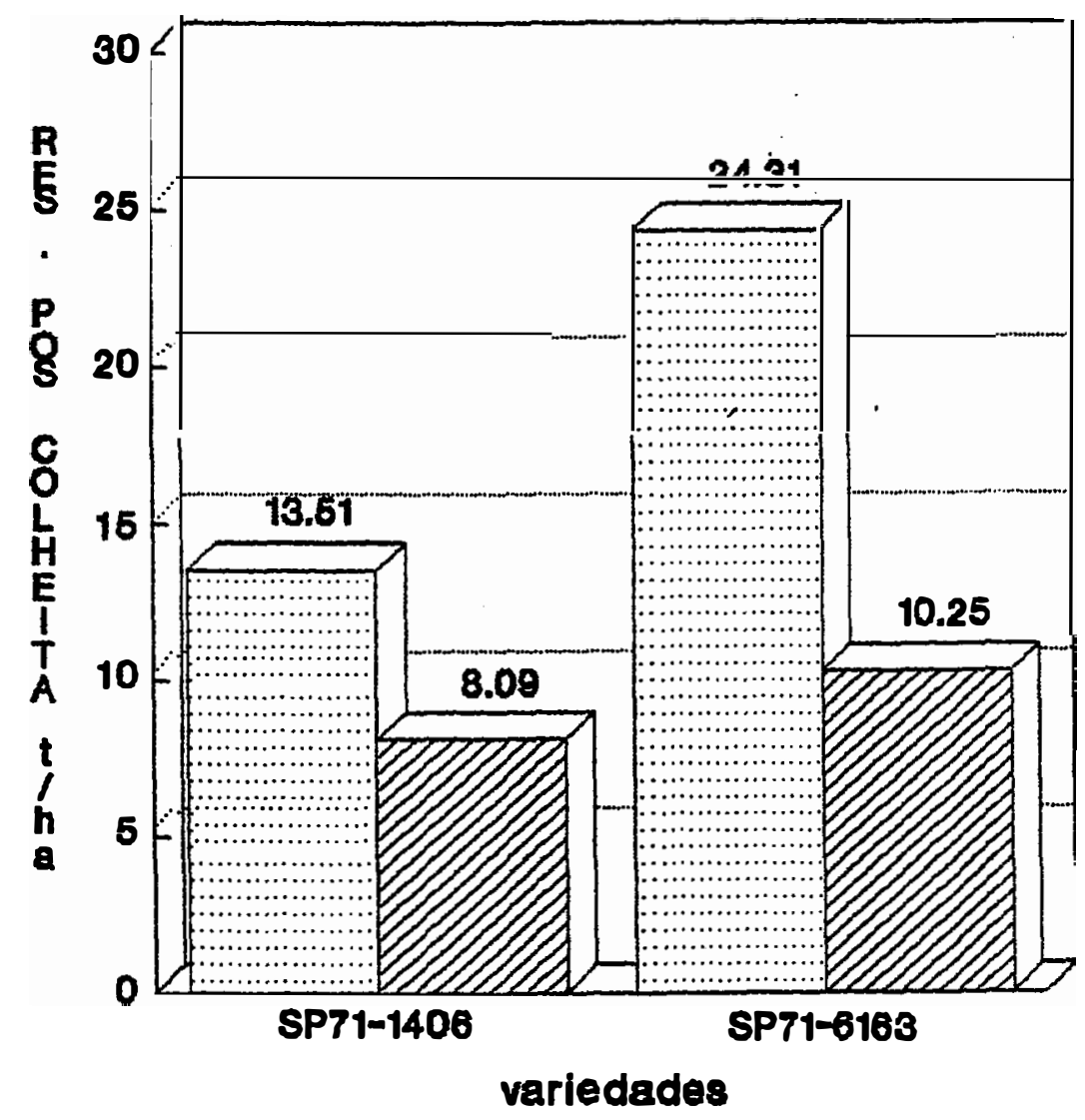

…... Cana Crua

FIGURA 7 - Resíduos médios obtidos em pós-colheita mecânica nos tratamentos.

relação à queimada. Quando compara-se as duas variedades, independentemente do tipo de cana (queimada ou crua), os maiores valores de resíduos de pós-colheita foram para a variedade SP71-6163. 
4.9. Determinação da energia contida nos resíduas de pós-colheita.

Nestes resíduos de pós-colheita foram realizadas as determinações de umidade \% nos componentes, cujos valores são apresentados na Tabela 31:

TABELA 31 - Resultados percentuais de umidade nos diferentes componentes dos resíduos

\begin{tabular}{cccc}
\hline CAMPO & Componente & CC & CQ \\
\hline \multirow{2}{*}{1} & Ponta & 81,4 & 82,70 \\
& Folha verde & 56,8 & 53,7 \\
& Palha & 15,13 & 10,50 \\
\hline \multirow{2}{*}{2} & Ponta & 80,1 & 78,60 \\
& Folha verde & 67,3 & 59,30 \\
& Palha & 18,70 & 8,80 \\
\hline
\end{tabular}

Observa-se pela Tabela 31 que o único componente que teve a umidade reduzida pela ação do fogo, foi o componente palha. Foram determinadas estas umidades para poder-se determinar o Poder Calorífico Superior(PCS) .

Os valores médios determinados para a energia contida no resíduo, expressos em Poder Calorífico Superior são apresentadas na tabela 32. 
TABELA 32 - Determinação da energia contida no resíduo pós-colheita.

\begin{tabular}{ccccccc}
\hline CAMPO & Tipo Cana & $\begin{array}{c}\text { Resíduos* } \\
\mathrm{kg} / \mathrm{ha}\end{array}$ & $\begin{array}{c}\text { PCS } \\
\mathrm{kcal} / \mathrm{kg}\end{array}$ & PCI & Mcal/ha & $\begin{array}{c}\text { Índice Total } \\
\%\end{array}$ \\
\hline 1 & $\mathrm{CC}$ & 13.514 & 4.365 & 2.148 & $58.988,6$ & $(100)$ \\
& $\mathrm{CQ}$ & 8.091 & 4.430 & 2.185 & $35.843,1$ & $(60,8)$ \\
\hline 2 & $\mathrm{CC}$ & 24.316 & 4.660 & 2.316 & $113.312,5$ & $(100)$ \\
& $\mathrm{CQ}$ & 10.250 & 4.485 & 2.216 & $45.971,2$ & $(40,6)$ \\
& & & & & & \\
\hline
\end{tabular}

Pela análise dos resultados da energia contida no resíduo, obtidos em $\mathrm{Mcal} /$ ha, na tabela 32 e pela figura 8 , observam-se que nos índices totais, para a variedade SP71-1406 a redução de energia/ha em Mcal/ha foi de 39,2\%, ao passo que no campo 2, para a variedade SP71-6163 esta redução, em razão da queimada foi de $59,40 \%$. Estes altos valores de perdas energéticas decorrentes da queima dos canaviais diferiram dos resultados obtidos para o corte manual por MOLINA JUNIOR (1991), RIPOLI (1991), TILLMANN (1994) e confirmando os valores obtidos para o corte mecânico por RIPOLI et al. (1991), e, por ABRAMO FILHO et al. (1993) para a SP716163, embora estudassem variedades com diversas idades, qualidades de queima diferentes e com outras produtividades agnícolas. 


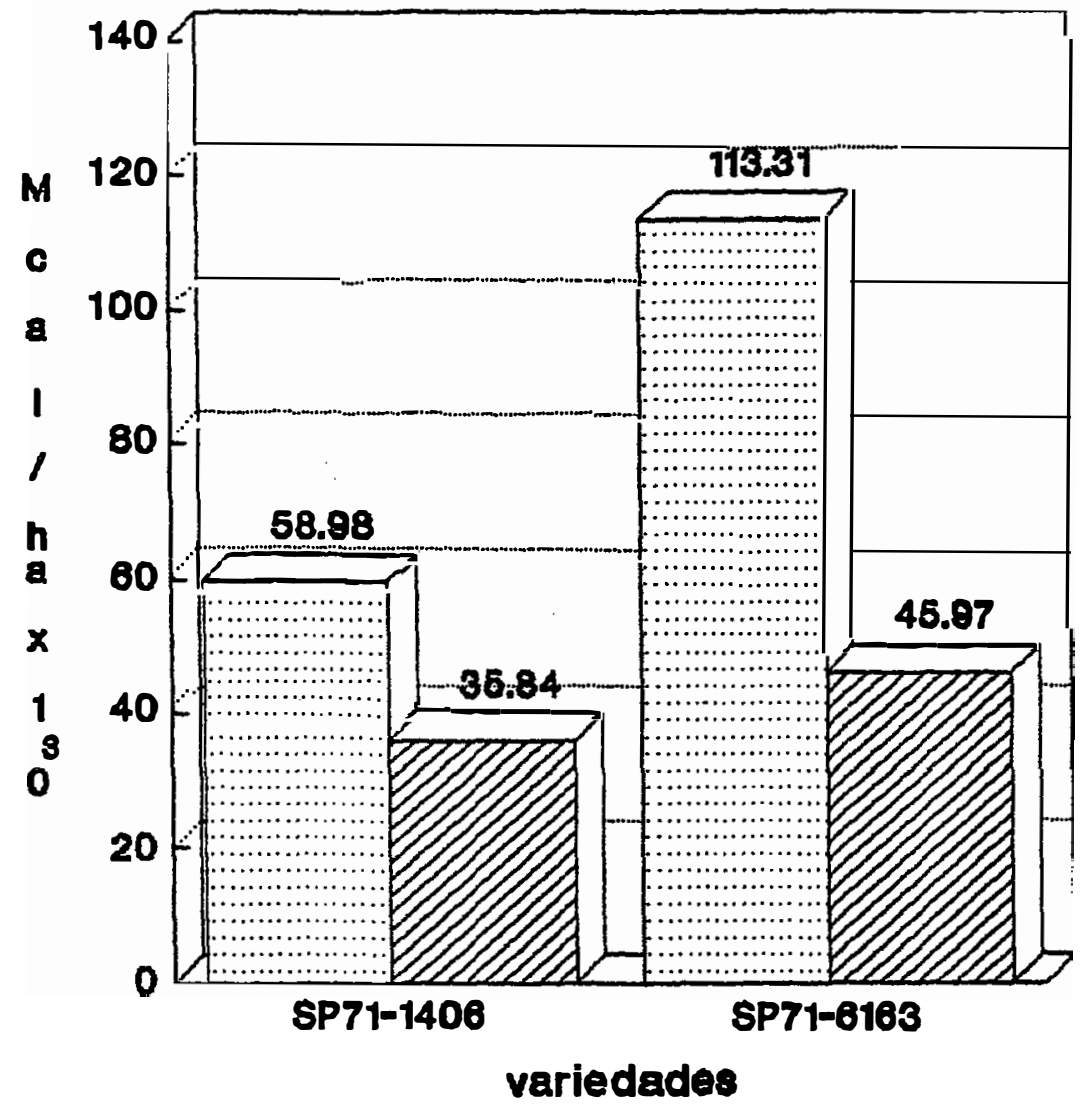

\section{Cana Crua Cana Queimada}

FIGURA 8 - Energia contida no resíduo de pós-colheita nos tratamentos.

\subsection{Vantagens indiretas do resíduo da cana crua.}

Para a conservação dos solos agricolas, este palhiço residual da colheita mecânica da cana crua que permanece sobre o terreno, de 13,51 t para a SP71-1406 e de 24,31 t para a variedades SP71-6163, contribuem na diminuição do impacto das gotas de 
chuva sobre o terreno, diminuindo o arrastro de material mineral, citados por LOMBARDI (1994).

Uma vantagem econômica importante dessa quantidade de resíduo de póscolheita presentes sobre a área, é que o mesmo, permanecendo uniformemente distribuído sobre o terreno, conforme pode-se observar nas 256 amostras retiradas nos 2 campos, sendo 64 amostras/tratamento, promovem, segundo MUZIK (1970) CRAFTS (1975), e LORENZI et al. (1989) e BALBO (1994) um controle às ervas invasoras, permitindo uma redução drástica no uso de herbicidas, obtendo uma economia por área de $10 \% \mathrm{em}$ relação as queimadas.

O palhiço total sobre o terreno em pós-colheita da cana crua, proporcionará ao solo um retorno de nutrientes aos solos agrícolas, principalmente o nitrogênio $(\mathrm{N})$, enxofre (S) e matéria orgânica, que a queima fatalmente reduzirá, conforme trabalhos de DEMATTÊ (1988), BODDEY et al. (1993), resultando também inúmeras vantagens citados por RIPOLI \& VILLA NOVA (1992), ABRAMO FILHO et al. (1993), CHURCHWARD \& POULSEN (1988) e BALBO (1994).

KIRCHHOFF (1991) afima: "A queima do canavial implicará em danos irreparáveis à humanidade, devido aos aspectos ligados a poluição atmosférica, por interferir na camada de ozônio". Para o ozônio $\left(\mathrm{O}_{3}\right)$ os trabalhos de WARNER (1968) e por FRANCO (1992) para a grande região de Ribeirão Preto/SP, confirmam as afirmações de autor.

A queima prévia do canavial para a colheita da cana-de-açúcar, traz inúmeros inconvenientes à região circunvizinha, devido às partículas sólidas em 
suspensão no ar, que são levadas para altas camadas da estratosfera terrestre, sendo arrastadas pelos eventuais ventos dominantes, às cidades, importunando e irritando moradores, sujando roupas, áreas livres públicas e particulares, conforme citados por JOHN (1994) nas principais cidades canavieiras.

Sabe-se que em diversos países canavieiros, a técnica da colheita mecânica da cana crua, avaliada na presente pesquisa, já se constitui uma realidade e que fatalmente à curto prazo, será adotada inquestionavelmente no Brasil, devido a principalmente aos aspectos ecológicos, conservacionistas, industriais e, principalmente, aos aspectos energéticos envolvidos no processo de queima prévia dos canaviais, gerando um desperdício inútil de energia, que poderá constituir em um futuro bem próximo, de lucros ao setor sucro-alcooleiro e principalmente ao país, conforme trabalhos de RIPOLI \& VILLA NOVA (1992). 


\section{CONCLUSÕES}

Em face aos resultados obtidos no presente trabalho, permite-se as seguintes conclusões:

- $\quad$ O sistema de colheita mecânica da cana crua foi plenamente viável, pois embora resultem numa diminuição no rendimento de corte, apresentam como vantagens melhoria na qualidade tecnológica, diminuição nas impurezas minerais, conservação do resíduo pós colheita sobre o solo e evitando uma perda energética pela queima dos canaviais.

- O componente do colmo que teve sua massa, mais reduzida pela queima do canavial, foram as folhas, representando uma redução de $5.423 \mathrm{~kg} / \mathrm{ha}$ para a SP711406 e de $14.066 \mathrm{~kg}$ / ha para a SP71-6163.

- O aumento na velocidade da colhedora resultou em decréscimos significativos no pol( \%) cana corrigida ( PCC ).

- Os aumentos na densidade de matéria prima e fibra(\%) nas cargas foram inversamente significativos à velocidade de deslocamento da colhedora.

- A queima do canavial resultou aumentos significativos na velocidade de deslocamento $(+18,36 \%)$, e na capacidade efetiva da colheita $(+15,60 \%)$. 
- A qualidade tecnológica do brix caldo, pol caldo e fibra foram significativamente superiores para a cana crua .

- Na SP71-1406 houve um acréscimo de 0,54\% na qualidade do PCC e de $601,4 \mathrm{~kg}$ de pol/ha para a cana crua, sendo na SP71-6163 reduzido de 0,53\% na PCC, resultando em $44 \mathrm{~kg}$ pol/ha para a cana crua.

- As perdas em cana crua após a colheita na SP71-1406 foram bem maiores que a cana queimada, ocasionadas por todos os componentes de perdas avaliados: ponta, tocos e rebolos. Para a SP71-6163 não houveram diferenças entre o total de cana.

- Na variedade SP71-6163, os acréscimos de resíduos em pós-colheita, propiciado pela cana crua foram bem superiores à SP71-1406, obtendo-se os seguintes valores percentuais de acréscimos em relação à cana-queimada: 67,01\% na SP71-1406 e de $137,27 \%$ na variedade SP71-6163.

- O potencial energético total de resíduo sobre o terreno é uma função varietal, obtendo sempre maiores valores para a variedade SP71-6163, independentemente do tipo de cana: crua ou queimada.

- A queima do canavial promoveu uma perda energética de $(39,2 \%)$ 23.143 Mcal/ha para a SP71-1406 e de 67.341 Mcal/ha (59,4\%) para a SP71-6163 em (PCS) Poder Calorífico Superior. 


\section{REFERÊNCIAS BIBLIOGRÁFICAS}

ABRAMO FILHO, J., MATSUOKA, S., SPERANDIO, M. L., RODRIGUES, R. C. D., MARCHETTI, L. L. Resíduos da colheita mecanizada de cana-crua. Álcool e Acúcar, São Paulo, v. 67, p. 3-25, 1993.

AGUILAR, A., PENA, V., FRIEDMAN, P., BRITO, B. La combustion de los resíduos agricolas de caña de azúcar. Parte I. Caracteristica de los Combustibles. Cuba Azúcar, Havana, ene/mar 1989, 40p.

ANUÁRIO ESTATÍSTICO BRASILEIRO, Rio de Janeiro, v:22, 1992, 413p.

ANUÁRIO ESTATÍSTICO DO ESTADO DE SÃO PAULO. Informações Econômicas do Instituto de Economia Agrícola. v.22 ; n 1, jan 1992, 82p.

ASSOCIAÇÃO BRASILEIRA DE NORMAS TÉCNICAS-ABNT. Carvão vegetal: determinação do poder calorífico - Método de Determinação. NBR-8633.Rio de Janeiro, 1984. 13p.

ARCENAUX, G., DAVIDSON, L .G. Some effects of trash in cane on milling results.

Sugar Joumal_New Orleans, v. 35, n. 10, p. 35-41, 1973.

ARNAL, J. I. Problematica de la quema de la caña. In: COSECHA MECANIZADA DE LA CAÑA DE AZÚCAR. Caracas: Distrib.Venez. de Azúcar, 1976. p.23-34. 
AYALA, H. G., DELFINI, A., BRAVO, D. Influencia del tipo de cosecha de caña de azúcar sobre las perdidas de sacarose en fabrica. In: Cosecha Mecanica Tucumán: Estación Experimental Agrícola de Tucumán, 1975. 5p. (Publicacion Miscelania, 53).

AYRES, A. S., HAGIHARA, H. H. A lysimeter study of losses of nitrogen and potassium. Hawaiian Planter's Record, Honolulu, v. 56, p. 255-275, 1963.

AZZI, G. M. Incidencia de matéria estranha nos processos de carregamento da cana-deaçúcar. Piracicaba/SP:RDSLQ, 1967. 112 p. (Doutorado - ESALQ/USP).

BALBO, L. A Colheita da cana crua. In: SEMINÁRIO DE COLHEITA MECÂNICA, 1, 1994, Ribeirão Preto. 5 p. (no prelo)

BELTRAME, L. F. S., GONDIM, L. A. P., TAYLOR, J. C. Estrutura e compactação na permeabilidade dos solos do R. G. do Sul. Revista Brasileira de Ciência do Solo, Campinas, v. 5, n. 3, p.145-149, 1981.

BERTELLI, L. G. Dezesseis anos de Proálcool. STAB. açúcar, alcool e subprodutos, Piracicaba, v. 11, n. 1, p. 19-20, set./out. 1992.

BIRKETT, L. S. The influence of tops and trash on the economics of sugar production. In: Congress of the ISSCT, 12, Puerto Rico, 1965. Proceedings: "Amsterdam: Elsevier, 1967. p.1636-1642.

BODDEY, R. M., OLIVEIRA, O. C., GUTMARĀES, H. D., URQUIAGA, S. Efeito da queima e aplicacões de vinhaça e adubo nitrogenado no rendimento e acúmulo de nitrogênio de cana-de-açúcar. In: CONGRESSO NACIONAL DA STAB, 5, 1993. p.82-86. 
BRITO, J. O., BARRICHELLO, L. E. G. Aspéctos técnicos na utilização da madeira e carvão vegetal como combustíveis. In: SEMINÁRIO DE ABASTECIMENTO ENERGÉTICO INDUSTRIAL COM RECURSOS FLORESTAIS, 2.,São Paulo, 1982. Anais._ S.Paulo: Secretaria da Ciência e Tecnologia, 1982. p.101-108.

BUREAU OF SUGAR EXPERIMENT STATIONS. Anual Report Sidney, 1987. 48p. CAMPOS, H. Estatística Experimental Não-Paramétrica. 4. ed. Piracicaba , ESALQ, 1984. $343 \mathrm{p}$.

CANA . Usinas investem US\$ 9,4 milhões na mecanização da colheita em São Paulo; Gazeta Mercantil , São Paulo, 28 out, 1992, p.21

CERRIZUELA, E. Cosecha de caña de azúcar. Tucumán: UNT/Facultad de Agronomia y Zootecnia, 1977. 34p. (Serie Didatica 43).

COCHAN, B. J., CLAYTON, J. E. Basic studies on mechanical detrashing of bulk sugarcane. In: CONGRESS OF ISSCT, 13, Taiwan, 1968. Proceedings. Amsterdam: Elsevier, 1969. p.1551-1561.

CRAFTS, A.S. Modern weed control. Berkeley: Univ. California Press, 1975. 440p.

CHURCHWARD, E. H., PULSEN, N. J. Review of harvest development. Proceedings of Australian Society of Sugar Cane Technologists, 1988. p. 1-6.

DAVIES, D. B., FINNEY, J. B., RICHARDSON, S. J. Relative effects of the tractor weight and wheel-slip in causing soil compaction. J. Soil Sci. v.24, n. 3, p. 399-409, 1973. 
DEGASPARI, N., BOTELHO, P. S. M., ALMEIDA, L. C., MACEDO N., ARAUJO J. R. A queima da cana-de-açúcar, os efeitos sobre a população da broca (Diatraea saccharalis- Fabr., 1794),seus predadores e parasitos. STAB, Piracicaba, v. 1, n. 5, p. 35-40, maio/jun. 1983.

DELGADO, A. A. A clarificação do caldo de cana despalhados manualmente e a fogo, em função do tempo de espera para a industrialização. Piracicaba/SP: ESALQ, 1975. 148p. (LIVRE DOCENCIA ESALQ/USP).

DEMATTÊ, J. L. I. Manejo dos solos ácidos dos trópicos úmidos, região Amazônica.

Campinas: Fundação Cargill, 1988. 215p.

DOAT, A. Le pouvoir calorique des bois tropical. Bois et forest des Tropiques. Paris, v. 172, p. 33-48, mar./abr, 1977.

ELIAS, J. F. Efeitos de la cosecha mecanica en la calidad industrial de la caña de azúcar. Famailla: INT., 1976. 14p.

FERNANDES A. C., OLIVEIRA, E. R. Impurezas em cartegamento de cana-de-açúcar. Boletim Tecnico COPERSUCAR. Piracicaba, n. 5, p. 5-8, 1977.

FERRARI, S. E., RODELLA A. A. Deterioração da cana-de-açúcar. In: CONGRESSO NACIONAL DA STAB, 1, Maceió, 1979. v. 2, p. 475-488.

FERRARI, S. E., FURLANI NETO, V. L., LOPES, J. J. C., STOLF, R. Industrial quality of mechanically and manually harvested sugar cane. In: CONGRESS OF ISSCT, 17, Manilla, 1980. Proceedings: Makati, 1980. v.1, p.800-809.

FRANÇA, G.V. \& FREIRE,O Levantamento Semi-detalhado dos solos de Ribeirão Preto. Piracicaba, São Paulo;ESALQ/USP Depto de Solos e Geologia. 1976, 249p. 
FRANCO, A R. Aspéctos médicos e epidemológicos da queimada de canaviais na região de Ribeirão Preto. In: CENTRO DE ESTUDOS BRASILEIROS. Ribeirão Preto: USP, 1992. 19p. (palestra).

FURLANI NETO, V. L. Incidência de matéria estranha e perdas nos processos de corte manual e com colhedoras - amontoadoras em cana-de-açucar (Saccharum spp). Piracicaba/SP: ESALQ. 1984. 120 p (DISSERTAÇÃO DE MESTRADO ESALQ/USP).

FURLANI NETO, V. L., ROLIM, J. C., RIPOLI, T. C. C., MONTEIRO, H., NOGUEIRA, R. R. Influência de dessecante na colheita da Cana-de- açúcar. In: CONGR. BRAS. ENG. AGRÍCOLA, 1989, Recife, 1989, São Paulo, n. 51, p. 1619, 1989.

FURLANI NETO, V. L., MONTEIRO, H., RIPOLI, T. C. C., NOGUEIRA, R. R. Comparative analysis between green cane and burned cane: raw matter quality, cane losses, crop residue and chopper harvest performance. In: CONGRESS OF ISSCT, 20, São Paulo, 1989. Proceedings._S.Paulo, 1989. v.2, p.1043-1050.

GAZETA MERCANTLL. Cana: usinas investem US\$ 9,4 milhões na mecanização da colheita em São Paulo. São Paulo, 28 out. 1992. p.21.

GROHMANN, F., QUEIROZ NETO, J. P. Efeito da compactação artificial de dois solos limo-argiloso sobre a penetração de raízes de arroz. Bragantia, Campinas, v. 25 , n. 38,$1966 ;$ p. $421-432$

HUMBERT, R.P. El cultivo de la cana de azùcar. Ed. Continental. Mex.1974, 719 p. 
JOHN, L. Máquina que colhe cana crua pode transformar os canaviais. $\underline{O \text { Estado de São }}$ Paulo_São Paulo, 25 nov.1992. Suplemento Agrícola, p.12-13.

JOHN L. Poluição no interior agrava doenças respiratórias. O_Estado de São Paulo, São Paulo. 17, jun. 1994. Ambiente, p. 12, C.A..

KIRCHHOFF,V. W. J. H. As queimadas da cana. S.José dos Campos. Transtec Editorial, 1991. 92p.

KIRCHHOFF, V. W. J. H., MARINHO, E. V. A., DIAS, P. L. S., PEREIRA, E. B., CALHEIROS, R., ANDRE, R., VOLPE, C. Enhancements of the $\mathrm{CO}$ and $\mathrm{O} 3$ from burnings in sugar cane fields. Journal of Atmospheric Chemistry. n. 12, p. $87-$ 102, jan 1991.

LAURE, C.J. Efeitos de queimadas sobre a atmosfera: produção de gases nocivos.. In: KIRCHHOFF, V. W. J. H. As queimadas da cana. São José dos Campos: Transtec Editorial, 1991. p. 32.

LAWTON, K. The influence of soil aeration on the growth and absorption of nutrients by corn plants. Soil Sci. Am.Proc. n. 10, p. 263-268, 1945.

LIMA L. O. T. Fatores que influenciam na colheita mecânica. SEMINÁRIO DE COLHEITA MECÂNICA, Ribeirão Preto, 1994. (no prelo).

LOMBARDI NETO, F. Terras pobres devem virar pasto ou mata. O Estado de São Paulo, 10, ago. 1994. Suplemento Agrícola, p. 5.

LORENZI, H. J., GANDINI, M. O., GAZON A. L. Trash balnkets: The potencial to control weeds and effect on ratoon cane development. In: CONGRESS OF ISSCT, 20. São Paulo, 1989. Proceedings. v.2, p. 1021-1025. 
MATSUOKA, S., ARIZONO, H. Avaliação de variedades pela capacidade de produção de biomassa e pelo valor energético. STAB. Piracicaba. nov/dez. p. 39-46, 1987.

MIALHE L.G. \& RIPOLI , T.C.C. Evaliation de cosechadoras automotrices de caña de azùcar. In: Distribuidora Venezuelana de Azùcares. Caracas, p.189-204.

MILAN, M. Improving operacional management of harvest, transport and mechanization for sugar cane in Brazil. Silsoe, 1992. 226p. (Ph. D.- CRANFIELD INSTITUTE ENGLAND).

MINISTÉRIO DA INDUSTRIA E COMÉRCIO - IAA/PLANALSUCAR. Ato n 32 de 28 de Agosto de 1989. Diário Oficial da União Brasilia. p.1571-1575, 08 set. 1989.

MINISTÉRIO DAS MINAS E ENERGIA/ELETROBRÁS - Aproveitamento Energético dos resíduos da agroindústria da cana-de-açúcar. Rio de Janeiro, 1983. 340 p.

MOLINA JUNIOR, W. $\underline{\text { F. Enfardamento de resíduos de colheita de cana-de-acúcar }}$ (Saccharum spp), avaliação dos desempenhos operacional e econômico. Piracicaba/SP: ESALQ, 1991. 101 p. (DISSERTAÇÃO DE MESTRADO ESALQ/USP).

MUTTON, M. J. R., STUPIEllo, J. P., MUTTON, M. A, BARBOSA, J. C. Consequências das impurezas minerais na avaliação da qualidade da cana. $\underline{\text { STAB}}$. álcool, açucar e subprodutos, Piracicaba. n. 10, p.17-22, mar./abr. 1992.

MUZIK, T. J. Weed biology and control. New York: McGraw Hill, 1970. 273 p. 
NOA, H. La caña de azúcar como base de un desarollo agro-industrial, postenible. In: CONFERÊNCIA MUNDIAL SOBRE O DESENVOLVIMENTO E O MEIO AMBIENTE. Rio de Janeiro, 1992. p.12-15.

ORLANDO FILHO, J.O. Aplicação de $\mathrm{N}$ e tipos de cultivos em área de colheita mecânica de cana crua e queimada. STAB, 1995.,p.18-25.

PARAZZI C., BOLSANELLO, J. Estudos preliminares da deterioração da cana-deaçúcar na região de Campos. Viçosa: IAA/PLANALSUCAR/UFV, 1980. p.1-10

PARISH, D. H. The efficacy of nitrogenous fertilizers. In: CONGRESS OF ISSCT, 12, Puerto Rico, 1965. Proceedings. Amsterdam, Elsevier, 1967. p.372- 378.

PEARSON, C. H. O. The conception of farming on sub-tropical soil, with the use of crop by product, trash as a means to improve yelds. In: CONGRESS OF ISSCT, 10, Hawaii, 1959. Proceedings. Amsterdam: Elsevier. 1960. p. 579-588.

PRIMAVESI, O., MELLO, F. A. F., LIBARDI, P. L. Seleção preliminar de parâmetros físicos mais adequados para estudar o efeito da compactação de amostras de solo sobre a produção de matéria seca vegetal do feijoeiro(Phaseolus vulgaris L.)1984. Anais da ESALQ, Piracicaba, n. 41, p.449-463.

RIZZI, A. L. Faltam caminhões para transportar a safra. Eu Rodo, Curitiba, v. 11, n. 58, p.16-21

RIPOLI, T. C. C. Utilização do material remanescente de colheita de cana-de-acúcar (Saccharum spp) equacionamento dos balanços energético e econômico. Piracicaba/SP: ESALQ, , 1991. 150p. (LIVRE DOCÊNCIA ESALQ-USP). 
RIPOLI, T. C. C., MIALHE L. G. Colheita manual vs. mecânica de cana-de-açúcar. STAB. açúcar, álcool e subprodutos, Piracicaba, v. 59, n. 3, p.27-37, 1987.

RIPOLI, T. C. C., MOLINA JUNIOR, W. F., STUPIELLO, J. P., NOGUEIRA, M. C., SACCOMANO, J. B. Potencial energético de resíduos de cosecha de la caña verde. STAB: álcool, açúcar e subprodutos, Piracicaba, v. 10, n. 1, p.22-26, 1991.

RIPOLI, T. C. C., VILLA NOVA, N. A. Colheita mecanizada da cana-de-açúcar: Novos Desafios. STAB: álcool, açúcar e subprodutos, Piracicaba, v. 11, n. 1, p.28-31, set./out. 1992.

ROSENBERG, N. J., WILLITS, N. A. Yeld and phisiological response of barley and beans grow in artificially compacted soil. Soil Sci.Am.Proc., n. 26, p.78-82, 1962.

SAMUELS, G. Foreign matter in sugar cane: some basics facts. In:ANUAL CONGRESS OF THE ASS. SUG. TEC. OF PUERTO RICO, 47, San Juan 1969. Proceedings. p. 52-62.

SANCHES, P. A. Properties and management of sois in the tropics. New York: Wiley, 1976. 619p.

SILVA, L. F., PEREIRA, C. P., MELO, A. A. O. Efeito da compactação do solo no desenvolvimento de plântulas de cacau e na penetração de suas raízes. REV.THEOBROMA. n. 7, p. 13-18, 1977.

STOLF, R., FERNANDES, J., FURLANI NETO, V. L. Penetrômetro de impacto modelo IAA/PLANALSUCAR-STOLF; recomendação para o seu uso. STAB, Piracicaba, v. 1, n. 3, p.18-23, jan/fev. 1983. 
STOLF, R. Teoria e teste experimental de fórmulas de transformação dos dados do penettrômetro de impacto em resistência do solo. Rev.Bras.Ci.Solo Campinas, v. 15, p.229-235, 1991.

STUPIELLO, J. P. Qualidade de cana-de-açúcar para a fabricação de álcool. Álcool \& Acúcar, São Paulo, n. 2, p.28- 32, jan. 1982.

STUPIELLO, J. P. Alguns aspéctos da qualidade da matéria prima. STAB, álcool, açúcar e subprodutos, Piracicaba, v. 7, n. 3/5, p.52-54, jun/jul. 1989.

TAKAHASHI, D. T. Fate of unrecovered fertilizer nitrogen in lysimeter studies with $\mathrm{N}^{15}$ .Hawaiian Planter's Record Honolulu 1970. v.58, p. 95-101.

THOMPSON, G. D. The production of trash and it effects as a mulch on the soil and sugar cane nutrition. In: CONGRESS SOUTH AFRICAN SUGAR TECNOLOGY ASSOCIATION, 40. Mount Edegecombe, 1969. Proceedings. p.1-10.

TILLMANN, C. A. C. Avaliação dos desempenhos operacional e econômico de sistema de colheita semi-mecanizada em cana-de-acucar, com e sem queima prévia. Piracicaba,SP: ESALQ, 1994. 111p. (DISSERTAÇÃO DE MESTRADOESALQ/USP).

VEIGA FILHO, A. A., SANTOS, Z. A. P. de S., VEIGA, J. E. R., OtANI, M. N., YOSHII, R. J. Análise da mecanização do corte da cana-de-açúcar no Estado de São Paulo. Informações Econômicas, São Paulo, v. 24, p.43-58, 1994.

VOMOCIL, J. A., FLOCKER, W. J. Degradation of structure of yolo loam by compaction. Soil Sci.Soc.Am.Proc., n. 29, p.7-12, 1965. 
VOORHEES, W. B., SENST, C. G., NELSON, W. W. Compaction and soil structure modification by wheel traffic in the Northern corn belt. Soil Sci. Am. Proc. $\mathrm{n} .42$, p.344-349, 1978.

WOOD, R.A. The influence of trash on nitrogen mineralization - immobilization relationship in sugar belt soils. In: ANUAL CONGRESS OF SOUTH AFRICAN SUGAR TECNOLOGY ASSOCIATION, 40, Mount Edgecombe, 1966. Proceedings. p. 253- 262.

WARNER, J. A reduction in rainfall associated with smoke from sugar cane fires - An inadvertent weather modification : Journal of Appl. Meteorology, v. 7, p. 247-251, 1968.

ZALAUF, W. E., CAPORALI, S. A., VIDEIRA, R. M. Cálculo preliminar da energia liberada anualmente na queima dos canaviais brasileiros. In: SIMPÓSIO SOBRE QUEIMA DE PALHA DE CANAVIAIS,2, Araraquara, 1985. p.1-7. 
A P Ê N D I C E 1 


\section{Relatbrio de Processamento de Daglos}

\section{Introdiggå}

O presente relatório objetiva auxiliar na interpretação dos resultados da análise dos dados obtidos em pesquisa científica, bem como, oferecer um conjunto de termos técnicos adequados para auxiliar a redação da dissertação.

\section{Dados utilzados no processamento.}

Inicia-se o relatório com informações pertinentes aos dados observados no esperimento.

\section{1. Estrutura do arquivo de dades}

Caso sejam necessárias novas análises, a estrutura do arquivo usado no armazenamento dos dados é de suma importância por permitir o reaproveitamento dos dados, sem que seja necessária a redigitação dos mesmos. A estrutura do Arquivo aparece na Tabela 1.

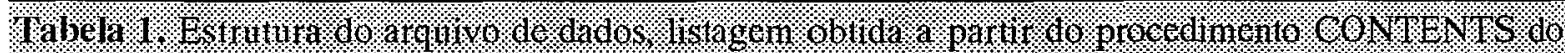

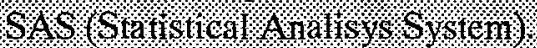

$\begin{array}{lll}\text { Data set Name: } & \text { C.VICTORl } & \text { Type: } \\ \text { Observations: } & 32 & \text { Record Len: } 172 \\ \text { Variables: } & 21 & \\ \text { Label: } & & \end{array}$

\begin{tabular}{|c|c|c|c|c|c|c|}
\hline$\#$ & Variable & Type & Len & Pos & Format & Label \\
\hline 8 & BRIX & Num & 8 & 60 & & Brix of \\
\hline 1 & CAMPO & Num & 8 & 4 & & Campo \\
\hline 7 & CAPACEFE & Num & 8 & 52 & & Capacidade Efetiva(t.cana/h) \\
\hline 13 & COLMOS & Num & 8 & 100 & & Colmos 8 \\
\hline 4 & DENSID & Num & 8 & 28 & & Densidade de Materia Prima \\
\hline 11 & FIBRA & Num & 8 & 84 & & Fibra 8 \\
\hline 19 & FRACOLMO & Num & 8 & 148 & & Perdas em Pedacos (kg) \\
\hline 15 & MATESMIN & Num & 8 & 116 & & Materia Estranha Mineral \\
\hline 16 & MATESTOT & Num & 8 & 124 & & Materia Estranha Total \\
\hline 14 & MATESVEG & Num & 8 & 108 & & Materia Estranha Vegetais \\
\hline 12 & PCC & Num & 8 & 92 & & Pol \& Cana Corrigido \\
\hline 9 & POL & Num & 8 & 68 & & Pol \& Caldo \\
\hline 17 & PONTAS & Num & 8 & 132 & & Perdas em Pontas (kg) \\
\hline 10 & PUREZA & Num & 8 & 76 & & Pureza o \\
\hline 5 & QTDMASSA & Num & 8 & 36 & & Quantidade de Massa Colhida (t/ha) \\
\hline 20 & REBOLOS & Num & 8 & 156 & & Perdas em Rebolos (kg) \\
\hline 3 & REP & Num & 8 & 20 & & Repeticoes \\
\hline 2 & TIPOCANA & Num & 8 & 12 & CANA. & Tipo de Cana \\
\hline 18 & Tocos & Num & 8 & 140 & & Perdas em Tocos (kg) \\
\hline 21 & TOTAL & Num & 8 & 164 & & Perdas Totais (kg) \\
\hline 6 & VELOCID & Num & 8 & 44 & & Velocidade $(\mathrm{km} / \mathrm{h})$ \\
\hline
\end{tabular}


anteriormente.

Os dados obtidos na pesquisa foram digitados e preencheram a estrutura listada

É obrigatória a perfeita coinciência dos dados obtidos no experimento com os dados usados na análise, daí a necessidade de uma séria correção da Tabela 2, o que garantirá a inexistência de erros de digitação.

\section{Analises efetwadas}

Em um primeiro passo, foi executada uma análise exploratória dos dados a fim de verificar, principalmente, a existência de valores discrepantes ou então a existência de heterogeneidade das variâncias. Essa análise se torna necessária para aumentar confiabilidade dos resultados da análise de variância.

Quando verificada a heterocedasticidade, estudou-se e aplicou-se uma transformação dos dados, observando-se se havia correção do problema.

Em vista dos objetivos do experimento achou-se conveniente a execução de uma análise de variância dos dados, na qual visa-se testar a hipótese de inexistência de efeito dos fatores estudados: "CAMPO" e "TIPO DE CANA".

Determinou-se a análise do experimento em parcelas subdivididas onde o fator e determinante das parcelas é o fator CAMPO e as sub-parcelas aleatorizadas "a posteriori" determinada pelo fator "TIPO DE CANA".

Cada uma das variáveis de resposta reconhecidas pelo asterisco na Tabela 1 será analisada de maneira independente, permitindo-se conclusões para cada uma delas.

\section{1 Analise de Varâncla.}

A análise de variância permitirá a tomada de decisão em relação a três hipóteses de nulidade, duas delas associadas aos fatores.

Em relação ao fator "CAMPO" tem-se a seguinte hipótese de nulidade:

$$
\text { Ho: Campo } 1 \text { = Campo } 2
$$

A rejeição da hipótese de nulidade implicará na aceitação de uma hipótese alternativa (Ha) enunciada a seguir:

\section{Ha: Campo $1 \neq$ Campo 2}

A rejeição da hipótese de nulidade Ho nos fornecerá indicativos de existência de diferenças entre os campos 1 e 2 . 
Uma segunda hipótese de nulidade será testada e se refere à inexistência de diferenças entre os "TIPOS DE CANA":

$$
\text { Ho: Cana Queimada = Cana Crua }
$$

A rejeição da hipótese de nulidade enunciada anteriormente implicará na aceitação de uma hipótese alternativa (Ha):

\section{Ha: Cana Queimada $\neq$ Cana Crua}

Como são testados dois fatores, pode ocorrer "Interação" entre os níveis dos fatores. A existência de interação implica num efeito causado pela ação conjunta dos dois fatores que difere das ações individuais. A hipótese de nulidade de interação Ho, enunciada abaixo:

Ho: Inexistência de Interação

Quando rejeitada, implica na hipótese alternativa:

Ha: Existência de Interação

E exige estudos adicionais a fim de se detectar quais são as combinações de tratamento que reagem de forma distinta da esperada quando se estudam os fatores em separado. 


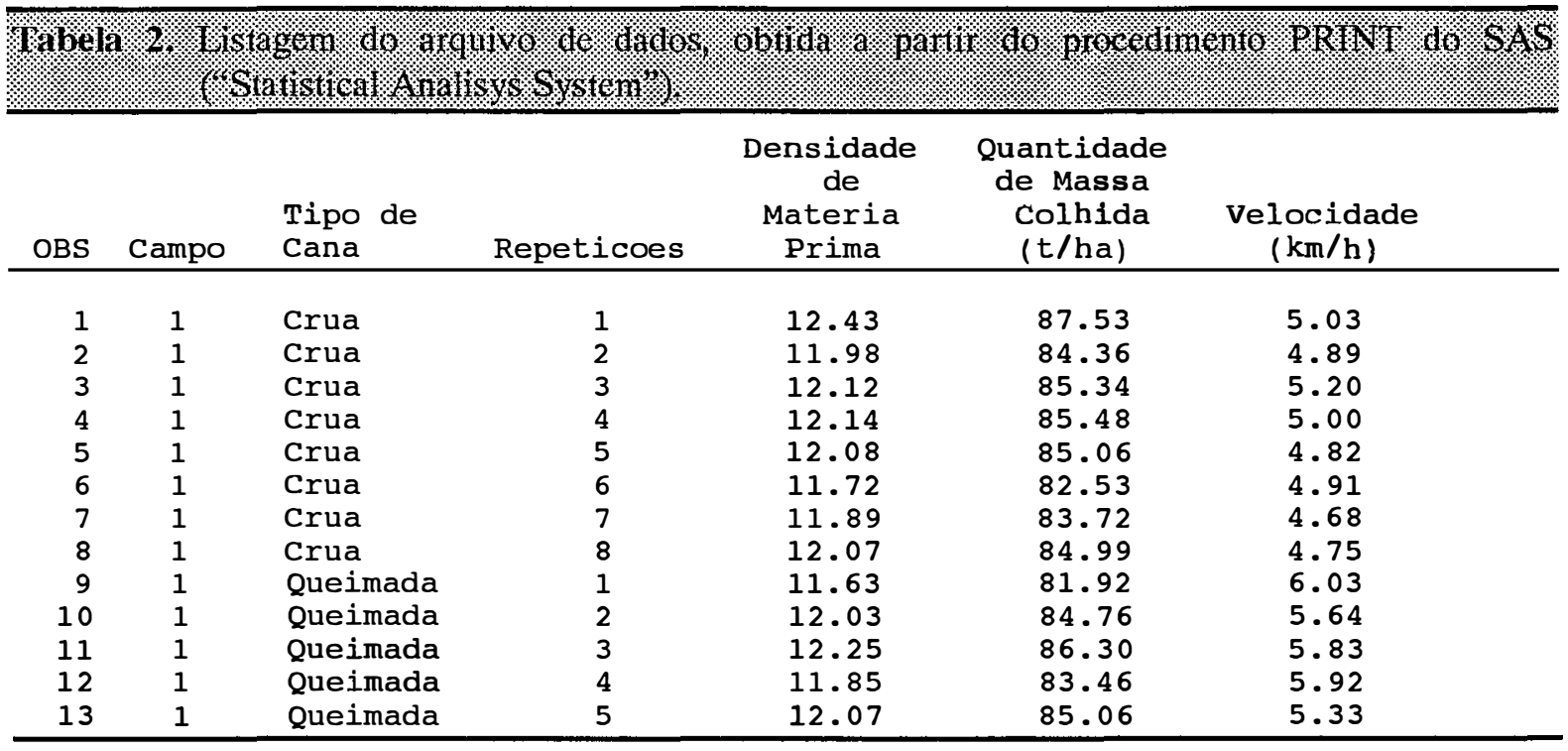

\begin{tabular}{rccccccc}
\hline & $\begin{array}{c}\text { Capacidade } \\
\text { OBS }\end{array}$ & $\begin{array}{c}\text { Brix } \\
\text { Efetiva(t.cana/h) }\end{array}$ & $\begin{array}{c}\text { Pol } \\
\text { } 8\end{array}$ & $\begin{array}{c}\text { Pureza } \\
\text { Caldo }\end{array}$ & $\begin{array}{c}\text { Fibra } \\
8\end{array}$ & $\begin{array}{c}\text { Pol } 8 \\
\text { Cana } \\
\text { Corrigido }\end{array}$ & $\begin{array}{c}\text { Colmos } \\
8\end{array}$ \\
\hline 1 & 62.52 & 20.60 & 18.02 & 87.48 & 14.49 & 14.17 & 94.40 \\
2 & 58.58 & 21.50 & 18.55 & 86.27 & 14.82 & 14.53 & 92.55 \\
3 & 63.02 & 22.10 & 18.76 & 84.88 & 15.41 & 14.59 & 92.86 \\
4 & 60.70 & 22.20 & 18.87 & 85.00 & 16.33 & 14.52 & 95.13 \\
5 & 58.22 & 21.80 & 18.86 & 86.51 & 13.07 & 15.08 & 95.70 \\
6 & 57.54 & 21.50 & 18.90 & 87.90 & 14.48 & 14.87 & 92.65 \\
7 & 55.64 & 21.80 & 18.52 & 84.95 & 15.82 & 14.34 & 93.38 \\
8 & 57.33 & 20.60 & 18.05 & 87.62 & 14.27 & 14.23 & 94.91 \\
9 & 70.12 & 20.20 & 17.43 & 86.29 & 14.05 & 13.78 & 91.52 \\
10 & 67.85 & 20.80 & 17.90 & 86.06 & 13.96 & 14.16 & 94.17 \\
11 & 71.41 & 21.10 & 18.27 & 86.59 & 14.27 & 14.40 & 95.79 \\
12 & 70.15 & 20.00 & 16.85 & 84.26 & 14.13 & 13.31 & 92.92 \\
13 & 64.33 & 19.60 & 17.04 & 86.93 & 13.79 & 13.51 & 94.13 \\
\hline
\end{tabular}

\begin{tabular}{rcccccccc}
\hline & $\begin{array}{r}\text { Materia } \\
\text { Estranha } \\
\text { Vegetais }\end{array}$ & $\begin{array}{c}\text { Materia } \\
\text { Estranha } \\
\text { Mineral }\end{array}$ & $\begin{array}{c}\text { Materia } \\
\text { Estranha } \\
\text { Total }\end{array}$ & $\begin{array}{c}\text { Perdas } \\
\text { em } \\
\text { Pontas } \\
(\mathrm{kg})\end{array}$ & $\begin{array}{c}\text { Perdas } \\
\text { em } \\
\text { Tocos } \\
(\mathrm{kg})\end{array}$ & $\begin{array}{c}\text { Perdas } \\
\text { em } \\
\text { Pedacos } \\
(\mathrm{kg})\end{array}$ & $\begin{array}{c}\text { Perdas } \\
\text { em } \\
\text { Rebolos } \\
(\mathrm{kg})\end{array}$ & $\begin{array}{c}\text { Perdas } \\
\text { Totais } \\
(\mathrm{kg})\end{array}$ \\
\hline & & & & & & & & \\
1 & 5.21 & 0.39 & 5.60 & 2.10 & 3.60 & 0.80 & 3.75 & 10.25 \\
2 & 6.93 & 0.52 & 7.45 & 2.20 & 3.00 & 0.75 & 6.90 & 14.85 \\
3 & 6.63 & 0.51 & 7.14 & 2.15 & 2.70 & 0.68 & 5.80 & 14.33 \\
4 & 4.43 & 0.43 & 4.86 & 2.25 & 0.60 & 0.65 & 4.20 & 11.70 \\
5 & 3.90 & 0.40 & 4.30 & 4.30 & 1.00 & 0.90 & 3.50 & 14.70 \\
6 & 6.82 & 0.53 & 7.35 & 3.50 & 0.85 & 1.35 & 2.20 & 13.90 \\
7 & 6.14 & 0.48 & 6.62 & 2.25 & 0.85 & 1.20 & 3.10 & 14.40 \\
8 & 4.67 & 0.42 & 5.09 & 2.80 & 1.00 & 0.60 & 3.30 & 15.70 \\
9 & 7.71 & 0.77 & 8.48 & 0.50 & 0.65 & 1.60 & 2.35 & 5.10 \\
10 & 5.30 & 0.53 & 5.83 & 0.38 & 0.75 & 1.50 & 2.60 & 7.23 \\
11 & 3.56 & 0.61 & 4.17 & 0.50 & 0.40 & 0.20 & 1.50 & 5.60 \\
12 & 6.39 & 0.69 & 7.08 & 0.35 & 0.30 & 0.14 & 1.60 & 6.39 \\
13 & 5.28 & 0.59 & 5.87 & 0.23 & 0.45 & 0.30 & 0.90 & 6.88 \\
\hline
\end{tabular}




\begin{tabular}{|c|c|c|c|c|c|c|}
\hline OBS & Campo & $\begin{array}{l}\text { Tipo de } \\
\text { Cana }\end{array}$ & Repeticoes & $\begin{array}{c}\text { Densidade } \\
\text { de } \\
\text { Materia } \\
\text { Prima }\end{array}$ & $\begin{array}{c}\text { Quantidade } \\
\text { de Massa } \\
\text { Colhida } \\
(t / h a)\end{array}$ & $\begin{array}{c}\text { Velocidade } \\
(\mathrm{km} / \mathrm{h})\end{array}$ \\
\hline 14 & 1 & Queimada & 6 & 11.93 & 84.01 & 6.00 \\
\hline 15 & 1 & Queimada & 7 & 12.03 & 84.71 & 5.57 \\
\hline 16 & 1 & Queimada & 8 & 11.65 & 82.03 & 5.92 \\
\hline 17 & 2 & Crua & 1 & 13.37 & 94.15 & 4.56 \\
\hline 18 & 2 & Crua & 2 & 12.75 & 89.78 & 4.37 \\
\hline 19 & 2 & Crua & 3 & 12.91 & 90.91 & 4.26 \\
\hline 20 & 2 & Crua & 4 & 12.64 & 89.01 & 4.62 \\
\hline 21 & 2 & Crua & 5 & 12.50 & 88.02 & 4.48 \\
\hline 22 & 2 & Crua & 6 & 12.58 & 88.58 & 4.22 \\
\hline 23 & 2 & Crua & 7 & 12.97 & 91.33 & 4.31 \\
\hline 24 & 2 & Crua & 8 & 13.00 & 91.54 & 4.30 \\
\hline 25 & 2 & Queimada & 1 & 12.03 & 84.72 & 5.46 \\
\hline 26 & 2 & Queimada & 2 & 12.51 & 88.09 & 4.93 \\
\hline
\end{tabular}

\begin{tabular}{|c|c|c|c|c|c|c|c|c|}
\hline OBS & \multicolumn{2}{|c|}{$\begin{array}{c}\text { Capacidade } \\
\text { Efetiva (t.cana/h) }\end{array}$} & \multicolumn{2}{|r|}{$\begin{array}{c}\text { Pol } \\
\text { \& } \\
\text { Caldo }\end{array}$} & $\begin{array}{c}\text { Pureza } \\
8\end{array}$ & \multicolumn{2}{|r|}{$\begin{array}{c}\text { Pol } 8 \\
\text { Cana } \\
\text { Corrigido }\end{array}$} & $\underset{8}{\text { Colmos }}$ \\
\hline $\begin{array}{l}14 \\
15 \\
16 \\
17 \\
18 \\
19 \\
20 \\
21 \\
22 \\
23 \\
24 \\
25 \\
26 \\
\end{array}$ & $\begin{array}{l}71 . \\
67 . \\
68 . \\
60 . \\
55 . \\
54 . \\
58 . \\
56 . \\
53 . \\
55 . \\
55 . \\
65 . \\
61 .\end{array}$ & & $\begin{array}{l}20.30 \\
21.00 \\
20.40 \\
21.98 \\
20.86 \\
22.00 \\
20.93 \\
22.16 \\
23.41 \\
21.94 \\
22.40 \\
21.17 \\
22.18\end{array}$ & $\begin{array}{l}17.88 \\
18.98 \\
17.37 \\
20.34 \\
19.28 \\
20.33 \\
19.37 \\
20.46 \\
21.64 \\
20.27 \\
20.71 \\
19.77 \\
21.20\end{array}$ & $\begin{array}{l}88.07 \\
90.38 \\
85.14 \\
92.56 \\
92.30 \\
92.41 \\
92.56 \\
92.36 \\
92.46 \\
92.40 \\
92.47 \\
93.42 \\
95.61\end{array}$ & $\begin{array}{l}14.40 \\
13.50 \\
14.14 \\
19.23 \\
20.12 \\
18.51 \\
17.39 \\
19.42 \\
18.50 \\
19.33 \\
17.66 \\
16.07 \\
15.80\end{array}$ & $\begin{array}{l}14.08 \\
15.10 \\
13.72 \\
15.43 \\
15.31 \\
15.13 \\
15.91 \\
14.95 \\
15.44 \\
14.80 \\
14.85 \\
15.85 \\
15.36\end{array}$ & $\begin{array}{l}93.54 \\
95.80 \\
94.57 \\
83.49 \\
92.57 \\
91.35 \\
87.72 \\
91.02 \\
92.75 \\
84.74 \\
83.56 \\
95.36 \\
94.96\end{array}$ \\
\hline OBS & $\begin{array}{l}\text { Materia } \\
\text { Estranha } \\
\text { Vegetais }\end{array}$ & $\begin{array}{r}\text { Materia } \\
\text { Estranha } \\
\text { Mineral } \\
\end{array}$ & $\begin{array}{c}\text { Materia } \\
\text { Estranha } \\
\text { Total }\end{array}$ & $\begin{array}{c}\text { Perdas } \\
\text { em } \\
\text { Pontas } \\
(\mathrm{kg}) \\
\end{array}$ & $\begin{array}{c}\text { Perdas } \\
\text { em } \\
\text { Tocos } \\
(\mathrm{kg}) \\
\end{array}$ & $\begin{array}{c}\text { Perdas } \\
\text { em } \\
\text { Pedacos } \\
(\mathrm{kg}) \\
\end{array}$ & $\begin{array}{c}\text { Perdas } \\
\text { em } \\
\text { Rebolos } \\
(\mathrm{kg}) \\
\end{array}$ & $\begin{array}{c}\text { Perdas } \\
\text { Totais } \\
(\mathrm{kg})\end{array}$ \\
\hline $\begin{array}{l}14 \\
15 \\
16 \\
17 \\
18 \\
19 \\
20 \\
21 \\
22 \\
23 \\
24 \\
25 \\
26\end{array}$ & $\begin{array}{r}5.73 \\
3.51 \\
4.88 \\
15.60 \\
6.30 \\
7.70 \\
11.30 \\
8.10 \\
6.30 \\
14.30 \\
15.40 \\
3.44 \\
4.04\end{array}$ & $\begin{array}{l}0.73 \\
0.69 \\
0.55 \\
0.91 \\
0.53 \\
0.95 \\
0.98 \\
0.88 \\
0.95 \\
0.96 \\
1.04 \\
1.20 \\
1.00\end{array}$ & $\begin{array}{r}6.46 \\
4.20 \\
5.43 \\
16.51 \\
6.83 \\
8.65 \\
12.28 \\
8.98 \\
7.25 \\
15.26 \\
16.44 \\
4.64 \\
5.04\end{array}$ & $\begin{array}{l}0.45 \\
0.45 \\
0.41 \\
0.20 \\
0.40 \\
0.50 \\
0.30 \\
0.60 \\
0.20 \\
0.90 \\
0.20 \\
0.90 \\
0.30\end{array}$ & $\begin{array}{l}0.50 \\
0.30 \\
0.25 \\
0.40 \\
1.40 \\
1.30 \\
3.00 \\
0.80 \\
1.40 \\
0.80 \\
1.30 \\
1.30 \\
1.10\end{array}$ & $\begin{array}{l}0.45 \\
0.60 \\
0.65 \\
1.00 \\
0.30 \\
0.50 \\
0.20 \\
0.30 \\
1.00 \\
1.60 \\
1.30 \\
1.30 \\
1.00\end{array}$ & $\begin{array}{l}1.10 \\
1.80 \\
2.00 \\
0.90 \\
1.60 \\
1.70 \\
4.10 \\
0.80 \\
2.30 \\
4.20 \\
0.80 \\
2.80 \\
1.60\end{array}$ & $\begin{array}{r}8.50 \\
10.15 \\
11.31 \\
2.50 \\
5.70 \\
7.00 \\
11.60 \\
7.50 \\
10.90 \\
14.50 \\
11.60 \\
6.30 \\
6.00\end{array}$ \\
\hline
\end{tabular}




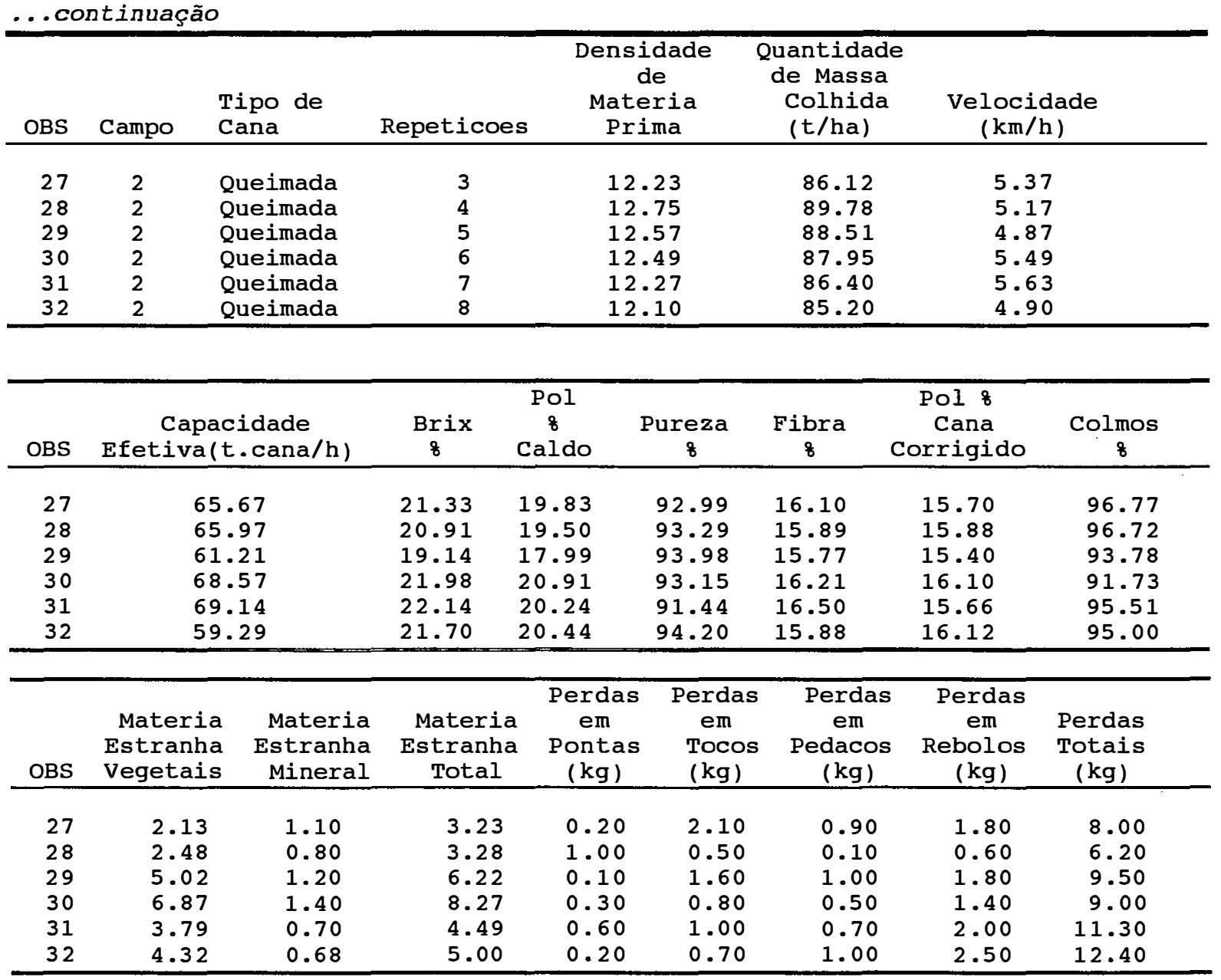

\subsection{Verificacáo da Homogeneidade de Vartancias:}

Uma característica de grande importância para a validação da análise de variância é a verificação da homogeneidade de variâncias.

Os testes estatísticos tendem a se tornar muito robustos (não mostrar diferenças que existem) quando as variâncias são muito diferentes de um conjunto de dados para outro. Inicialmente, será mostrado na Tabela 3, as variâncias calculadas para cada variável em cada grupo.

A homogeneidade de variâncias diz respeito à inexistência de valores muito distantes entre as menores e maiores variâncias. 


\begin{tabular}{|c|c|c|c|c|c|}
\hline 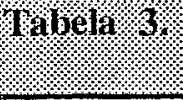 & $10 \% 10 \%$ & anchas & 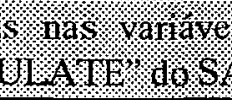 & 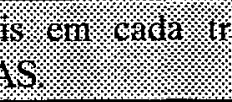 & Hanemov \\
\hline Campo & $\begin{array}{l}\text { Tipo de } \\
\text { Cana }\end{array}$ & $\begin{array}{l}\text { Densidade de } \\
\text { Materia } \\
\text { Prima }\end{array}$ & $\begin{array}{l}\text { Quantidade } \\
\text { de Massa } \\
\text { Colhida } \\
\text { (t/ha) }\end{array}$ & $\begin{array}{c}\text { Velocidade } \\
(\mathrm{km} / \mathrm{h})\end{array}$ & $\begin{array}{c}\text { Capacidade } \\
\text { Efetiva(t.ca- } \\
\text { na/h) }\end{array}$ \\
\hline $\begin{array}{l}1 \\
2\end{array}$ & $\begin{array}{l}\text { Crua } \\
\text { Queimada } \\
\text { Crua } \\
\text { Queimada }\end{array}$ & $\begin{array}{l}0,04 \\
0,05 \\
0,08 \\
0,06\end{array}$ & $\begin{array}{l}2,11 \\
2,28 \\
3,97 \\
3,09\end{array}$ & $\begin{array}{l}0,03 \\
0,06 \\
0,02 \\
0,09\end{array}$ & $\begin{array}{r}6,88 \\
6,02 \\
5,56 \\
12,71 \\
\end{array}$ \\
\hline Campo & $\begin{array}{l}\text { Tipo de } \\
\text { Cana }\end{array}$ & Brix & Pol \& Caldo & Pureza 8 & Fibra 8 \\
\hline $\begin{array}{l}1 \\
2\end{array}$ & $\begin{array}{l}\text { Crua } \\
\text { Queimada } \\
\text { Crua } \\
\text { Queimada }\end{array}$ & $\begin{array}{l}0,38 \\
0,26 \\
0,66 \\
0,99\end{array}$ & $\begin{array}{l}0,13 \\
0,48 \\
0,56 \\
0,98\end{array}$ & $\begin{array}{l}1,61 \\
3,49 \\
0,01 \\
1,41\end{array}$ & $\begin{array}{l}1,03 \\
0,08 \\
0,86 \\
0,06\end{array}$ \\
\hline Campo & $\begin{array}{l}\text { Tipo de } \\
\text { Cana }\end{array}$ & Pol \& Cana & Colmos & $\begin{array}{l}\text { Matéria } \\
\text { Estranha } \\
\text { Vegetal }\end{array}$ & $\begin{array}{l}\text { Matéria } \\
\text { Estranha } \\
\text { Mineral }\end{array}$ \\
\hline $\begin{array}{l}1 \\
2\end{array}$ & $\begin{array}{l}\text { Crua } \\
\text { Queimada } \\
\text { Crua } \\
\text { Queimada }\end{array}$ & $\begin{array}{l}0,10 \\
0,32 \\
0,14 \\
0,08 \\
\end{array}$ & $\begin{array}{r}1,53 \\
2,05 \\
16,18 \\
2,67\end{array}$ & $\begin{array}{r}1,41 \\
1,94 \\
16,27 \\
2,22 \\
\end{array}$ & $\begin{array}{l}0,00 \\
0,01 \\
0,02 \\
0,07\end{array}$ \\
\hline Campo & $\begin{array}{l}\text { Tipo de } \\
\text { Cana }\end{array}$ & $\begin{array}{l}\text { Matéria } \\
\text { Estranha } \\
\text { Total }\end{array}$ & $\begin{array}{l}\text { Perdas em } \\
\text { Pontas ( } \mathrm{kg})\end{array}$ & $\begin{array}{l}\text { Perdas em } \\
\text { Tocos (kg) }\end{array}$ & $\begin{aligned} \text { Perdas } & \text { em } \\
\text { Pedacos } & (\mathrm{kg})\end{aligned}$ \\
\hline $\begin{array}{l}1 \\
2\end{array}$ & $\begin{array}{l}\text { Crua } \\
\text { Queimada } \\
\text { Crua } \\
\text { Queimada }\end{array}$ & $\begin{array}{r}1,54 \\
2,07 \\
16,94 \\
2,67\end{array}$ & $\begin{array}{l}0,65 \\
0,01 \\
0,06 \\
0,12\end{array}$ & $\begin{array}{l}1,42 \\
0,03 \\
0,60 \\
0,27\end{array}$ & $\begin{array}{l}0,07 \\
0,32 \\
0,27 \\
0,14\end{array}$ \\
\hline Campo & $\begin{array}{l}\text { Tipo de } \\
\text { Cana }\end{array}$ & $\begin{array}{r}\text { Perdas } \\
\text { Rebolos }\end{array}$ & $\begin{array}{l}\text { em } \\
(\mathrm{kg})\end{array}$ & $\begin{array}{l}\text { Perdas } \\
\text { otais (kg) }\end{array}$ & \\
\hline $\begin{array}{l}1 \\
2\end{array}$ & $\begin{array}{l}\text { Crua } \\
\text { Queimada } \\
\text { Crua } \\
\text { Queimada }\end{array}$ & $\begin{array}{l}2,35 \\
0,34 \\
1,95 \\
0,45\end{array}$ & & $\begin{array}{r}3,31 \\
4,78 \\
15,24 \\
5,84\end{array}$ & \\
\hline
\end{tabular}

Uma das exigências do modelo matemático de Análise de Variância é a homogeneidade de variâncias. De uma maneira simplista, pode-se dizer que as variâncias dentro dos tratamentos devem ser próximas.

\subsubsection{VERIFICAÇĀO DA HOMOGENEIDADE DE VARIÂNCIAS.}

Para verificar a validade da pressuposição de homogeneidade de variâncias, utilizaremos o teste de Hartley, segundo o qual são consideradas homogêneas as variâncias cuja relação entre a maior e a menor variância é menor que um valor tabelado e dependente do número de tratamentos e repetições do experimento. Nesse caso, o valor limite é 8,44. 


\subsubsection{Regressão entre Média e Variância.}

Por fim, uma transformação bem sucedida deve romper a relação verificada anteriormente entre a média e a variância, o que será testado a seguir, na Tabela 8.

\begin{tabular}{|c|c|c|c|}
\hline Variável & Rótulo & & $\begin{array}{c}\mathrm{Pr}>\mathrm{F} \\
\text { Modelo }\end{array}$ \\
\hline $\begin{array}{l}\text { COLMOS } \\
\text { MA TFSTOT }\end{array}$ & Colmos 8 & & 0.0073 \\
\hline MATESTOT & Materia Estranha & Total & 0.8328 \\
\hline MATESVEG & Materia Estranha & Vegetais & 0.4780 \\
\hline $\begin{array}{l}\text { PONTAS } \\
\text { TOCOS }\end{array}$ & Perdas em Pontas & $(\mathrm{kg})$ & 0.6077 \\
\hline TOCOS & Perdas em Tocos & (kg) & 0.3969 \\
\hline
\end{tabular}

O valor da Probabilidade $>|F|$ para o modelo mostra que é razoável a inexistência de relação entre as médias e variâncias, com nível $\alpha$ de significância de $5 \%$ o que indica o rompimento da relação entre médias e variâncias em todas as variáveis, exceto a variável COLMOS.

Os valores das variâncias, entretanto, mostram haver homocedasticidade na variável, note na tabela 7 que a maior e a menor variância diferem em valores inferiores à segunda casa decimal.

\section{Analise de Variancia.}

Os resultados da análise de variância são listados a seguir e comentados.

\subsubsection{VARIÁVEIS CLASSIFICATÓRIAS.}

A seguir, na Tabela 9, são sintetizadas as informações referentes às variáveis classificatórias e sobre o número de observações utilizadas na análise.

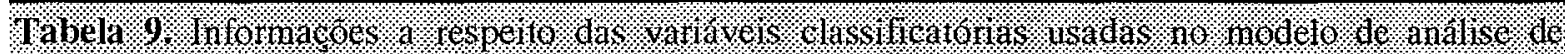
\%10.0

$\begin{aligned} & \text { Avaliacao de Colheita Mecanica } \\ & \text { Analise de Variancia }\end{aligned}$
$\begin{aligned} & \text { General Linear Models Procedure } \\ & \text { Class Level Information }\end{aligned}$
Class
LAMPO
Levels


O valor do coeficiente angular nos dá um indicativo do tipo de transformação que deve ser aplicada. As variáveis FIBRA e PUREZA que não são destacadas com negrito, acima, não precisam ser transformadas uma vez que o modelo não é estatisticamante significativo, não sendo razoável a idéia de dependência entre médias e variâncias.

Inicialmente as variáveis serão transformadas de acordo com a função definida na coluna rotulada Transformação na Tabela 5.

A variável colmos não apresenta um valor de coeficiente angular que mostre uma transformação adequada. Optaremos por transformá-la em logarítmo e verificar a existência de homocedasticidade.

\subsubsection{VERIFICAÇĀO DA ADEQUAÇĀO DA TRANSFORMAÇĀO.}

Uma vez determinada a transformação mais adequada, deve-se verificar se houve uma melhora nos dados o que pode ser feito através da re-execução das análises, dessa vez nos dados transformados.

\subsubsection{Normalidade dos resíduos.}

Inicialmente, pode-se constatar que há evidências de que os dados transformados apresentam distribuição normal, conforme a estatística W mostra na Tabela 6.

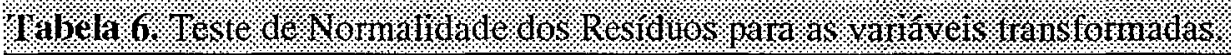

\begin{tabular}{|c|c|c|}
\hline Variável & Rótulo & $\operatorname{Pr}<W$ \\
\hline COLMOS & Colmos 8 & 0.1292 \\
\hline MATESTOT & Materia Estranha Total & 0.2970 \\
\hline MATESVEG & Materia Estranha Vegetais & 0.8889 \\
\hline PONTAS & Perdas em Pontas (kg) & 0.9419 \\
\hline TOCOS & Perdas em Tocos (kg) & 0.4661 \\
\hline
\end{tabular}

O teste mostra ser razoável assumir a pressuposição de normalidade nos resíduos dos dados transformados.

\subsubsection{Homogeneidade de Variâncias.}

A partir dos valores transformados, novas variâncias podem ser obtidas e comparadas.

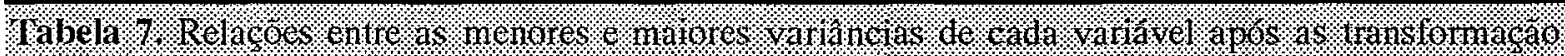
010010

\begin{tabular}{|c|c|c|c|c|}
\hline Variável & Rótulo & $\begin{array}{c}\text { Maior } \\
\text { Variância }\end{array}$ & $\begin{array}{c}\text { Menor } \\
\text { Variânica } \\
\end{array}$ & Relação \\
\hline COLMOS & Colmos 8 & 0,00 & 0,00 & 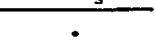 \\
\hline MATESTOT & Materia Estranha Total & 0,00 & 0,00 & - \\
\hline MATESVEG & Materia Estranha Vegetais & 0,01 & 0,00 & $\cdot$ \\
\hline PONTAS & Perdas em Pontas (kg) & 0,65 & 0,06 & 10,8 \\
\hline TOCOS & Perdas em Tocos (kg) & 0,48 & 0,15 & 3,2 \\
\hline
\end{tabular}

Observa-se que os valores das variâncias se aproximaram muito em quando comparamos com os valores originais. 
A Tabela 4 listada a seguir mostra a relação entre a maior e menor variância para cada variável.

\begin{tabular}{|c|c|c|c|c|}
\hline Variável & Rótulo & $\begin{array}{c}\text { Maior } \\
\text { Variância }\end{array}$ & $\begin{array}{c}\text { Menor } \\
\text { Variânica } \\
\end{array}$ & Relação \\
\hline $\begin{array}{l}\text { BRIX } \\
\text { CAPACEFE }\end{array}$ & $\begin{array}{l}\text { Brix } \% \\
\text { Capacidade Efetiva(t.cana/h) }\end{array}$ & 0,99 & $\begin{array}{l}0,26 \\
5,56\end{array}$ & 3,8 \\
\hline COLMOS & Colmos \& & 16,2 & 1,53 & 10,6 \\
\hline DENSID & Densidade de Materia Prima & 0,08 & 0,04 & 2,0 \\
\hline FIBRA & Fibra \& & 1,03 & 0,06 & 17,2 \\
\hline FRACOLMO & Perdas em Pedacos (kg) & 0,32 & 0,07 & 4,6 \\
\hline MATESMIN & Materia Estranha Mineral & 0,07 & 0,01 & 7,0 \\
\hline MATESTOT & Materia Estranha Total & 16,9 & 1,54 & 11,0 \\
\hline MATESVEG & Materia Estranha Vegetais & 16,3 & 1,41 & 11,6 \\
\hline PCC & Pol \& Cana Corrigido & 0,32 & 0,08 & 4,0 \\
\hline POL & Pol \& Caldo & 0,98 & 0,13 & 7,5 \\
\hline PONTAS & Perdas em Pontas (kg) & 0,65 & 0,01 & 65,0 \\
\hline PUREZA & Pureza 8 & 3,49 & 0,01 & 349,0 \\
\hline QTDMASSA & Quantidade de Massa Colhida (t/ha) & 3,97 & 2,11 & 1,8 \\
\hline REBOLOS & Perdas em Rebolos (kg) & 2,35 & 0,34 & 6,9 \\
\hline Tocos & Perdas em Tocos (kg) & 1,42 & 0,03 & 47,3 \\
\hline TOTAL & Perdas Totais (kg) & 15,2 & 3,31 & 4,6 \\
\hline VELOCID & Velocidade (km/h) & 0,09 & 0,02 & 4,5 \\
\hline
\end{tabular}

Segundo o teste adotado, há um indicativo de que as variáveis listadas em negrito na Tabela 4 devem receber um tratamento mais cuidadoso em função das grandes diferenças de variâncias observadas. Uma possibilidade é a correção do problema a partir da transformação de dados.

\subsubsection{ESTUdO DO TIPO DE TRANSFORMAÇĀO A AdOTAR.}

A adoção de uma transformação de dados pode ser precedida de um estudo que visa determinar qual é a transformação mais adequada.

A fim de se determinar essa tranformação, pode-se executar uma regressão linear entre o logarítmo das médias e das variâncias. Caso haja relação entre o aumento das médias e variâncias, pode-se determinar a transformação mais adequada, através do coeficiente angular da regressão obtida.

A Tabela 5 lista o resultado dessa regressão e o coeficiente angular da regressão é mostrado em negrito.

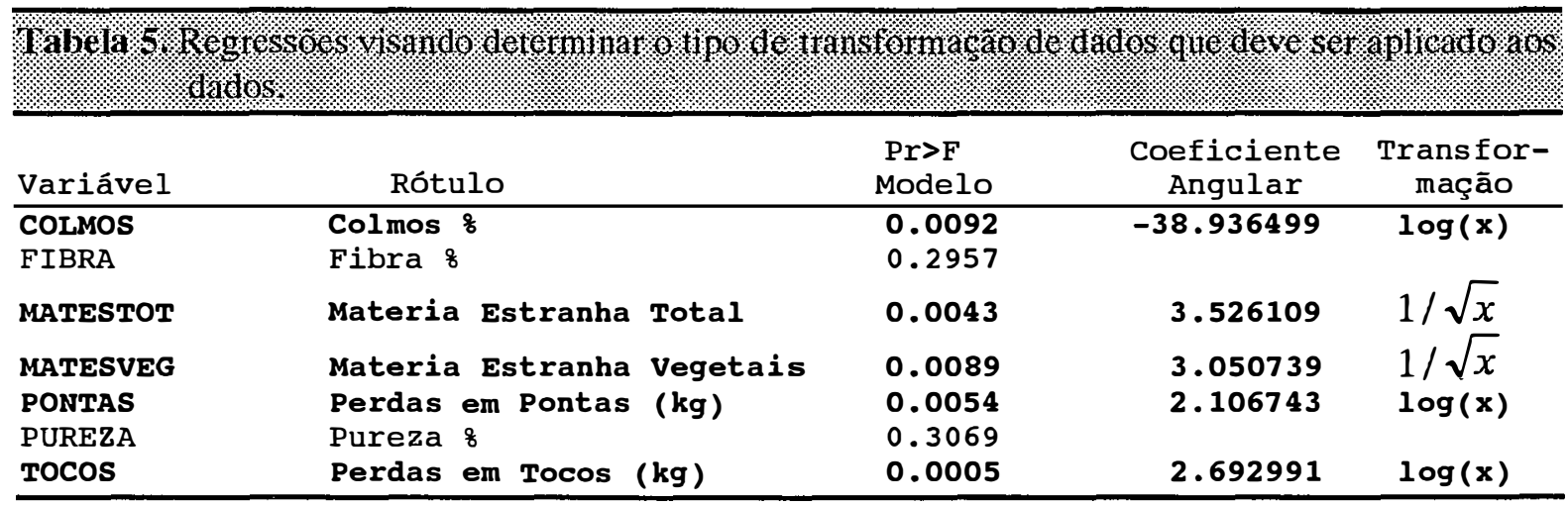


Observa-se que foram descritas duas variáveis cujo conteúdo foi estabelecido pelo pesquisador: REP, com 8 níveis CAMPO, com 2 níveis e TIPOCANA com 2 níveis.

$\mathrm{O}$ número de observações no arquivo é 32 que corresponde às 32 talhões medidos.

Uma vez definidas essas informações que são válidas para todas as variáveis de resposta estudadas, serão listados a seguir os resultados da análise de Variância.

\subsubsection{ANÁLISE DE VARIÂNCIA.}

Inicialmente, na Tabela 10, são listados os resultados da análise de variância para o modelo. Através do valor rotulado de $\operatorname{Pr}>\mathrm{F}$, temos um nível de significância mínimo de 5\% para rejeitar a hipótese de que todos os tratamentos são iguais.

\begin{tabular}{|c|c|c|c|}
\hline \multicolumn{4}{|l|}{ 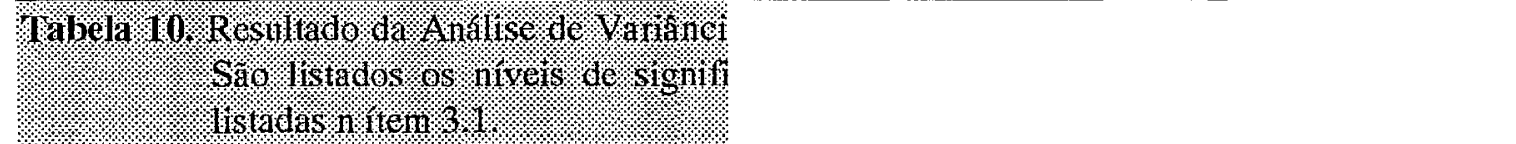 } \\
\hline Rótulo & $\begin{array}{r}\text { Pr>F } \\
\text { Campo }\end{array}$ & $\begin{array}{l}\text { Pr>F } \\
\text { Tipo Cana }\end{array}$ & $\begin{array}{c}\text { Pr>F } \\
\text { Campos } x \text { Tipo Cana } \\
\text { (Interação) }\end{array}$ \\
\hline Brix 8 & 0,0403 & 0,0051 & 0,4068 \\
\hline 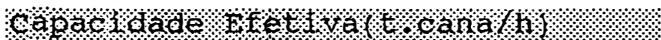 & 00040 & 00001 & $043 \%$ \\
\hline $\begin{array}{c}\text { Colmos }{ }^{8} \\
\log (\text { Colmos })^{2}\end{array}$ & $\begin{array}{l}0,0160 \\
0,0161\end{array}$ & $\begin{array}{l}0,0033 \\
0,0035\end{array}$ & $\begin{array}{l}0,0041 \\
0,0043\end{array}$ \\
\hline 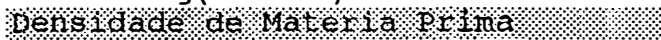 & 0000 & 0014 & 013 \\
\hline Fibra 8 & 0,0001 & 0,0001 & 0,0017 \\
\hline 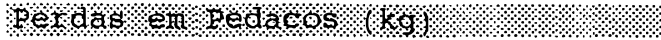 & $0860 \%$ & 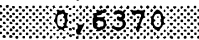 & $048 \%$ \\
\hline Materia Estranha Mineral & 0,0001 & 0,0312 & 0,5526 \\
\hline 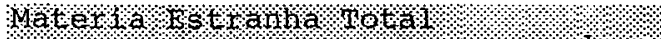 & 0101 & 0003 & 00049 \\
\hline $11.1 \%$ - & 00019 & $0000 \%$ & $0006 \%$ \\
\hline Materia Estranha Vegetais & 0,0422 & 0,0020 & 0,0038 \\
\hline $1 / \operatorname{sqrt}(\text { Mat.Est.Vegetal) })^{1}$ & 0,4996 & 0,0016 & 0,0047 \\
\hline 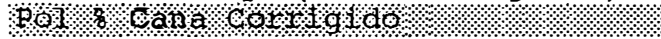 & 00002 & $6 \% 92$ & $008 \%$ \\
\hline Pol \& Caldo & 0,0001 & 0,0380 & 0,3100 \\
\hline 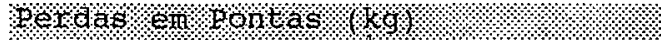 & 010004 & 01000 & $0100 \%$ \\
\hline $1 \% 101(1) 1401$ & 00005 & 000004 & 000016 \\
\hline Pureza 8 & 0,0001 & 0,1449 & 0,4827 \\
\hline 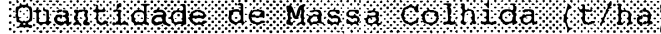 & $100000 \%$ & 0180 & $013 \%$ \\
\hline Perdas em Rebolos (kg) & 0,0518 & 0,0209 & 0,0066 \\
\hline 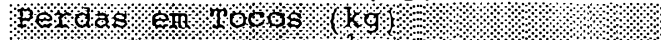 & 0616 & 0102 & 00069 \\
\hline 1. & 0128 & 00045 & 00104 \\
\hline Perdas Totais ( $\mathrm{kg})$ & 0,0197 & 0,0001 & 0,0003 \\
\hline 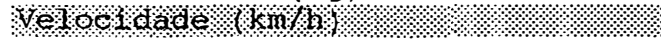 & 0,0001 & 0000 & $0 \% 835$ \\
\hline
\end{tabular}

IVariável Transformada

A partir dos dados da Tabela 10, podemos tirar as conclusões pertinentes em relação a cada uma das variáveis estudadas.

\subsubsection{Brix \%.}

Verifica-se na Tabela 10 que a interação da entre Campo e Tipo de Cana não é estatisticamente significativa, com isso, passamos para a análise das médias dos dois fatores, conforme mostradas na Tabela 11. 


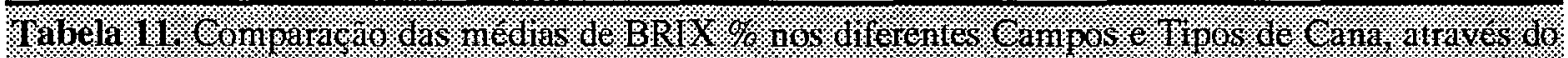
teste.to.

\begin{tabular}{lccccc} 
& \multicolumn{2}{c}{ Campo $^{*}$} & & \multicolumn{2}{c}{ Tipo de Cana** } \\
\cline { 2 - 3 } \cline { 5 - 6 } Variável & 1 & 2 & & Crua & Queimada \\
Brix \% & 20,9687 & 21,6394 & & 21,7363 & 20,8719
\end{tabular}

\footnotetext{
- Indica diferença estatística significativa entre as médias, com nível $\alpha$ (alfa) de significância de 5\% e

“* indica diferença estatística significativa entre as médias, com nível $\alpha$ (alfa) de significância de $1 \%$.
}

\subsubsection{Capacidade Efetiva (t.cana/h).}

Verifica-se na Tabela 10 que a interação da entre Campo e Tipo de Cana não é estatisticamente significativa, com isso, passamos para a análise das médias dos dois fatores, conforme mostradas na Tabela 12.

\begin{tabular}{|c|c|c|c|c|}
\hline \multicolumn{5}{|c|}{ 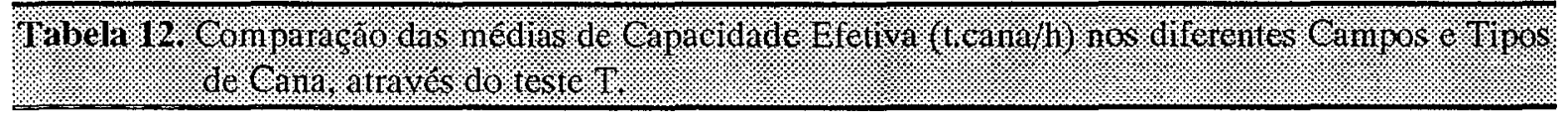 } \\
\hline & \multicolumn{2}{|c|}{ Campo* } & \multicolumn{2}{|c|}{ Tipo de Cana** } \\
\hline Variável & 1 & 2 & Crua & Queimada \\
\hline Capacidade Efetiva (t.cana/h) & 64,0600 & 60,5125 & 57,7800 & 66,7925 \\
\hline
\end{tabular}

.. Indica diferença estatística significativa entre as médias, com nível $\alpha$ (alfa) de significância de 5\% e

•* indica diferença estatística significativa entre as médias, com nível $\alpha$ (alfa) de significância de $1 \%$.

\subsubsection{Colmos \%.}

Como pode ser observada na Tabela 10, a interação entre "campo" e "tipo de cana" é significativa. Quando isso ocorre, conclusōes gerais não são interessantes já que a combinação de níveis pode gerar resultados diferentes.

Para solucionar esse probema, analisa-se as médias das 4 combinações de níveis dos fatores, o que é feito na Tabela 13.

\begin{tabular}{|c|c|c|c|c|c|c|}
\hline \multirow[t]{3}{*}{ Tabelâl' } & \multicolumn{2}{|c|}{ S. } & Sobro. $0.1 \%$ & 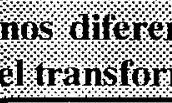 & \multicolumn{2}{|c|}{ 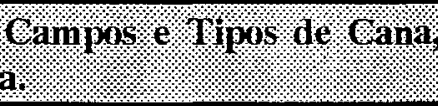 } \\
\hline & \multirow{2}{*}{\multicolumn{2}{|c|}{$\begin{array}{l}\text { Variável } \\
\text { Colmos \% }\end{array}$}} & \multicolumn{4}{|c|}{ Campo } \\
\hline & & & & & & \\
\hline \multirow[t]{2}{*}{ Campo } & Tipo & & Crua & Queimada & Crua & Queimada \\
\hline & & Médias & 93.9475 & 94.0550 & 88.4000 & 94.9787 \\
\hline \multirow[t]{2}{*}{1} & Crua & 93.9475 & $\cdots$ & & * & \\
\hline & Queimada & 94.0550 & & -- & ** & \\
\hline \multirow[t]{2}{*}{2} & Crua & 88.4000 & ** & 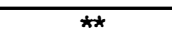 & $\cdots$ & $\hbar \star$ \\
\hline & Queimada & 94.9787 & & & $\star \star$ & --- \\
\hline
\end{tabular}

\footnotetext{
- Indica diferença estatística significativa entre as médias, com nível $\alpha$ (alfa) de significância de $5 \%$ e

** indica diferença estatística significativa entre as médias, com nível $\alpha$ (alfa) de significância de $1 \%$.
}

Para visualizar essas diferenças, desenhou-se o Gráfico 1 mostrado a seguir. 


\section{Avaliacao de Colheita Mecanica Grafico de Barras Horizontais \\ Colmos \%}

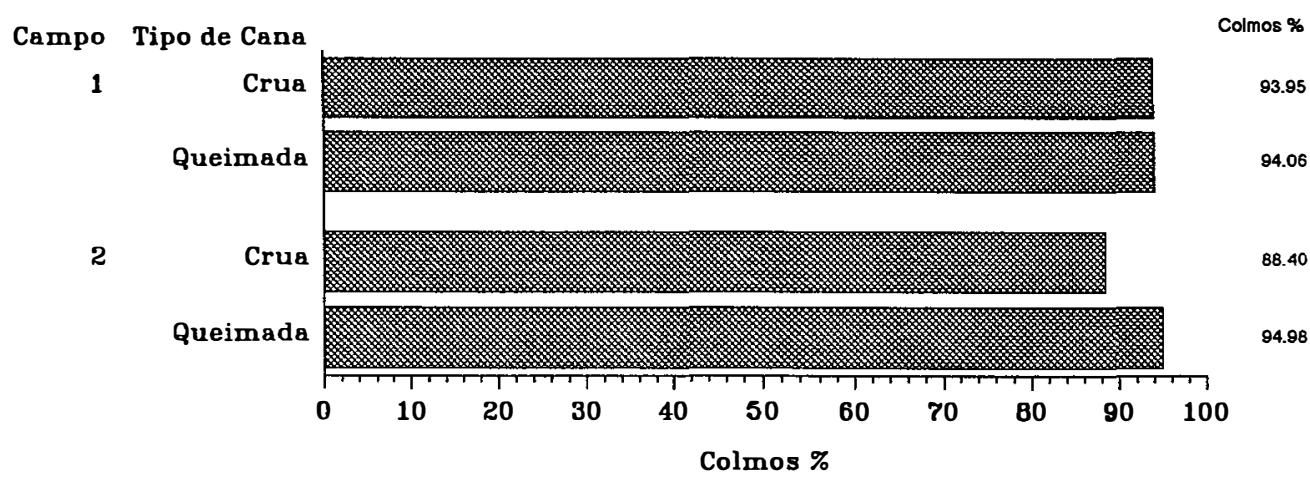

Enquanto que no campo 1 há uma grande igualdade no comportamento dos tipos de cana (crua e queimada) enquanto que no campo 2 pode ser observadas diferenças entre os dois tipos.

A análise estatística dos dados transformados apresentaram o mesmo resultado que a dos dados originais em relação à análise de variância e dos testes de comparação de médias.

\subsubsection{Densidade de Matéria Prima.}

Verifica-se na Tabela 10 que a interação da entre Campo e Tipo de Cana não é estatisticamente significativa, com isso, passamos para a análise das médias dos dois fatores, conforme mostradas na Tabela 14.

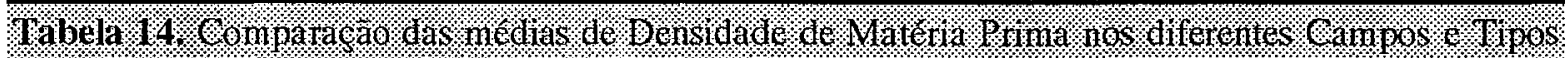

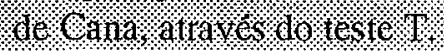

\begin{tabular}{|c|c|c|c|c|}
\hline \multirow[b]{2}{*}{ Variável } & \multicolumn{2}{|c|}{ Campo"* } & \multicolumn{2}{|c|}{ Tipo de Cana* } \\
\hline & 1 & 2 & Crua & Queimada \\
\hline Densidade de Matéria Prima & 11,9919 & 12,6044 & 12,4469 & 12,1494 \\
\hline
\end{tabular}




\subsubsection{Fibra \%.}

Como pode ser observada na Tabela 10, a interação entre "campo" e "tipo de cana" é significativa. Quando isso ocorre, conclusōes gerais não são interessantes já que a combinação de níveis pode gerar resultados diferentes.

Para solucionar esse probema, analisa-se as médias das 4 combinações de níveis dos fatores, o que é feito na Tabela 15.

\begin{tabular}{|c|c|c|c|c|c|c|}
\hline \multirow{2}{*}{\multicolumn{3}{|c|}{$\begin{array}{l}\text { Variável } \\
\text { Fibra \% }\end{array}$}} & \multicolumn{4}{|c|}{ Campo } \\
\hline & & & \multicolumn{2}{|c|}{1} & \multicolumn{2}{|c|}{2} \\
\hline \multirow[t]{2}{*}{ Campo } & Tipo & & Crua & Queimada & Crua & Queimada \\
\hline & & Médias & 14.8363 & 14.0300 & 18.7700 & 16.0275 \\
\hline \multirow[t]{2}{*}{1} & Crua & 14.8363 & 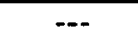 & * & 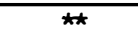 & 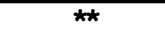 \\
\hline & Queimada & 14.0300 & * & $\cdots$ & 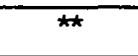 & 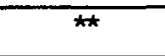 \\
\hline \multirow[t]{2}{*}{2} & Crua & 18.7700 & $\star \star$ & 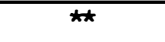 & --- & 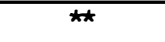 \\
\hline & Queimada & 16.0275 & $\star \star$ & $\star \star$ & $\star \star$ & $\cdots$ \\
\hline
\end{tabular}

Indica diferença estatística significativa entre as médias, com nível $\alpha$ (alfa) de significância de 5\% e

** indica diferença estatística significativa entre as médias, com nível $\alpha$ (alfa) de significância de 1\% .

Para visualizar essas diferenças, desenhou-se o Gráfico 2 mostrado abaixo.

Grafico 2. Frofleor 1010 .

\section{Avaliacao de Colheita Mecanica \\ Grafico de Barras Horizontais Fibra \%}

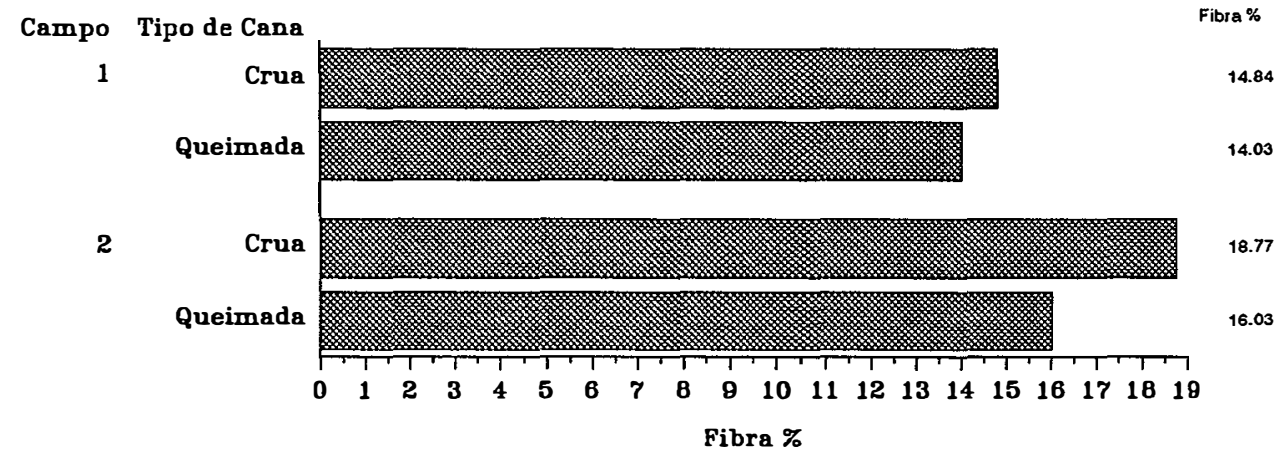


Verifica-se no Gráfico 2 que as diferenças da porcentagem de fibra entre os dois tipos de cana é maior no campo 2 que no campo 1

Adicionalmente, a diferença é significativa com nível de significância de $5 \%$ quando se compara cana crua dos campos 1 e dois. Qualquer outra comparação é significativa com significância de $1 \%$.

\subsubsection{Perdas em Pedaços (kg).}

Verifica-se na Tabela 10 que a interação da entre Campo e Tipo de Cana não é estatisticamente significativa, com isso, passamos para a análise das médias dos dois fatores, conforme mostradas na Tabela 16.

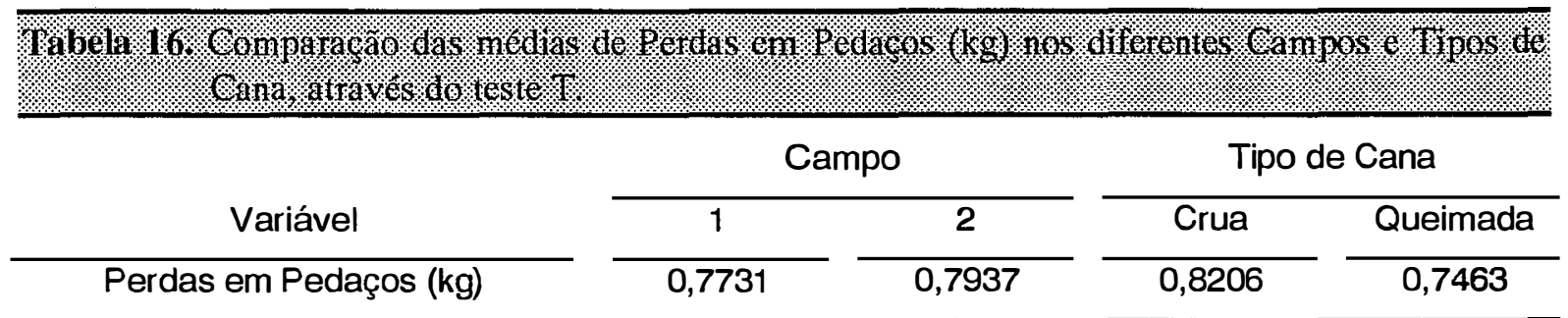

\footnotetext{
- Indica diferença estatística significativa entre as médias, com nível $\alpha$ (alfa) de significância de 5\% e * indica diferença estatística significativa entre as médias, com nível $\alpha$ (alfa) de significância de 1\% .
}

\subsubsection{Matéria Estranha Mineral.}

Verifica-se na Tábela 10 que a interação da entre Campo e Tipo de Cana não é estatisticamente significativa, com isso, passamos para a análise das médias dos dois fatores, conforme mostradas na Tabela 17.

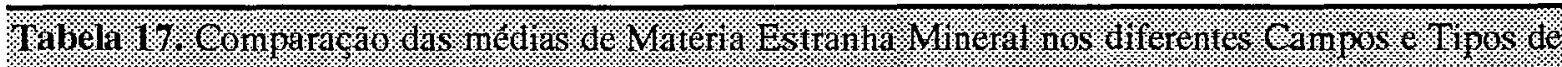

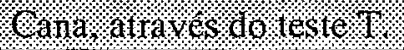

\begin{tabular}{|c|c|c|c|c|}
\hline \multirow[b]{2}{*}{ Variável } & \multicolumn{2}{|c|}{ Campo" } & \multicolumn{2}{|c|}{ Tipo de Cana* } \\
\hline & 1 & 2 & Crua & Queimada \\
\hline Matéria Estranha Mineral & 0,5525 & 0,9550 & 0,6800 & 0,8275 \\
\hline
\end{tabular}

\footnotetext{
* Indica diferença estatística significativa entre as médias, com nível $\alpha$ (alfa) de significância de 5\% e

"* indica diferença estatística significativa entre as médias, com nível $\alpha$ (alfa) de significância de $1 \%$.
}

\subsubsection{Matéria Estranha Total.}

Como pode ser observada na Tabela 10, a interação entre "campo" e "tipo de cana" é significativa. Quando isso ocorre, conclusōes gerais não são interessantes já que a combinação de níveis pode gerar resultados diferentes.

Para solucionar esse probema, analisa-se as médias das 4 combinaçōes de níveis dos fatores, o que é feito na Tabela 18. 


\begin{tabular}{|c|c|c|c|c|c|c|}
\hline \multirow{3}{*}{\multicolumn{3}{|c|}{ 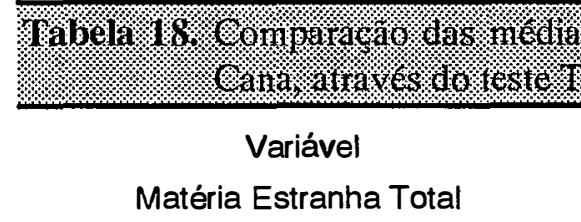 }} & arieressing & 1. & 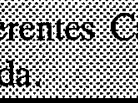 & $7_{1}^{19}$ \\
\hline & & & \multicolumn{4}{|c|}{ Campo } \\
\hline & & & \multicolumn{2}{|c|}{1} & \multicolumn{2}{|c|}{2} \\
\hline \multirow[t]{2}{*}{ Campo } & Tipo & & Crua & Queimada & Crua & Queimada \\
\hline & & Médias & 6.0513 & 5.9400 & 11.5250 & 5.0212 \\
\hline \multirow[t]{2}{*}{1} & Crua & 6.0513 & $\cdots$ & & $\star \star$ & \\
\hline & Queimada & 5.9400 & & $\cdots$ & 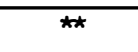 & \\
\hline \multirow[t]{2}{*}{2} & Crua & 11.5250 & ** & 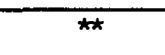 & -- & ** \\
\hline & Queimada & 5.0212 & & & $\star \star$ & --- \\
\hline
\end{tabular}

"Indica diferença estatística significativa entre as médias, com nível $\alpha$ (alfa) de significância de 5\% e

** indica diferença estatística significativa entre as médias, com nível $\alpha$ (alfa) de significância de $1 \%$.

Para visualizar essas diferenças, desenhou-se o Gráfico 3 mostrado abaixo.

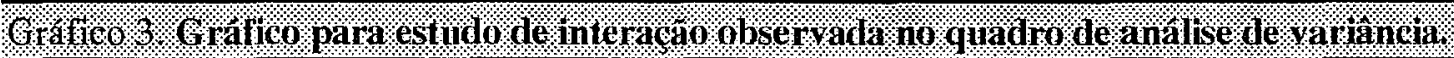

\section{Avaliacao de Colheita Mecanica Grafico de Barras Horizontais \\ Materia Estranha Total}

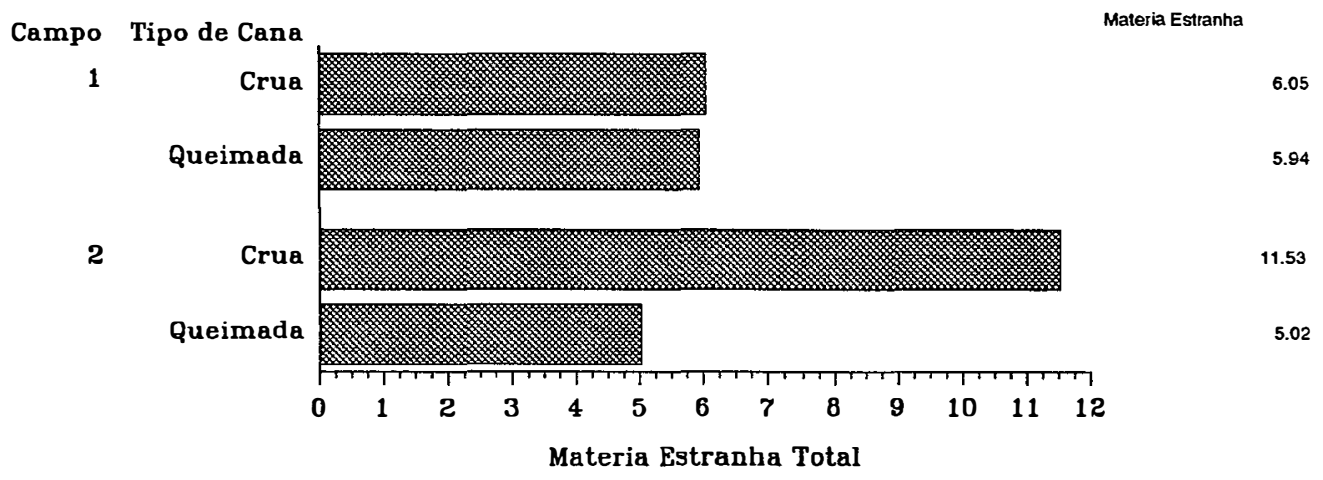

Verifica-se que a interação é justificada por diferenças de comportamento dos campos em cada um dos tipos de cana. Inicialmente, verifica-se que o teor de matéria estranha total da cana crua é significativamente maior no campo 2 que no campo 1.

O mesmo nāo ocorre no caso da cana queimada, onde não há diferença estatística significativa entre os campos. A análise estatística dos dados transformados apresentaram o mesmo 
resultado que a dos dados originais em relação à análise de variância e dos testes de comparação de médias.

\subsubsection{Matéria Estranha Vegetal.}

Como pode ser observada na Tabela 10, a interação entre "campo" e "tipo de cana" é significativa. Quando isso ocorre, conclusōes gerais não são interessantes já que a combinação de níveis pode gerar resultados diferentes.

Para solucionar esse probema, analisa-se as médias das 4 combinaçōes de níveis dos fatores, o que é feito na Tabela 19.

\begin{tabular}{|c|c|c|c|c|c|c|}
\hline \multicolumn{7}{|c|}{ 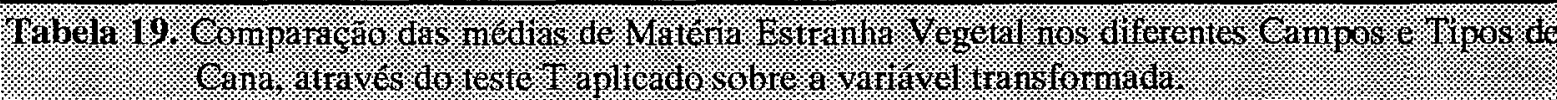 } \\
\hline \multirow{2}{*}{\multicolumn{3}{|c|}{$\begin{array}{l}\text { Variável } \\
\text { Matéria Estranha Vegetal }\end{array}$}} & \multicolumn{4}{|c|}{ Campo } \\
\hline & & & & & & \\
\hline \multirow[t]{2}{*}{ Campo } & Tipo & & Crua & Queimada & Crua & Queimada \\
\hline & & Médias & 5.5913 & 5.2950 & 10.6250 & 4.0113 \\
\hline \multirow[t]{2}{*}{1} & Crua & 5.5913 & $\ldots$ & & * & * \\
\hline & Queimada & 5.2950 & & --- & 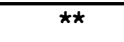 & \\
\hline \multirow[t]{2}{*}{2} & Crua & 10.6250 & * & 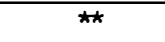 & -- & 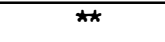 \\
\hline & Queimada & 4.0113 & * & & $\star \star$ & -- \\
\hline
\end{tabular}

\footnotetext{
Indica diferença estatística significativa entre as médias, com nível $\alpha$ (alfa) de significância de 5\% e

- indica diferença estatística significativa entre as médias, com nível $\alpha$ (alfa) de significância de $1 \%$. Para visualizar essas diferenças, desenhou-se o Gráfico 4 mostrado abaixo.
}

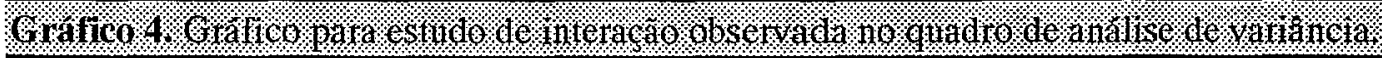

\section{Avaliacao de Colheita Mecanica \\ Grafico de Barras Horizontais \\ Materia Estranha Vegetal}

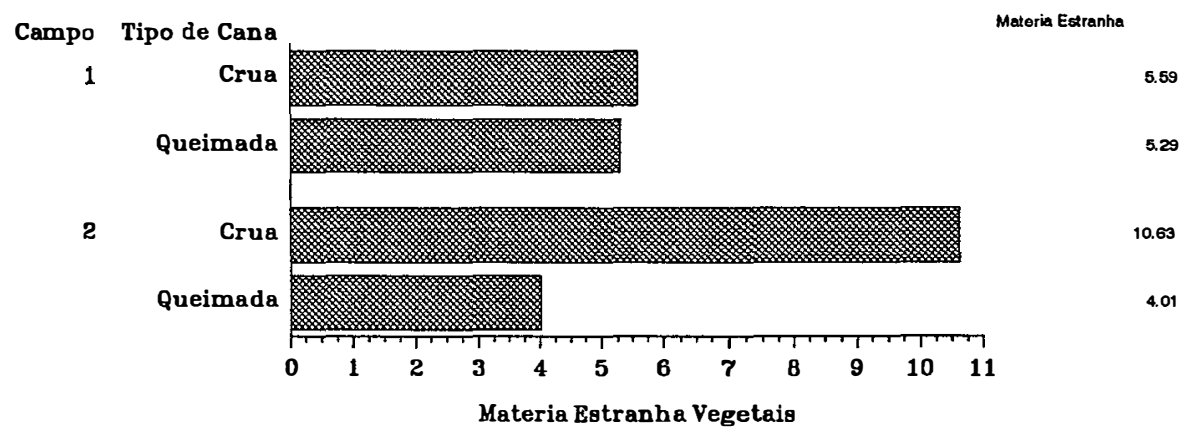


A análise mostra que as diferenças entre os tipos de cana no campo 2 é bem mais evidente que as diferenças observadas no campo 1

Os resultados apresentados na comparação de médias se referem à análise de valores transformados cujos resultados diferiram dos observados originalmente.

\subsubsection{Pol \% Cana Corrigido.}

Como pode ser observada na Tabela 10, a interação entre "campo" e "tipo de cana" é significativa. Quando isso ocorre, conclusões gerais não são interessantes já que a combinação de níveis pode gerar resultados diferentes.

Para solucionar esse probema, analisa-se as médias das 4 combinações de níveis dos fatores, o que é feito na Tabela 20.

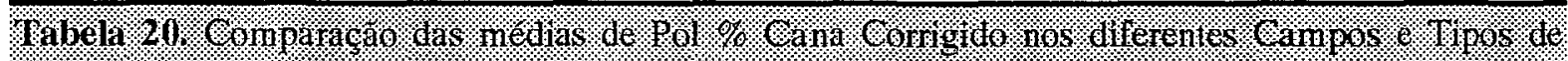

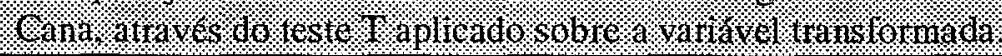

\begin{tabular}{|c|c|c|c|c|c|c|}
\hline \multirow{2}{*}{\multicolumn{3}{|c|}{$\begin{array}{c}\text { Variável } \\
\text { Matéria Estranha Vegetal }\end{array}$}} & \multicolumn{4}{|c|}{ Campo } \\
\hline & & & \multicolumn{2}{|c|}{1} & \multicolumn{2}{|c|}{2} \\
\hline \multirow[t]{2}{*}{ Campo } & Tipo & & Crua & Queimada & Crua & Queimada \\
\hline & & Médias & 14.5413 & 14.0075 & 15.2275 & 15.7587 \\
\hline \multirow[t]{2}{*}{1} & Crua & 14.5413 & $\cdots$ & $\star$ & $\star \star$ & $\star \star$ \\
\hline & Queimada & 14.0075 & * & --- & $\star \star$ & $\star \star$ \\
\hline \multirow[t]{2}{*}{2} & Crua & 15.2275 & $\star \star$ & $\star \star$ & -- & $\star$ \\
\hline & Queimada & 15.7587 & $\star \star$ & $\star \star$ & * & 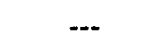 \\
\hline
\end{tabular}

\footnotetext{
- Indica diferença estatística significativa entre as médias, com nível $\alpha$ (alfa) de significância de 5\% e

** indica diferença estatística significativa entre as médias, com nível $\alpha$ (alfa) de significância de $1 \%$.
}

O Gráfico 5 mostra as diferenças. 


\section{Avaliacao de Colheita Mecanica \\ Grafico de Barras Horizontais \\ Pol \% Cana Corrigido}

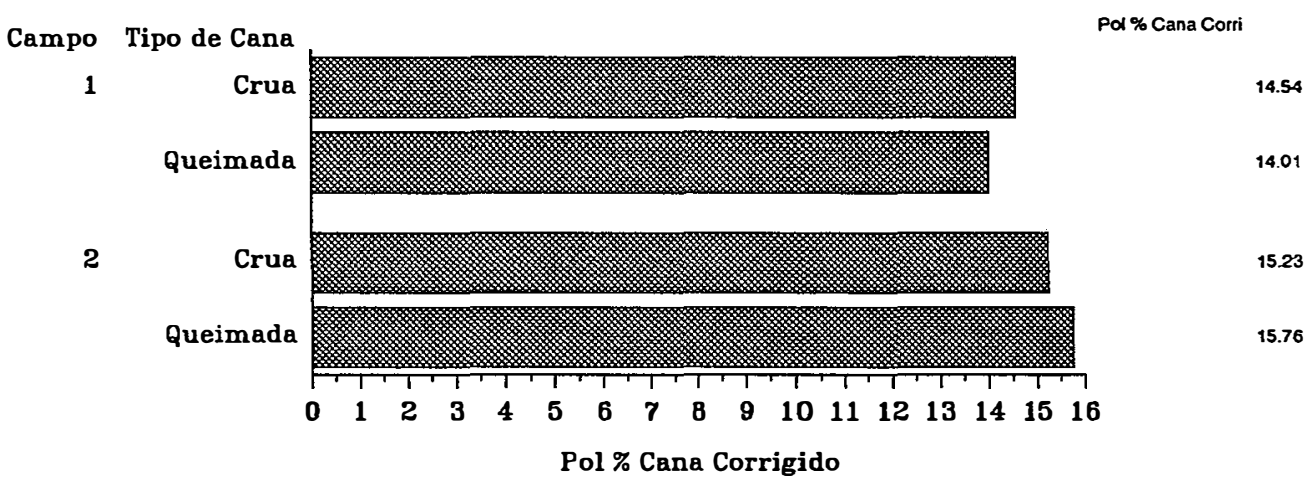

Pode-se verificar no gráfico e na análise estatística que no campo 1 a cana crua apresenta média significativamente superior que a cana queimada ao passo que no campo 2 , a cana queimada é que apresenta média estatisticamente superior.

\subsubsection{Pol \% Caldo.}

Verifica-se na Tabela 10 que a interação da entre Campo e Tipo de Cana não é estatisticamente significativa, com isso, passamos para a análise das médias dos dois fatores, conforme mostradas na Tabela 21.

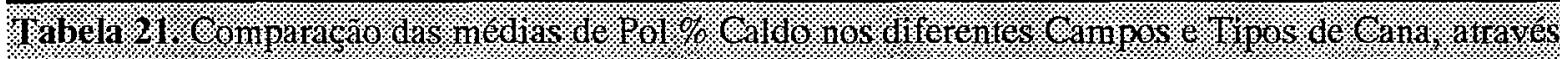
Aiviteste.ts

\begin{tabular}{|c|c|c|c|c|}
\hline \multirow[b]{2}{*}{ Variável } & \multicolumn{2}{|c|}{ Campo * } & \multicolumn{2}{|c|}{ Tipo de Cana* } \\
\hline & 1 & 2 & Crua & Queimada \\
\hline Matéria Estranha Mineral & 18,1406 & 20,1425 & 19,4331 & 18,8500 \\
\hline
\end{tabular}




\subsubsection{Perdas em Pontas (kg) .}

Como pode ser observada na Tabela 10, a interação entre "campo" e "tipo de cana" é significativa. Quando isso ocorre, conclusões gerais não são interessantes já que a combinação de níveis pode gerar resultados diferentes.

Para solucionar esse probema, analisa-se as médias das 4 combinações de níveis dos fatores, o que é feito na Tabela 22.

\begin{tabular}{|c|c|c|c|c|c|c|}
\hline $191 \% 14$ & 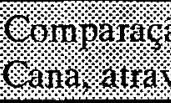 & 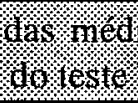 & Merars. & H. & 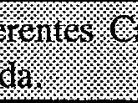 & 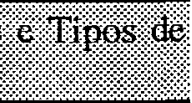 \\
\hline & Variável & & & & & \\
\hline & as em Pontas & & & & & \\
\hline Campo & Tipo & & Crua & Queimada & Crua & Queimada \\
\hline & & Médias & 2.69375 & 0.40875 & 0.41250 & 0.45000 \\
\hline 1 & Crua & 2.69375 & -- & 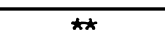 & $\star \star$ & 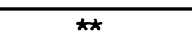 \\
\hline & Queimada & 0.40875 & 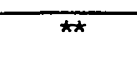 & $\cdots$ & & \\
\hline 2 & Crua & 0.41250 & $\star \star$ & & -- & \\
\hline & Queimada & 0.45000 & $\star \star$ & & & -- \\
\hline
\end{tabular}

\footnotetext{
* Indica diferença estatística significativa entre as médias, com nível $\alpha$ (alfa) de significância de $5 \%$ e

** indica diferença estatística significativa entre as médias, com nível $\alpha$ (alfa) de significância de $1 \%$.
}

Para visualizar essas diferenças, desenhou-se o Gráfico 6 mostrado abaixo.

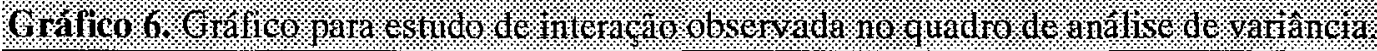




\section{Avaliacao de Colheita Mecanica \\ Grafico de Barras Horizontais \\ Perdas em Pontas (kg)}

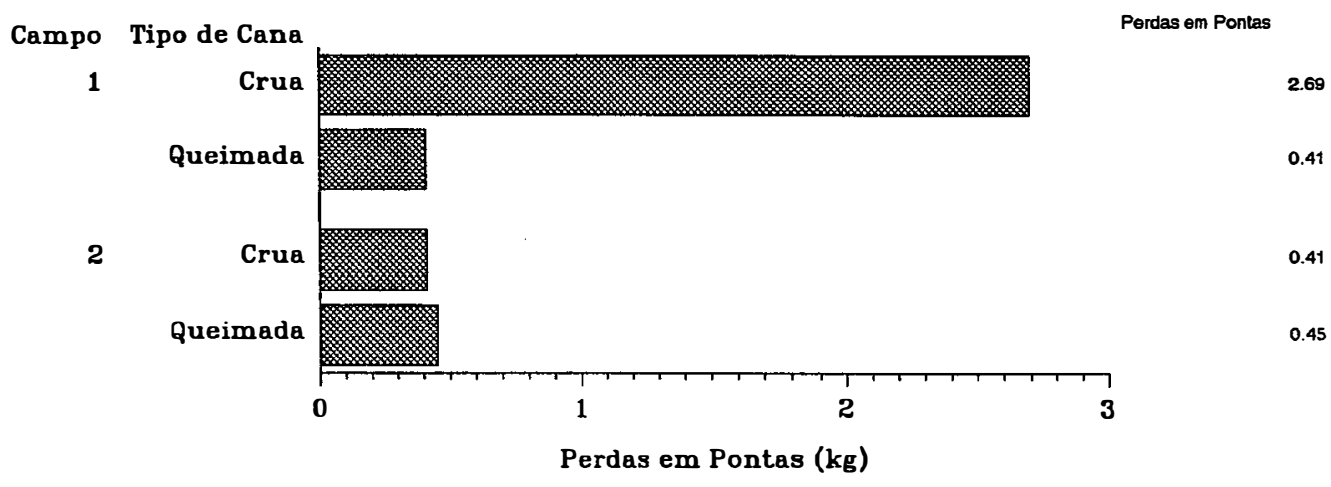

Observa-se que a combinação de cana crua com o campo 1 gera um comportamento completamente diferente das demais combinações.

Os resultados apresentados na comparação de médias se referem à análise de valores transformados cujos resultados diferiram dos observados originalmente.

\subsubsection{Pureza \% .}

Verifica-se na Tabela 10 que a interação da entre Campo e Tipo de Cana não é estatisticamente significativa, com isso, passamos para a análise das médias dos dois fatores, conforme mostradas na Tabela 23.

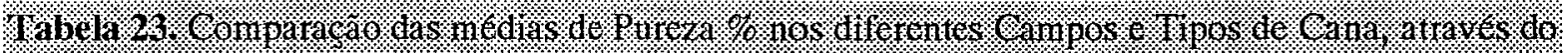
1.st.

\begin{tabular}{|c|c|c|c|c|}
\hline \multirow[b]{2}{*}{ Variável } & \multicolumn{2}{|c|}{ Campo" } & \multicolumn{2}{|c|}{ Tipo de Cana } \\
\hline & 1 & 2 & Crua & Queimada \\
\hline Pureza \% & 86,5206 & 92,9750 & 89,3831 & 90,1125 \\
\hline
\end{tabular}

* Indica diferença estatística significativa entre as médias, com nível $\alpha$ (alfa) de significância de 5\% e ** indica diferença estatística significativa entre as médias, com nível $\alpha$ (alfa) de significância de $1 \%$. 


\subsubsection{Quantidade de Massa Colhida (t/ha) .}

Verifica-se na Tabela 10 que a interação da entre Campo e Tipo de Cana não é estatisticamente significativa, com isso, passamos para a análise das médias dos dois fatores, conforme mostradas na Tabela 24.

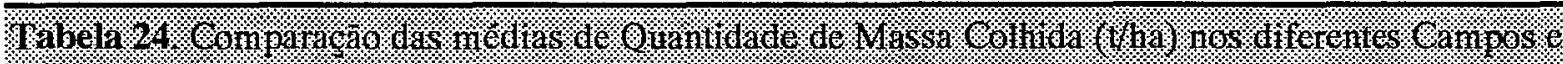

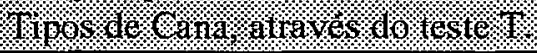

\begin{tabular}{|c|c|c|c|c|}
\hline \multirow[b]{2}{*}{ Variável } & \multicolumn{2}{|c|}{ Campo } & \multicolumn{2}{|c|}{ Tipo de Cana * } \\
\hline & $\frac{1}{1}$ & 2 & Crua & Queimada \\
\hline Quantidade de Massa Colhida (t/ha) & 84,4537 & 88,7556 & 87,6456 & 85,5637 \\
\hline
\end{tabular}

- Indica diferença estatística significativa entre as médias, com nível $\alpha$ (alfa) de significância de 5\% e

** indica diferença estatística significativa entre as médias, com nível $\alpha$ (alfa) de significância de $1 \%$.

\subsubsection{Perdas em Rebolos (kg) .} significativa.

Como pode ser observada na Tabela 10, a interação entre "campo" e "tipo de cana" é

Para solucionar esse probema, analisa-se as médias das 4 combinações de níveis dos fatores, o que é feito na Tabela 25.

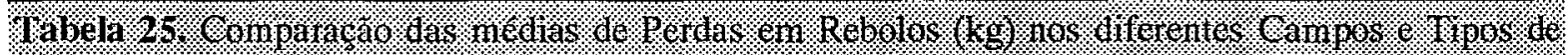

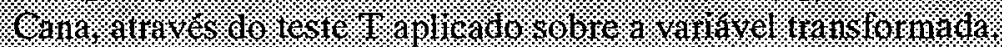

\begin{tabular}{|c|c|c|c|c|c|c|}
\hline \multirow{2}{*}{\multicolumn{3}{|c|}{$\begin{array}{c}\text { Variável } \\
\text { Perdas em Rebolos }(\mathrm{kg})\end{array}$}} & \multicolumn{4}{|c|}{ Campo } \\
\hline & & & \multicolumn{2}{|c|}{1} & \multicolumn{2}{|c|}{2} \\
\hline \multirow[t]{2}{*}{ Campo } & Tipo & & Crua & Queimada & Crua & Queimada \\
\hline & & Médias & 4.09375 & 1.73125 & 2.05000 & 1.81250 \\
\hline \multirow[t]{2}{*}{1} & Crua & 4.09375 & $-\cdots$ & 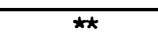 & $\star \star$ & 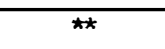 \\
\hline & Queimada & 1.73125 & $\star \star$ & -- & & \\
\hline \multirow[t]{2}{*}{2} & Crua & 2.05000 & 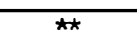 & & --- & \\
\hline & Queimada & 1.81250 & ** & & & $\ldots$ \\
\hline
\end{tabular}

\footnotetext{
"Indica diferença estatística significativa entre as médias, com nível $\alpha$ (alfa) de significância de 5\% e

* indica diferença estatística significativa entre as médias, com nível $\alpha$ (alfa) de significância de $1 \%$.
}

Para visualizar essas diferenças, desenhou-se o Gráfico 7 mostrado a seguir. 


\section{Avaliacao de Colheita Mecanica Grafico de Barras Horizontais \\ Perdas em Rebolos (kg)}

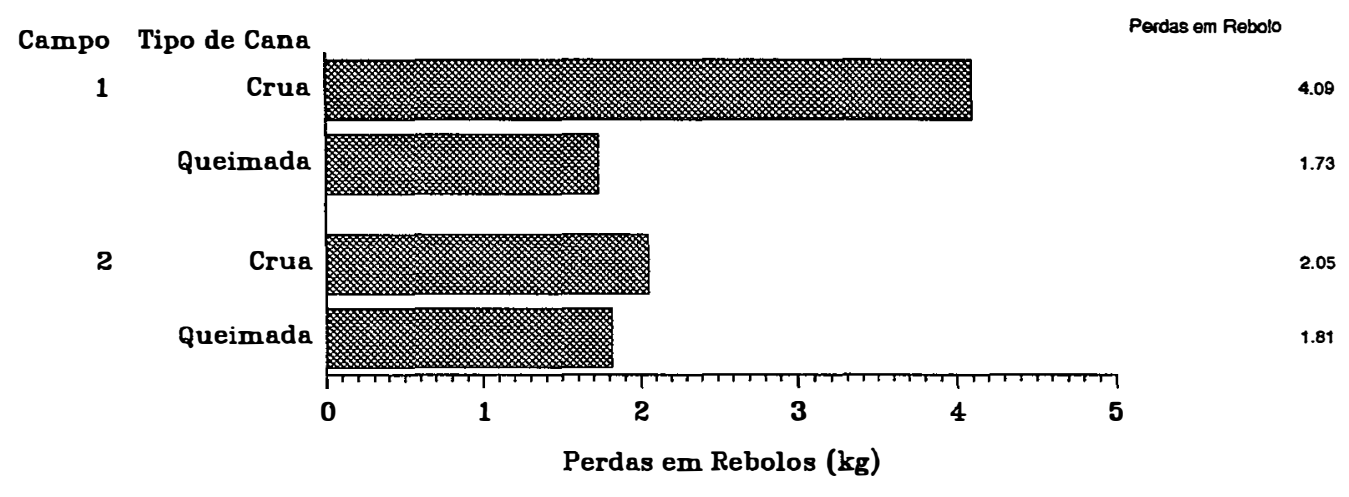

Verifica-se que a combinação e cana crua e campo 1 gera resultados completamente diferentes dos demais.

\subsubsection{Perdas em Tocos (kg).}

significativa.

Como pode ser observada na Tabela 10, a interação entre "campo" e "tipo de cana" é

Para solucionar esse probema, analisa-se as médias das 4 combinações de níveis dos fatores, o que é feito na Tabela 26.

\begin{tabular}{|c|c|c|c|c|c|c|}
\hline \multirow{3}{*}{\multicolumn{3}{|c|}{ 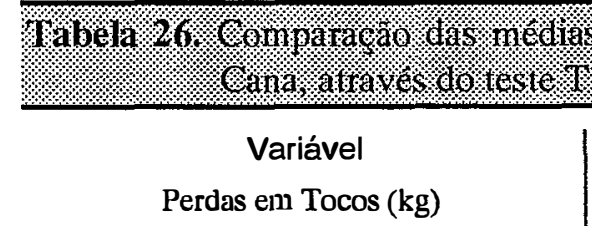 }} & 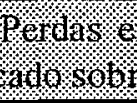 & 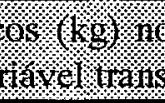 & (2) & 1011195 \\
\hline & & & \multicolumn{4}{|c|}{ Campo } \\
\hline & & & \multicolumn{2}{|c|}{1} & \multicolumn{2}{|c|}{2} \\
\hline \multirow[t]{2}{*}{ Campo } & Tipo & & Crua & Queimada & Crua & Queimada \\
\hline & & Médias & 1.70000 & 0.45000 & 1.30000 & 1.13750 \\
\hline \multirow[t]{2}{*}{1} & Crua & 1.70000 & $\cdots$ & *ᄎ & & \\
\hline & Queimada & 0.45000 & \#\# & $\cdots$ & 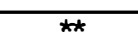 & 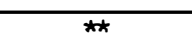 \\
\hline \multirow[t]{2}{*}{2} & Crua & 1.30000 & & $\star \star \star$ & $\cdots$ & \\
\hline & Queimada & 1.13750 & & $\star \star$ & & --- \\
\hline
\end{tabular}

\footnotetext{
* Indica diferença estatística significativa entre as médias, com nível $\alpha$ (alfa) de significância de $5 \%$ e

* indica diferença estatística significativa entre as médias, com nível $\alpha$ (alfa) de significância de $1 \%$.
} 
Para visualizar essas diferenças, desenhou-se o Gráfico 8 mostrado abaixo.

\section{Avaliacao de Colheita Mecanica \\ Grafico de Barras Horizontais \\ Perdas em Tocos (kg)}

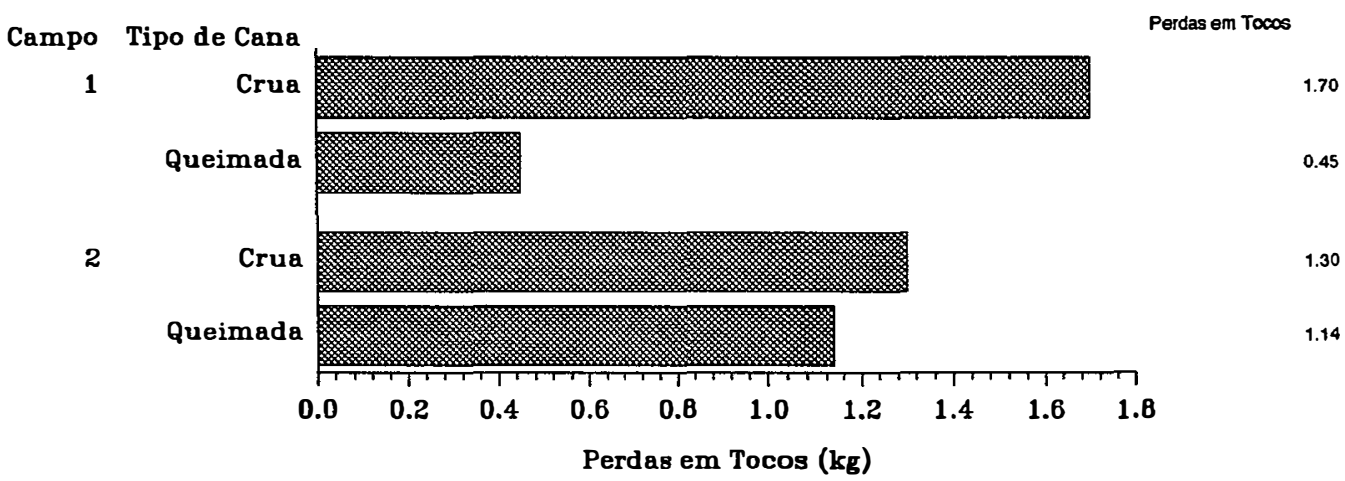

3.3.2.17. Perdas Totais .

Como pode ser observada na Tabela 10, a interação entre "campo" e "tipo de cana" é significativa.

Para solucionar esse probema, analisa-se as médias das 4 combinações de níveis dos fatores, o que é feito na Tabela 27.

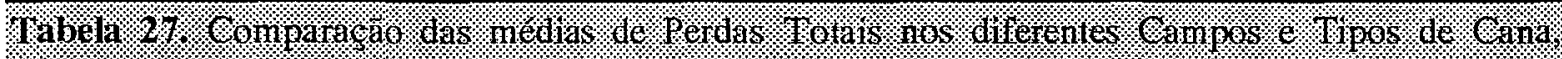

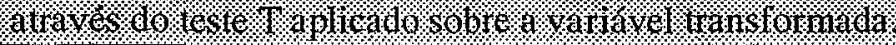

\begin{tabular}{|c|c|c|c|c|c|c|}
\hline \multirow{2}{*}{\multicolumn{3}{|c|}{$\begin{array}{c}\text { Variável } \\
\text { Perdas Totais }\end{array}$}} & \multicolumn{4}{|c|}{ Campo } \\
\hline & & & \multicolumn{2}{|c|}{1} & \multicolumn{2}{|c|}{2} \\
\hline \multirow[t]{2}{*}{ Campo } & Tipo & & Crua & Queimada & Crua & Queimada \\
\hline & & Médias & 13.7287 & 7.6450 & 8.9125 & 8.5875 \\
\hline \multirow[t]{2}{*}{1} & Crua & 13.7287 & -- & $\star \star$ & $\star \star \star$ & $\star \star$ \\
\hline & Queimada & 7.6450 & $\star \star$ & -- & & \\
\hline \multirow[t]{2}{*}{2} & Crua & 8.9125 & $\star \star \star$ & & --- & \\
\hline & Queimada & 8.5875 & $\star \star$ & & & $\cdots$ \\
\hline
\end{tabular}

\footnotetext{
"Indica diferença estatística significativa entre as médias, com nível $\alpha$ (alfa) de significância de 5\% e

* indica diferença estatística significativa entre as médias, com nível $\alpha$ (alfa) de significância de $1 \%$.
} 
Para visualizar essas diferenças, desenhou-se o Gráfico 9 mostrado abaixo.

\section{Avaliacao de Colheita Mecanica Grafico de Barras Horizontais Perdas Totais (kg)}

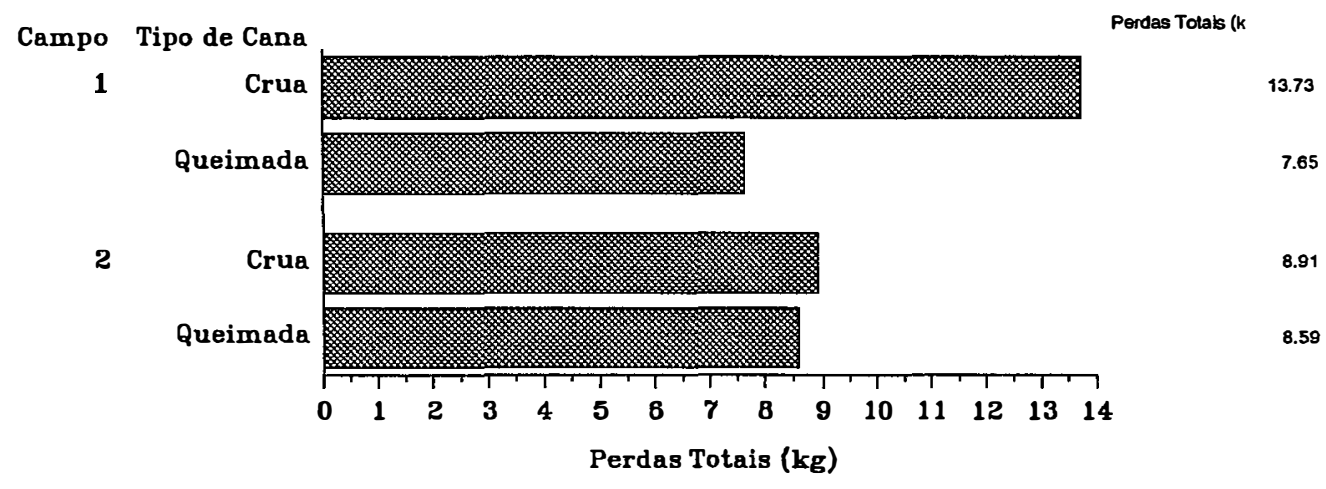

A cana crua no campo 1 apresenta comprtamento completamente diferente dos demais.

\subsubsection{Velocidade $(\mathrm{km} / \mathrm{h})$.}

Verifica-se na Tabela 10 que a interação da entre Campo e Tipo de Cana não é estatisticamente significativa, com isso, passamos para a análise das médias dos dois fatores, conforme mostradas na Tabela 28.

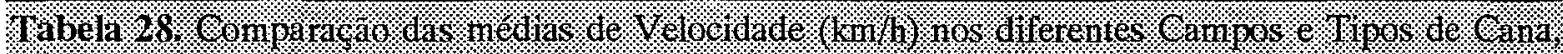
117.

\begin{tabular}{|c|c|c|c|c|}
\hline \multirow[b]{2}{*}{ Variável } & \multicolumn{2}{|c|}{ Campo } & \multicolumn{2}{|c|}{ Tipo de Cana } \\
\hline & 1 & 2 & Crua & Queimada \\
\hline Velocidade $(\mathrm{km} / \mathrm{h})$ & 5,3450 & 4,8087 & 4,6500 & 5,5037 \\
\hline
\end{tabular}

\footnotetext{
- Indica diferença estatística significativa entre as médias, com nível $\alpha$ (alfa) de significância de 5\% e

* indica diferença estatística significativa entre as médias, com nível $\alpha$ (alfa) de significância de $1 \%$.
} 


\subsubsection{Avaliação de Resíduos Pós-Colheita .}

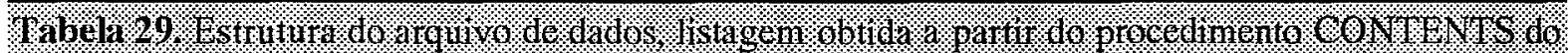

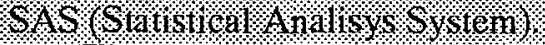

$\begin{array}{lll}\text { Data set Name: } & \text { C.POSCOL } & \text { Type: } \\ \text { Observations: } & 256 & \text { Record Len: } 44 \\ \text { Variables: } & 5 & \\ \text { Label: } & & \end{array}$

----Alphabetic List of Variables and Attributes-----

\# Variable Type Len Pos Format Label

1 CAMPO Num 8 8 4 Campo

5 POSCOL Num $8 \quad 36$ Residuo Pos-Colheita

3 REP1 Num 8 20

4 REP2 Num 8 28 $\quad$ Re-Repeticoes

2 TIPOCANA Num $8 \quad 12$ CANA. Tipo de Cana

A listagem dos dados a serem analisados aparece na Tabela 30.

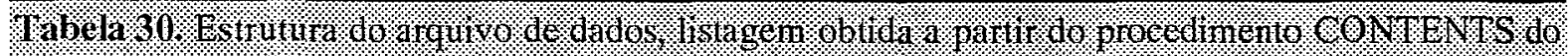

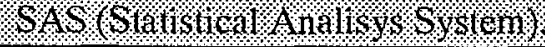

\begin{tabular}{|c|c|c|c|c|c|}
\hline OBS & Campo & $\begin{array}{l}\text { Tipo } \\
\text { de } \\
\text { Cana }\end{array}$ & Repeticoes & Re-Repeticoes & $\begin{array}{c}\text { Residuo } \\
\text { Pos-Colheita }\end{array}$ \\
\hline 1 & 1 & Crua & 1 & 1 & 37.2 \\
\hline 2 & 1 & Crua & 1 & 2 & 41.5 \\
\hline 3 & 1 & Crua & 1 & 3 & 40.2 \\
\hline 4 & 1 & Crua & 1 & 4 & 35.7 \\
\hline 5 & 1 & Crua & 1 & 5 & 38.6 \\
\hline 6 & 1 & Crua & 1 & 6 & 41.1 \\
\hline 7 & 1 & Crua & 1 & 7 & 36.8 \\
\hline 8 & 1 & Crua & 1 & 8 & 34.4 \\
\hline 9 & 1 & Crua & 2 & 1 & 31.9 \\
\hline 10 & 1 & Crua & 2 & 2 & 42.2 \\
\hline 11 & 1 & Crua & 2 & 3 & 37.8 \\
\hline 12 & 1 & Crua & 2 & 4 & 33.4 \\
\hline 13 & 1 & Crua & 2 & 5 & 40.9 \\
\hline 14 & 1 & Crua & 2 & 6 & 38.4 \\
\hline 15 & 1 & Crua & 2 & 7 & 39.6 \\
\hline 16 & 1 & Crua & 2 & 8 & 40.2 \\
\hline 17 & 1 & Crua & 3 & 1 & 41.0 \\
\hline 18 & 1 & Crua & 3 & 2 & 37.9 \\
\hline 19 & 1 & Crua & 3 & 3 & 33.7 \\
\hline 20 & 1 & Crua & 3 & 4 & 42.2 \\
\hline 21 & 1 & Crua & 3 & 5 & 39.3 \\
\hline 22 & 1 & Crua & 3 & 6 & 36.8 \\
\hline 23 & 1 & Crua & 3 & 7 & 39.7 \\
\hline 24 & 1 & Crua & 3 & 8 & 34.6 \\
\hline 25 & 1 & Crua & 4 & 1 & 39.4 \\
\hline 26 & 1 & Crua & 4 & 2 & 35.7 \\
\hline 27 & 1 & Crua & 4 & 3 & 37.8 \\
\hline 28 & 1 & Crua & 4 & 4 & 41.5 \\
\hline 29 & 1 & Crua & 4 & 5 & 36.6 \\
\hline 30 & 1 & Crua & 4 & 6 & 39.2 \\
\hline 31 & 1 & Crua & 4 & 7 & 41.4 \\
\hline 32 & 1 & Crua & 4 & 8 & 39.8 \\
\hline 33 & 1 & Crua & 5 & 1 & 43.2 \\
\hline 34 & 1 & Crua & 5 & 2 & 36.1 \\
\hline 35 & 1 & Crua & 5 & 3 & 34.8 \\
\hline
\end{tabular}




\begin{tabular}{|c|c|c|c|c|c|}
\hline OBS & Campo & $\begin{array}{l}\text { Tipo } \\
\text { de } \\
\text { Cana }\end{array}$ & Repeticoes & Re-Repeticoes & $\begin{array}{c}\text { Residuo } \\
\text { Pos-Colheita }\end{array}$ \\
\hline 36 & 1 & Crua & 5 & 4 & 37.5 \\
\hline 37 & 1 & Crua & 5 & 5 & 38.8 \\
\hline 38 & 1 & Crua & 5 & 6 & 33.9 \\
\hline 39 & 1 & Crua & 5 & 7 & 41.8 \\
\hline 40 & 1 & Crua & 5 & 8 & 39.4 \\
\hline 41 & 1 & Crua & 6 & 1 & 34.1 \\
\hline 42 & 1 & Crua & 6 & 2 & 33.9 \\
\hline 43 & 1 & Crua & 6 & 3 & 43.0 \\
\hline 44 & 1 & Crua & 6 & 4 & 37.9 \\
\hline 45 & 1 & Crua & 6 & 5 & 38.9 \\
\hline 46 & 1 & Crua & 6 & 6 & 39.0 \\
\hline 47 & 1 & Crua & 6 & 7 & 41.2 \\
\hline 48 & 1 & Crua & 6 & 8 & 38.4 \\
\hline 49 & 1 & Crua & 7 & 1 & 33.9 \\
\hline 50 & 1 & Crua & 7 & 2 & 41.7 \\
\hline 51 & 1 & Crua & 7 & 3 & 38.4 \\
\hline 52 & 1 & Crua & 7 & 4 & 39.7 \\
\hline 53 & 1 & Crua & 7 & 5 & 36.4 \\
\hline 54 & 1 & Crua & 7 & 6 & 41.3 \\
\hline 55 & 1 & Crua & 7 & 7 & 38.7 \\
\hline 56 & 1 & Crua & 7 & 8 & 39.1 \\
\hline 57 & 1 & Crua & 8 & 1 & 42.2 \\
\hline 58 & 1 & Crua & 8 & 2 & 37.4 \\
\hline 59 & 1 & Crua & 8 & 3 & 33.4 \\
\hline 60 & 1 & Crua & 8 & 4 & 36.0 \\
\hline 61 & 1 & Crua & 8 & 5 & 37.9 \\
\hline 62 & 1 & Crua & 8 & 6 & 39.9 \\
\hline 63 & 1 & Crua & 8 & 7 & 42.1 \\
\hline 64 & 1 & Crua & 8 & 8 & 39.6 \\
\hline 65 & 1 & Queimada & 1 & 1 & 21.9 \\
\hline 66 & 1 & Queimada & 1 & 2 & 20.4 \\
\hline 67 & 1 & Queimada & 1 & 3 & 19.4 \\
\hline 68 & 1 & Queimada & 1 & 4 & 23.8 \\
\hline 69 & 1 & Queimada & 1 & 5 & 22.9 \\
\hline 70 & 1 & Queimada & 1 & 6 & 22.8 \\
\hline 71 & 1 & Queimada & 1 & 7 & 25.9 \\
\hline 72 & 1 & Queimada & 1 & 8 & 22.4 \\
\hline 73 & 1 & Queimada & 2 & 1 & 22.4 \\
\hline 74 & 1 & Queimada & 2 & 2 & 23.4 \\
\hline 75 & 1 & Queimada & 2 & 3 & 25.4 \\
\hline 76 & 1 & Queimada & 2 & 4 & 18.9 \\
\hline 77 & 1 & Queimada & 2 & 5 & 22.9 \\
\hline 78 & 1 & Queimada & 2 & 6 & 23.4 \\
\hline 79 & 1 & Queimada & 2 & 7 & 25.2 \\
\hline 80 & 1 & Queimada & 2 & 8 & 19.7 \\
\hline 81 & 1 & Queimada & 3 & 1 & 19.7 \\
\hline 82 & 1 & Queimada & 3 & 2 & 23.4 \\
\hline 83 & 1 & Queimada & 3 & 3 & 22.7 \\
\hline 84 & 1 & Queimada & 3 & 4 & 20.0 \\
\hline 85 & 1 & Queimada & 3 & 5 & 26.7 \\
\hline 86 & 1 & Queimada & 3 & 6 & 19.9 \\
\hline 87 & 1 & Queimada & 3 & 7 & 22.4 \\
\hline 88 & 1 & Queimada & 3 & 8 & 23.1 \\
\hline 89 & 1 & Queimada & 4 & 1 & 23.9 \\
\hline 90 & 1 & Queimada & 4 & 2 & 17.3 \\
\hline 91 & 1 & Queimada & 4 & 3 & 26.4 \\
\hline 92 & 1 & Queimada & 4 & 4 & 19.4 \\
\hline 93 & 1 & Queimada & 4 & 5 & 25.4 \\
\hline 94 & 1 & Queimada & 4 & 6 & 23.4 \\
\hline 95 & 1 & Queimada & 4 & 7 & 24.8 \\
\hline 96 & 1 & Queimada & 4 & 8 & 25.1 \\
\hline
\end{tabular}




\begin{tabular}{|c|c|c|c|c|c|}
\hline OBS & Campo & $\begin{array}{c}\text { Tipo } \\
\text { de } \\
\text { Cana }\end{array}$ & Repeticoes & Re-Repeticoes & $\begin{array}{c}\text { Residuo } \\
\text { Pos-Colheita }\end{array}$ \\
\hline 97 & 1 & Queimada & 5 & 1 & 22.9 \\
\hline 98 & 1 & Queimada & 5 & 2 & 20.5 \\
\hline 99 & 1 & Queimada & 5 & 3 & 26.9 \\
\hline 100 & 1 & Queimada & 5 & 4 & 24.8 \\
\hline 101 & 1 & Queimada & 5 & 5 & 22.1 \\
\hline 102 & 1 & Queimada & 5 & 6 & 20.2 \\
\hline 103 & 1 & Queimada & 5 & 7 & 26.9 \\
\hline 104 & 1 & Queimada & 5 & 8 & 24.9 \\
\hline 105 & 1 & Queimada & 6 & 1 & 23.8 \\
\hline 106 & 1 & Queimada & 6 & 2 & 19.3 \\
\hline 107 & 1 & Queimada & 6 & 3 & 25.4 \\
\hline 108 & 1 & Queimada & 6 & 4 & 19.4 \\
\hline 109 & 1 & Queimada & 6 & 5 & 20.3 \\
\hline 110 & 1 & Queimada & 6 & 6 & 22.9 \\
\hline 111 & 1 & Queimada & 6 & 7 & 22.4 \\
\hline 112 & 1 & Queimada & 6 & 8 & 26.7 \\
\hline 113 & 1 & Queimada & 7 & 1 & 26.7 \\
\hline 114 & 1 & Queimada & 7 & 2 & 20.4 \\
\hline 115 & 1 & Queimada & 7 & 3 & 25.0 \\
\hline 116 & 1 & Queimada & 7 & 4 & 23.3 \\
\hline 117 & 1 & Queimada & 7 & 5 & 22.9 \\
\hline 118 & 1 & Queimada & 7 & 6 & 31.8 \\
\hline 119 & 1 & Queimada & 7 & 7 & 21.5 \\
\hline 120 & 1 & Queimada & 7 & 8 & 19.5 \\
\hline 121 & 1 & Queimada & 8 & 1 & 19.2 \\
\hline 122 & 1 & Queimada & 8 & 2 & 23.4 \\
\hline 123 & 1 & Queimada & 8 & 3 & 26.8 \\
\hline 124 & 1 & Queimada & 8 & 4 & 24.5 \\
\hline 125 & 1 & Queimada & 8 & 5 & 21.8 \\
\hline 126 & 1 & Queimada & 8 & 6 & 23.3 \\
\hline 127 & 1 & Queimada & 8 & 7 & 21.9 \\
\hline 128 & 1 & Queimada & 8 & 8 & 25.1 \\
\hline 129 & 2 & Crua & 1 & 1 & 65.3 \\
\hline 130 & 2 & Crua & 1 & 2 & 68.2 \\
\hline 131 & 2 & Crua & 1 & 3 & 62.7 \\
\hline 132 & 2 & Crua & 1 & 4 & 69.1 \\
\hline 133 & 2 & Crua & 1 & 5 & 73.2 \\
\hline 134 & 2 & Crua & 1 & 6 & 69.4 \\
\hline 135 & 2 & Crua & 1 & 7 & 70.1 \\
\hline 136 & 2 & Crua & 1 & 8 & 71.3 \\
\hline 137 & 2 & Crua & 2 & 1 & 62.7 \\
\hline 138 & 2 & Crua & 2 & 2 & 72.5 \\
\hline 139 & 2 & Crua & 2 & 3 & 72.0 \\
\hline 140 & 2 & Crua & 2 & 4 & 77.0 \\
\hline 141 & 2 & Crua & 2 & 5 & 63.5 \\
\hline 142 & 2 & Crua & 2 & 6 & 63.3 \\
\hline 143 & 2 & Crua & 2 & 7 & 71.4 \\
\hline 144 & 2 & Crua & 2 & 8 & 70.3 \\
\hline 145 & 2 & Crua & 3 & 1 & 65.4 \\
\hline 146 & 2 & Crua & 3 & 2 & 71.6 \\
\hline 147 & 2 & Crua & 3 & 3 & 70.4 \\
\hline 148 & 2 & Crua & 3 & 4 & 70.6 \\
\hline 149 & 2 & Crua & 3 & 5 & 67.9 \\
\hline 150 & 2 & Crua & 3 & 6 & 69.1 \\
\hline 151 & 2 & Crua & 3 & 7 & 68.7 \\
\hline 152 & 2 & Crua & 3 & 8 & 69.4 \\
\hline 153 & 2 & Crua & 4 & 1 & 68.4 \\
\hline 154 & 2 & Crua & 4 & 2 & 65.7 \\
\hline 155 & 2 & Crua & 4 & 3 & 73.0 \\
\hline 156 & 2 & Crua & 4 & 4 & 72.1 \\
\hline
\end{tabular}




\begin{tabular}{|c|c|c|c|c|c|}
\hline OBS & Campo & $\begin{array}{c}\text { Tipo } \\
\text { de } \\
\text { Cana }\end{array}$ & Repeticoes & Re-Repeticoes & $\begin{array}{c}\text { Residuo } \\
\text { Pos-Colheita }\end{array}$ \\
\hline 157 & 2 & Crua & 4 & 5 & 62.4 \\
\hline 158 & 2 & Crua & 4 & 6 & 67.5 \\
\hline 159 & 2 & Crua & 4 & 7 & 71.0 \\
\hline 160 & 2 & Crua & 4 & 8 & 69.9 \\
\hline 161 & 2 & Crua & 5 & 1 & 68.4 \\
\hline 162 & 2 & Crua & 5 & 2 & 71.5 \\
\hline 163 & 2 & Crua & 5 & 3 & 63.3 \\
\hline 164 & 2 & Crua & 5 & 4 & 67.4 \\
\hline 165 & 2 & Crua & 5 & 5 & 70.4 \\
\hline 166 & 2 & Crua & 5 & 6 & 71.9 \\
\hline 167 & 2 & Crua & 5 & 7 & 70.8 \\
\hline 168 & 2 & Crua & 5 & 8 & 69.1 \\
\hline 169 & 2 & Crua & 6 & 1 & 68.7 \\
\hline 170 & 2 & Crua & 6 & 2 & 66.6 \\
\hline 171 & 2 & Crua & 6 & 3 & 68.8 \\
\hline 172 & 2 & Crua & 6 & 4 & 73.4 \\
\hline 173 & 2 & Crua & 6 & 5 & 75.6 \\
\hline 174 & 2 & Crua & 6 & 6 & 66.4 \\
\hline 175 & 2 & Crua & 6 & 7 & 68.4 \\
\hline 176 & 2 & Crua & 6 & 8 & 68.4 \\
\hline 177 & 2 & Crua & 7 & 1 & 66.9 \\
\hline 178 & 2 & Crua & 7 & 2 & 65.0 \\
\hline 179 & 2 & Crua & 7 & 3 & 72.4 \\
\hline 180 & 2 & Crua & 7 & 4 & 69.7 \\
\hline 181 & 2 & Crua & 7 & 5 & 71.2 \\
\hline 182 & 2 & Crua & 7 & 6 & 72.6 \\
\hline 183 & 2 & Crua & 7 & 7 & 68.0 \\
\hline 184 & 2 & Crua & 7 & 8 & 67.8 \\
\hline 185 & 2 & Crua & 8 & 1 & 69.5 \\
\hline 186 & 2 & Crua & 8 & 2 & 66.7 \\
\hline 187 & 2 & Crua & 8 & 3 & 71.4 \\
\hline 188 & 2 & Crua & 8 & 4 & 70.7 \\
\hline 189 & 2 & Crua & 8 & 5 & 67.4 \\
\hline 190 & 2 & Crua & 8 & 6 & 69.3 \\
\hline 191 & 2 & Crua & 8 & 7 & 71.1 \\
\hline 192 & 2 & Crua & 8 & 8 & 66.3 \\
\hline 193 & 2 & Queimada & 1 & 1 & 29.4 \\
\hline 194 & 2 & Queimada & 1 & 2 & 26.7 \\
\hline 195 & 2 & Queimada & 1 & 3 & 34.2 \\
\hline 196 & 2 & Queimada & 1 & 4 & 31.0 \\
\hline 197 & 2 & Queimada & 1 & 5 & 30.4 \\
\hline 198 & 2 & Queimada & 1 & 6 & 26.4 \\
\hline 199 & 2 & Queimada & 1 & 7 & 30.1 \\
\hline 200 & 2 & Queimada & 1 & 8 & 30.4 \\
\hline 201 & 2 & Queimada & 2 & 1 & 28.7 \\
\hline 202 & 2 & Queimada & 2 & 2 & 27.9 \\
\hline 203 & 2 & Queimada & 2 & 3 & 24.8 \\
\hline 204 & 2 & Queimada & 2 & 4 & 29.1 \\
\hline 205 & 2 & Queimada & 2 & 5 & 28.0 \\
\hline 206 & 2 & Queimada & 2 & 6 & 32.4 \\
\hline 207 & 2 & Queimada & 2 & 7 & 31.0 \\
\hline 208 & 2 & Queimada & 2 & 8 & 30.1 \\
\hline 209 & 2 & Queimada & 3 & 1 & 31.3 \\
\hline 210 & 2 & Queimada & 3 & 2 & 26.4 \\
\hline 211 & 2 & Queimada & 3 & 3 & 27.9 \\
\hline 212 & 2 & Queimada & 3 & 4 & 24.8 \\
\hline 213 & 2 & Queimada & 3 & 5 & 32.8 \\
\hline 214 & 2 & Queimada & 3 & 6 & 31.3 \\
\hline 215 & 2 & Queimada & 3 & 7 & 29.4 \\
\hline 216 & 2 & Queimada & 3 & 8 & 30.0 \\
\hline 217 & 2 & Queimada & 4 & 1 & 27.4 \\
\hline
\end{tabular}




\begin{tabular}{|c|c|c|c|c|c|}
\hline OBS & Campo & $\begin{array}{l}\text { Tipo } \\
\text { de } \\
\text { Cana }\end{array}$ & Repeticoes & Re-Repeticoes & $\begin{array}{c}\text { Residuo } \\
\text { Pos-Colheita }\end{array}$ \\
\hline 218 & 2 & Queimada & 4 & 2 & 26.8 \\
\hline 219 & 2 & Queimada & 4 & 3 & 34.2 \\
\hline 220 & 2 & Queimada & 4 & 4 & 31.2 \\
\hline 221 & 2 & Queimada & 4 & 5 & 26.2 \\
\hline 222 & 2 & Queimada & 4 & 6 & 30.1 \\
\hline 223 & 2 & Queimada & 4 & 7 & 29.9 \\
\hline 224 & 2 & Queimada & 4 & 8 & 27.1 \\
\hline 225 & 2 & Queimada & 5 & 1 & 25.7 \\
\hline 226 & 2 & Queimada & 5 & 2 & 31.4 \\
\hline 227 & 2 & Queimada & 5 & 3 & 25.8 \\
\hline 228 & 2 & Queimada & 5 & 4 & 30.4 \\
\hline 229 & 2 & Queimada & 5 & 5 & 27.4 \\
\hline 230 & 2 & Queimada & 5 & 6 & 28.3 \\
\hline 231 & 2 & Queimada & 5 & 7 & 30.4 \\
\hline 232 & 2 & Queimada & 5 & 8 & 31.3 \\
\hline 233 & 2 & Queimada & 6 & 1 & 30.3 \\
\hline 234 & 2 & Queimada & 6 & 2 & 25.9 \\
\hline 235 & 2 & Queimada & 6 & 3 & 30.0 \\
\hline 236 & 2 & Queimada & 6 & 4 & 31.4 \\
\hline 237 & 2 & Queimada & 6 & 5 & 26.7 \\
\hline 238 & 2 & Queimada & 6 & 6 & 22.9 \\
\hline 239 & 2 & Queimada & 6 & 7 & 26.7 \\
\hline 240 & 2 & Queimada & 6 & 8 & 31.8 \\
\hline 241 & 2 & Queimada & 7 & 1 & 24.9 \\
\hline 242 & 2 & Queimada & 7 & 2 & 30.4 \\
\hline 243 & 2 & Queimada & 7 & 3 & 29.0 \\
\hline 244 & 2 & Queimada & 7 & 4 & 25.7 \\
\hline 245 & 2 & Queimada & 7 & 5 & 28.4 \\
\hline 246 & 2 & Queimada & 7 & 6 & 31.3 \\
\hline 247 & 2 & Queimada & 7 & 7 & 33.1 \\
\hline 248 & 2 & Queimada & 7 & 8 & 28.6 \\
\hline 249 & 2 & Queimada & 8 & 1 & 31.0 \\
\hline 250 & 2 & Queimada & 8 & 2 & 27.7 \\
\hline 251 & 2 & Queimada & 8 & 3 & 29.3 \\
\hline 252 & 2 & Queimada & 8 & 4 & 26.6 \\
\hline 253 & 2 & Queimada & 8 & 5 & 33.5 \\
\hline 254 & 2 & Queimada & 8 & 6 & 32.1 \\
\hline 255 & 2 & Queimada & 8 & 7 & 28.4 \\
\hline 256 & 2 & Queimada & 8 & 8 & 29.1 \\
\hline
\end{tabular}

O passo seguinte é a análise das variâncias para verificaçāo da heterocedasticidade. As variâncias sāo mostrada na Tabela 31 .

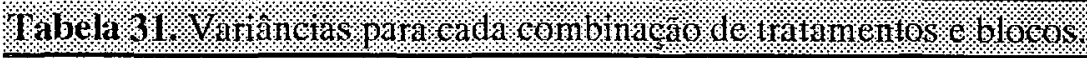

Analysis Variable : POSCOL Residuo Pos-Colheita

Campo=1 Tipo de Cana=Crua

\begin{tabular}{rrrr} 
REP1 & N Obs & Mean & Variance \\
\hline 1 & 8 & 38.1875000 & 6.7298214 \\
2 & 8 & 38.0500000 & 13.1428571 \\
3 & 8 & 38.1500000 & 8.9342857 \\
4 & 8 & 38.9250000 & 4.4135714 \\
5 & 8 & 38.1875000 & 10.6726786 \\
6 & 8 & 38.3000000 & 9.7885714 \\
7 & 8 & 38.6500000 & 6.4742857 \\
8 & 8 & 38.5625000 & 9.0883929 \\
\hline
\end{tabular}


Campo=1 Tipo de Cana=Queimada

\begin{tabular}{rrrr} 
REP1 & N Obs & Mean & Variance \\
\hline 1 & 8 & 22.4375000 & 3.9798214 \\
2 & 8 & 22.6625000 & 5.4398214 \\
3 & 8 & 22.2375000 & 5.5941071 \\
4 & 8 & 23.2125000 & 10.1469643 \\
5 & 8 & 23.6500000 & 6.9714286 \\
6 & 8 & 22.5250000 & 7.5135714 \\
7 & 8 & 23.8875000 & 15.7412500 \\
8 & 8 & 23.2500000 & 5.4200000 \\
\hline
\end{tabular}

Campo=2 Tipo de Cana $=$ Crua

\begin{tabular}{rrrrr} 
REP1 & N Obs & Mean & Variance \\
\hline 1 & 8 & 68.6625000 & 11.0598214 \\
2 & 8 & 69.0875000 & 27.8669643 \\
& 3 & 8 & 69.1375000 & 3.6512500 \\
& 4 & 8 & 68.7500000 & 12.4257143 \\
& 5 & 8 & 69.1000000 & 7.8857143 \\
& 6 & 8 & 69.5375000 & 10.5683929 \\
& 7 & 8 & 69.2000000 & 7.4828571 \\
\hline
\end{tabular}

Campo=2 Tipo de Cana=Queimada

\begin{tabular}{rrrrr} 
REP1 & N & Mbs & Mean & Variance \\
\hline 1 & 8 & 29.8250000 & 6.1335714 \\
2 & 8 & 29.0000000 & 5.2457143 \\
3 & 8 & 29.2375000 & 7.3341071 \\
4 & 8 & 29.1125000 & 7.5212500 \\
5 & 8 & 28.8375000 & 5.5626786 \\
6 & 8 & 28.2125000 & 9.8183929 \\
7 & 8 & 28.9250000 & 7.4621429 \\
8 & 8 & 29.7125000 & 5.3869643 \\
\hline
\end{tabular}

A listagem não mostra variâncias muito discrepantes o que sujere a aplicação da análise de variância dos dados originais. Análise cujo resultado é apresentado na Tabela 10. A partir dos valores de significância observados, constatou-se uma maior adequação do estudo da interação, também para esse fator. O estudo é apresentado a partir da Tabela 32 a seguir.

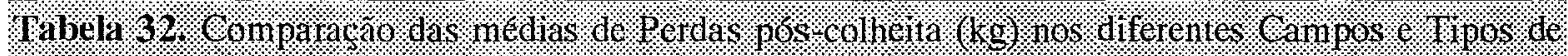

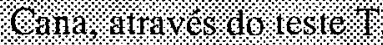

\begin{tabular}{|c|c|c|c|c|c|c|}
\hline \multirow{2}{*}{\multicolumn{3}{|c|}{$\begin{array}{c}\text { Variável } \\
\text { Perdas em Pontas }(\mathrm{kg})\end{array}$}} & \multicolumn{4}{|c|}{ Campo } \\
\hline & & & \multicolumn{2}{|c|}{1} & \multicolumn{2}{|c|}{2} \\
\hline \multirow[t]{2}{*}{ Campo } & Tipo & & Crua & Queimada & Crua & Queimada \\
\hline & & Médias & 38.3766 & 22.9828 & 69.0656 & 29.1078 \\
\hline \multirow[t]{2}{*}{1} & Crua & 38.3766 & -- & $\star \star$ & $\star \star$ & $\star \star$ \\
\hline & Queimada & 22.9828 & $\star \star$ & --- & $\star \star$ & $\star \star$ \\
\hline \multirow[t]{2}{*}{2} & Crua & 69.0656 & $\star \star$ & $\star \star$ & ... & $\star \star$ \\
\hline & Queimada & 29.1078 & $\star \star$ & $\star \star$ & 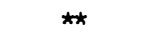 & --- \\
\hline
\end{tabular}


* Indica diferença estatística significativa entre as médias, com nível $\alpha$ (alfa) de significância de 5\% e

** indica diferença estatística significativa entre as médias, com nível $\alpha$ (alfa) de significância de $1 \%$.

E o estudo é favorecido pela análise do Gráfico 10:

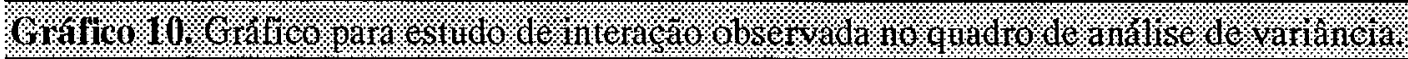

\section{Avaliacao de Colheita Mecanica \\ Grafico de Barras Horizontais \\ Avaliacao de Residuos Pos-Colheita}

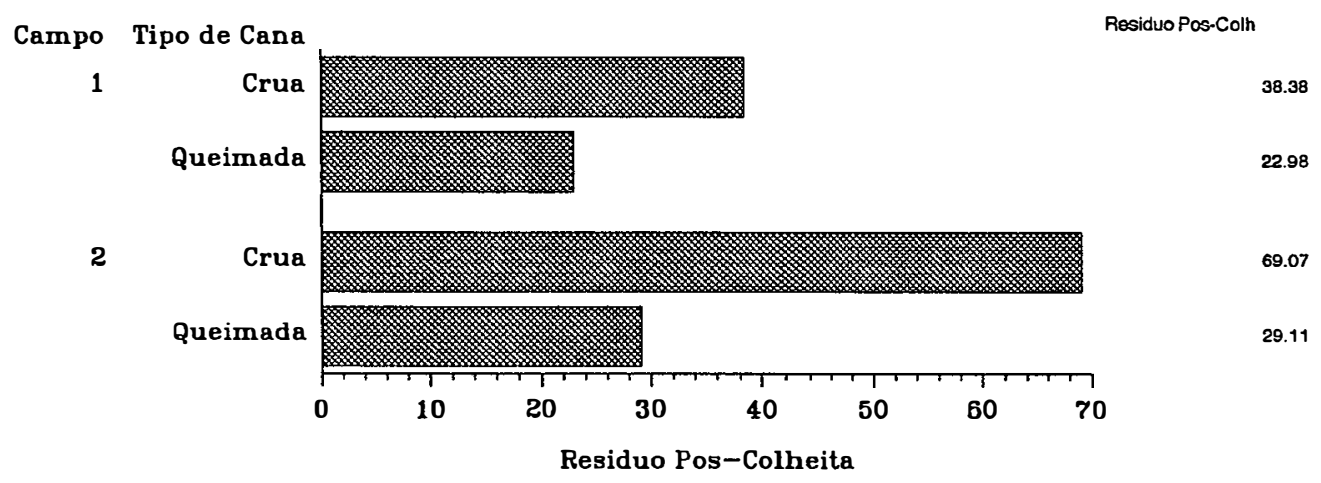

\subsection{ANÁlise de CorRELAÇĀo.}

Um último estudo diz respeito às análises de correlações lineares, cujos coeficientes de Pearson são listados, bem como os valores da estatística $T$ que testa se é razoável afirmar que esse coeficiente é igual a zero. Os resultados são apresentados na Tabela 33.

\begin{tabular}{|c|c|c|c|c|}
\hline & VELOCID & MATESVEG & MATESMIN & MATESTOT \\
\hline WWSY & 60665 & $1 \% 5 \%$ & $1066 \%$ & $16603 \%$ \\
\hline 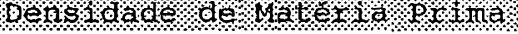 & $1000001 \%$ & 1000000.1 & $0.0058 \%$ & $000000 \%$ \\
\hline PCC & $-0.38167 \star$ & -0.00788 & $0.58230 \star \star$ & 0.03711 \\
\hline Pol \& Cana Corrigido & 0.0311 & 0.9658 & 0.0005 & 0.8402 \\
\hline 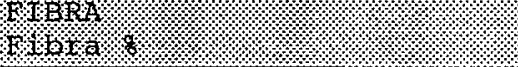 & $100000 \%$ & $\% 0,0 \%$ & $10101 \%$ & $0 \% 10 \% 1 \%$ \\
\hline
\end{tabular}

\footnotetext{
" Indica diferença estatística significativa entre as médias, com nível $\alpha$ (alfa) de significância de 5\% e
}

** indica diferença estatística significativa entre as médias, com nível $\alpha$ (alfa) de significância de $1 \%$. 
A P Ê N D I C E 2 
TABELA 1. Determinações de campo na colheita mecânica de cana-crua - CAMPO 1

\begin{tabular}{ccccc}
\hline Repetição & Distância $(\mathrm{m})$ & $\begin{array}{c}\text { Massa Cargas } \\
(\mathrm{kg})\end{array}$ & $\begin{array}{c}\text { Densidade da } \\
\text { Matéria-prima C } \\
(\mathrm{kg} / \mathrm{m})\end{array}$ & $\begin{array}{c}\text { Massa Colheita } \\
(\mathrm{t} / \mathrm{ha})\end{array}$ \\
\hline 1 & $1.042,00$ & $12.960,00$ & 12,43 & 87,53 \\
2 & 930,00 & $11.150,00$ & 11,98 & 84,36 \\
3 & $1.033,00$ & $12.520,00$ & 12,12 & 85,34 \\
4 & $1.020,00$ & $12.390,00$ & 12,14 & 85,48 \\
5 & $1.020,00$ & $12.330,00$ & 12,08 & 85,06 \\
6 & 972,00 & $11.400,00$ & 11,72 & 82,53 \\
7 & $1.042,00$ & $12.390,00$ & 11,89 & 83,72 \\
8 & $1.016,00$ & $12.270,00$ & 12,07 & 84,99 \\
\hline$M$ & $1.009,38$ & $12.176,25$ & 12,05 & 84,88 \\
\hline
\end{tabular}

TABELA 2.Determinações de campo na colheita mecânica de cana-queimada-CAMPO 1

\begin{tabular}{ccccc}
\hline Repetição & Distância $(\mathrm{m})$ & $\begin{array}{c}\text { Massa Cargas } \\
(\mathrm{kg})\end{array}$ & $\begin{array}{c}\text { Densidade da } \\
\text { Matéria-prima } \\
(\mathrm{kg} / \mathrm{m})\end{array}$ & $\begin{array}{c}\text { Massa Colheita } \\
(\mathrm{t} / \mathrm{ha})\end{array}$ \\
\hline 1 & $1.108,00$ & $12.890,00$ & 11,63 & 81,92 \\
2 & $1.124,00$ & $13.530,00$ & 12,03 & 84,76 \\
3 & 696,00 & $8.530,00$ & 12,25 & 86,3 \\
4 & $1.080,00$ & $12.800,00$ & 11,85 & 83,46 \\
5 & 702,00 & $8.480,00$ & 12,07 & 85,06 \\
6 & $1.173,00$ & $14.000,00$ & 11,93 & 84,01 \\
7 & 811,00 & $9.760,00$ & 12,03 & 84,71 \\
8 & $1.152,00$ & $13.430,00$ & 11,65 & 82,03 \\
\hline$M$ & 980,75 & $11.677,50$ & 11,93 & 84,03 \\
\hline
\end{tabular}


TABELA 3.Determinações de campo na colheita mecânica de cana-crua-CAMPO 2

\begin{tabular}{ccccc}
\hline Repetição & Distância $(\mathrm{m})$ & $\begin{array}{c}\text { Massa Cargas } \\
(\mathrm{kg})\end{array}$ & $\begin{array}{c}\text { Densidade da } \\
\text { Matéria-prima } \\
(\mathrm{kg} / \mathrm{m})\end{array}$ & $\begin{array}{c}\text { Massa Colheita } \\
(\mathrm{t} / \mathrm{ha})\end{array}$ \\
\hline 1 & 888,00 & $11.770,00$ & 13,37 & 94,15 \\
2 & 908,00 & $11.580,00$ & 12,75 & 89,78 \\
3 & 640,00 & $8.270,00$ & 12,91 & 90,91 \\
4 & 910,00 & $11.510,00$ & 12,64 & 89,01 \\
5 & 930,00 & $11.650,00$ & 12,50 & 88,02 \\
6 & 918,00 & $11.550,00$ & 12,58 & 88,58 \\
7 & 638,00 & $8.280,00$ & 12,97 & 91,33 \\
8 & 636,00 & $8.270,00$ & 13,00 & 91,54 \\
\hline M & 808,50 & $10.360,00$ & 12,84 & 90,42 \\
\hline
\end{tabular}

TABELA 4.Determinações de campo na colheita mecânica de cana-queimada-CAMPO 2

\begin{tabular}{ccccc}
\hline Repetição & Distância $(\mathrm{m})$ & $\begin{array}{c}\text { Massa Cargas } \\
(\mathrm{kg})\end{array}$ & $\begin{array}{c}\text { Densidade da } \\
\text { Matéria-prima } \\
(\mathrm{kg} / \mathrm{m})\end{array}$ & $\begin{array}{c}\text { Massa Colheita } \\
(\mathrm{t} / \mathrm{ha})\end{array}$ \\
\hline 1 & 800,00 & $9.620,00$ & 12,03 & 84,72 \\
2 & 810,00 & $10.140,00$ & 12,51 & 88,09 \\
3 & 810,00 & $9.910,00$ & 12,23 & 86,12 \\
4 & 813,00 & $10.370,00$ & 12,75 & 89,78 \\
5 & 815,00 & $10.250,00$ & 12,57 & 88,51 \\
6 & 817,00 & $10.210,00$ & 12,49 & 87,95 \\
7 & 810,00 & $9.940,00$ & 12,27 & 86,4 \\
8 & $1.143,00$ & $13.830,00$ & 12,10 & 85,2 \\
\hline $\mathbf{M}$ & 852,25 & $10.533,75$ & 12,37 & 87,10 \\
\hline
\end{tabular}


TABELA 5. Velocidades Efetivas da Colhedora x Densidade da Matéria-prima x Capacidade Efetiva cana-crua - Campo 1.

\begin{tabular}{cccc}
\hline Repetição & $\begin{array}{c}\text { Velocidade Efetiva } \\
(\mathrm{km} / \mathrm{h})\end{array}$ & $\begin{array}{c}\text { Densidade da Maté- } \\
\text { ria-prima } \\
(\mathrm{kg} / \mathrm{m})\end{array}$ & $\begin{array}{c}\text { Capaciade Efetiva } \\
(\mathrm{t} \mathrm{cana} / \mathrm{h}\end{array}$ \\
\hline 1 & 5,03 & 12,43 & 62,52 \\
2 & 4,89 & 11,98 & 58,58 \\
3 & 5,2 & 12,12 & 63,02 \\
4 & 5 & 12,14 & 60,7 \\
5 & 4,82 & 12,08 & 58,22 \\
6 & 4,91 & 11,72 & 57,54 \\
7 & 4,68 & 11,89 & 55,64 \\
8 & 4,75 & 12,07 & 57,33 \\
\hline $\mathbf{M}$ & 4,91 & 12,05 & 59,11 \\
\hline
\end{tabular}

TABELA 6. Velocidades Efetivas da Colhedora x Densidade da Matéria-prima x Capacidade Efetiva cana-queimada - Campo 1.

\begin{tabular}{cccc}
\hline Repetição & $\begin{array}{c}\text { Velocidade Efetiva } \\
(\mathrm{km} / \mathrm{h})\end{array}$ & $\begin{array}{c}\text { Densidade da Maté- } \\
\text { ria-prima } \\
(\mathrm{kg} / \mathrm{m})\end{array}$ & $\begin{array}{c}\text { Capaciade Efetiva } \\
(\mathrm{t} \text { cana/h }\end{array}$ \\
\hline 1 & 6,03 & 11,63 & 70,12 \\
2 & 5,64 & 12,03 & 67,85 \\
3 & 5,83 & 12,25 & 71,41 \\
4 & 5,92 & 11,85 & 70,15 \\
5 & 5,33 & 12,07 & 64,33 \\
6 & 6 & 11,93 & 71,58 \\
7 & 5,57 & 12,03 & 67 \\
8 & 5,92 & 11,65 & 68,97 \\
\hline$M$ & 5,78 & 11,93 & 68,95 \\
\hline
\end{tabular}


TABELA 7. Velocidades Efetivas da Colhedora $x$ Densidade da Matéria-prima x Capacidade Efetiva cana-crua - Campo 2.

\begin{tabular}{cccc}
\hline Repetição & $\begin{array}{c}\text { Velocidade Efetiva } \\
(\mathrm{km} / \mathrm{h})\end{array}$ & $\begin{array}{c}\text { Densidade da Maté- } \\
\text { ra-prima } \\
(\mathrm{kg} / \mathrm{m})\end{array}$ & $\begin{array}{c}\text { Capaciade Efetiva } \\
(\mathrm{t} \text { cana/h }\end{array}$ \\
\hline 1 & 4,56 & 13,37 & 60,96 \\
2 & 4,37 & 12,75 & 55,71 \\
3 & 4,26 & 12,91 & 54,99 \\
4 & 4,62 & 12,64 & 58,39 \\
5 & 4,48 & 12,5 & 56 \\
6 & 4,22 & 12,58 & 53,08 \\
7 & 4,31 & 12,97 & 55,9 \\
8 & 4,3 & 13 & 55,9 \\
\hline$M$ & 4,39 & 12,84 & 56,36 \\
\hline
\end{tabular}

TABELA 8. Velocidades Efetivas da Colhedora x Densidade da Matéria-prima x Capacidade Efetiva cana-queimada - Campo 1.

\begin{tabular}{cccc}
\hline Repetição & $\begin{array}{c}\text { Velocidade Efetiva } \\
(\mathrm{km} / \mathrm{h})\end{array}$ & $\begin{array}{c}\text { Densidade da Maté- } \\
\text { ria-prima } \\
(\mathrm{kg} / \mathrm{m})\end{array}$ & $\begin{array}{c}\text { Capaciade Efetiva } \\
(\mathrm{t} \text { cana/h }\end{array}$ \\
\hline 1 & 5,46 & 12,03 & 65,75 \\
2 & 4,93 & 12,51 & 61,67 \\
3 & 5,37 & 12,23 & 65,67 \\
4 & 5,17 & 12,75 & 65,97 \\
5 & 4,87 & 12,57 & 61,21 \\
6 & 5,49 & 12,49 & 68,57 \\
7 & 5,63 & 12,27 & 69,14 \\
8 & 4,9 & 12,1 & 59,29 \\
\hline $\mathbf{M}$ & 5,18 & 12,36 & 64,02 \\
\hline
\end{tabular}


TABELA 9. Análises tecnológicas nas massas de cana-crua colhidas mecanicamente Campo 1.

\begin{tabular}{cccccc}
\hline Repetição & Brix \% & Pol \% caldo & Pureza \% & Fibra \% & $\begin{array}{c}\text { Pol \% Cana } \\
\text { Corrigido } \\
\text { (PCC) }\end{array}$ \\
\hline 1 & 20,6 & 18,02 & 87,48 & 14,49 & 14,17 \\
2 & 21,5 & 18,55 & 86,27 & 14,82 & 14,53 \\
3 & 22,1 & 18,76 & 84,88 & 15,41 & 14,59 \\
4 & 22,2 & 18,87 & 85 & 16,33 & 14,52 \\
5 & 21,8 & 18,86 & 86,51 & 13,07 & 15,08 \\
6 & 21,5 & 18,9 & 87,9 & 14,48 & 14,87 \\
7 & 21,8 & 18,52 & 84,95 & 15,82 & 14,34 \\
8 & 20,6 & 18,05 & 87,62 & 14,27 & 14,23 \\
\hline M & 21,5 & 18,56 & 86,28 & 14,83 & 14,54 \\
\hline
\end{tabular}

TABELA 10. Análises tecnológicas nas massas de cana-queimada colhidas mecanicamente - Campo 1.

\begin{tabular}{cccccc}
\hline Repetição & Brix \% & Pol \% caldo & Pureza \% & Fibra \% & $\begin{array}{c}\text { Pol \% Cana } \\
\text { Corrigido } \\
\text { (PCC) }\end{array}$ \\
\hline 1 & 20,2 & 17,43 & 86,29 & 14,05 & 13,78 \\
2 & 20,8 & 17,9 & 86,06 & 13,96 & 14,16 \\
3 & 21,1 & 18,27 & 86,59 & 14,27 & 14,4 \\
4 & 20 & 16,85 & 84,26 & 14,13 & 13,31 \\
5 & 19,6 & 17,04 & 86,93 & 13,79 & 13,51 \\
6 & 20,3 & 17,88 & 88,07 & 14,4 & 14,08 \\
7 & 21 & 18,98 & 90,38 & 13,5 & 15,1 \\
8 & 20,4 & 17,37 & 85,14 & 14,14 & 13,72 \\
\hline M & 20,42 & 17,71 & 86,72 & 14,03 & 14 \\
\hline
\end{tabular}


TABELA 11. Análises tecnológicas nas massas de cana-crua colhidas mecanicamente Campo 2.

\begin{tabular}{cccccc}
\hline Repetição & Brix \% & Pol \% caldo & Pureza \% & Fibra \% & $\begin{array}{c}\text { Pol \% Cana } \\
\text { Corrigido } \\
\text { (PCC) }\end{array}$ \\
\hline 1 & 21,98 & 20,34 & 92,56 & 19,23 & 15,43 \\
2 & 20,86 & 19,28 & 92,3 & 20,12 & 15,31 \\
3 & 22 & 20,33 & 92,41 & 18,51 & 15,13 \\
4 & 20,93 & 19,37 & 92,56 & 17,39 & 15,91 \\
5 & 22,16 & 20,46 & 92,36 & 19,42 & 14,95 \\
6 & 23,41 & 21,64 & 92,46 & 18,5 & 15,44 \\
7 & 21,94 & 20,27 & 92,4 & 19,33 & 14,8 \\
8 & 22,4 & 20,71 & 92,47 & 17,66 & 14,85 \\
\hline M & 21,96 & 20,3 & 92,44 & 18,77 & 15,23 \\
\hline
\end{tabular}

TABELA 12. Análises tecnológicas nas massas de cana-queimada colhidas mecanicamente - Campo 2.

\begin{tabular}{cccccc}
\hline Repetição & Brix \% & Pol \% caldo & Pureza \% & Fibra \% & $\begin{array}{c}\text { Pol \% Cana } \\
\text { Corrigido } \\
\text { (PCC) }\end{array}$ \\
\hline 1 & 21,17 & 19,77 & 93,42 & 16,07 & 15,85 \\
2 & 22,18 & 21,2 & 95,61 & 15,8 & 15,36 \\
3 & 21,33 & 19,83 & 92,99 & 16,1 & 15,7 \\
4 & 20,91 & 19,5 & 93,29 & 15,89 & 15,88 \\
5 & 19,14 & 17,99 & 93,98 & 15,77 & 15,4 \\
6 & 21,98 & 20,91 & 93,15 & 16,21 & 16,1 \\
7 & 22,14 & 20,24 & 91,44 & 16,5 & 15,66 \\
8 & 21,7 & 20,44 & 94,2 & 15,88 & 16,12 \\
\hline M & 21,32 & 19,99 & 93,76 & 16,03 & 15,76 \\
\hline
\end{tabular}


TABELA 13. Determinações das matérias estranhas nas massas colhidas cana-crua Campo 1.

\begin{tabular}{cccccc}
\hline Repetição & Massa Total & Colmos & \multicolumn{2}{c}{ Massa de Matéria Estranha } & Total \\
& $\mathbf{( k g )}$ & $(\mathbf{k g})$ & Vegetal & Mineral & \\
\hline 1 & $\mathbf{7 , 9 4 8}$ & $\mathbf{7 , 5 0 2}$ & 0,414 & 0,032 & 0,446 \\
2 & 8,741 & 8,089 & 0,605 & 0,046 & 0,651 \\
3 & 7,144 & 6,633 & 0,473 & 0,038 & 0,511 \\
4 & 4,500 & 4,280 & 0,199 & 0,021 & 0,22 \\
5 & 6,631 & 6,345 & 0,258 & 0,028 & 0,286 \\
6 & 7,154 & 6,628 & 0,487 & 0,038 & 0,525 \\
7 & 9,840 & 9,188 & 0,604 & 0,048 & 0,652 \\
8 & 6,331 & 6,000 & 0,295 & 0,027 & 0,322 \\
\hline
\end{tabular}

TABELA 14. Determinações das matérias estranhas nas massas colhidas cana-queimada Campo 1.

\begin{tabular}{cccccc}
\hline Repetição & Massa Total & Colmos & \multicolumn{2}{c}{ Massa de Matéria Estranha } & Total \\
& $(\mathbf{k g})$ & $(\mathbf{k g})$ & Vegetal & Mineral & \\
\hline 1 & $\mathbf{8 , 7 6 3}$ & $\mathbf{8 , 0 1 9}$ & 0,675 & 0,068 & 0,743 \\
2 & 7,272 & 6,848 & 0,385 & 0,039 & 0,424 \\
3 & 3,023 & 2,895 & 0,107 & 0,02 & 0,127 \\
4 & 10,430 & 9,691 & 0,666 & 0,073 & 0,739 \\
5 & 5,623 & 5,292 & 0,296 & 0,031 & 0,327 \\
6 & 7,085 & 6,627 & 0,405 & 0,052 & 0,457 \\
7 & 5,694 & 5,454 & 0,199 & 0,04 & 0,239 \\
8 & 9,376 & 8,866 & 0,457 & 0,053 & 0,51 \\
\hline
\end{tabular}


TABELA 15. Determinações das matérias estranhas nas massas colhidas cana-crua Campo 2.

\begin{tabular}{cccccc}
\hline Repetição & Massa Total & Colmos & \multicolumn{2}{c}{ Massa de Matéria Estranha } & Total \\
& $(\mathbf{k g})$ & $(\mathbf{k g})$ & Vegetal & Mineral & \\
\hline 1 & 5,643 & 4,711 & 0,878 & 0,054 & 0,932 \\
2 & 5,024 & 4,650 & 0,348 & 0,025 & 0,373 \\
3 & 6,020 & 5,499 & 0,46 & 0,06 & 0,52 \\
4 & 6,388 & 5,603 & 0,423 & 0,062 & 0,485 \\
5 & 5,775 & 5,256 & 0,465 & 0,047 & 0,512 \\
6 & 1,654 & 1,534 & 0,104 & 0,015 & 0,119 \\
7 & 4,528 & 3,837 & 0,646 & 0,044 & 0,69 \\
8 & 6,337 & 5,295 & 1,054 & 0,066 & 1,12 \\
\hline
\end{tabular}

TABELA 16. Determinações das matérias estranhas nas massas colhidas cana-queimada Campo 2.

\begin{tabular}{cccccc}
\hline Repetição & Massa Total & Colmos & \multicolumn{2}{c}{ Massa de Matéria Estranha } & Total \\
& $(\mathrm{kg})$ & $(\mathrm{kg})$ & Vegetal & Mineral & \\
\hline 1 & 4,750 & 4,529 & 0,163 & 0,057 & 0,22 \\
2 & 8,141 & 7,730 & 0,328 & 0,082 & 0,41 \\
3 & 4,546 & 4,399 & 0,097 & 0,05 & 0,147 \\
4 & 4,182 & 4,044 & 0,103 & 0,034 & 0,137 \\
5 & 3,843 & 3,603 & 0,193 & 0,047 & 0,24 \\
6 & 4,643 & 4,259 & 0,318 & 0,035 & 0,353 \\
7 & 4,065 & 3,882 & 0,154 & 0,029 & 0,183 \\
8 & 6,872 & 6,528 & 0,296 & 0,047 & 0,343 \\
\hline
\end{tabular}


TABELA 17. Determinações Percentuais dos componentes da matéria estranha nas cargas de cana-crua - Campo 1.

\begin{tabular}{ccccc}
\hline Repetição & Colmos & \multicolumn{2}{c}{ Matéria estranha \% } & Total \\
\cline { 3 - 4 } & $(\%)$ & Vegetal & Mineral & \\
\hline 1 & 94,40 & 5,21 & 0,39 & 5,60 \\
2 & 92,55 & 6,93 & 0,52 & 7,45 \\
3 & 92,86 & 6,63 & 0,51 & 7,14 \\
4 & 95,13 & 4,43 & 0,43 & 4,86 \\
5 & 95,70 & 3,90 & 0,40 & 4,30 \\
6 & 92,65 & 6,82 & 0,53 & 7,35 \\
7 & 93,38 & 6,14 & 0,48 & 6,62 \\
8 & 94,91 & 4,67 & 0,42 & 5,09 \\
\hline$M$ & 93,95 & 5,59 & 0,46 & 6,05 \\
\hline
\end{tabular}

TABELA 18. Determinações Percentuais dos componentes da matéria estranha nas cargas de cana-queimada - Campo 1.

\begin{tabular}{ccccc}
\hline Repetição & Colmos & \multicolumn{2}{c}{ Matéria estranha \% } & Total \\
\cline { 3 - 4 } & $(\%)$ & Vegetal & Mineral & \\
\hline 1 & 91,52 & 7,71 & 0,77 & 8,48 \\
2 & 94,17 & 5,30 & 0,53 & 5,83 \\
3 & 95,79 & 3,56 & 0,61 & 4,17 \\
4 & 92,92 & 6,39 & 0,69 & 7,08 \\
5 & 94,13 & 5,28 & 0,59 & 5,87 \\
6 & 93,54 & 5,73 & 0,73 & 6,46 \\
7 & 95,80 & 3,51 & 0,69 & 4,2 \\
8 & 94,57 & 4,88 & 0,55 & 5,43 \\
\hline M & 94,03 & 5,30 & 0,67 & 5,97 \\
\hline
\end{tabular}


TABELA 19. Determinações Percentuais dos componentes da matéria estranha nas cargas de cana-crua - Campo 2.

\begin{tabular}{ccccc}
\hline Repetição & Colmos & \multicolumn{2}{c}{ Matéria estranha \% } & Total \\
\cline { 3 - 4 } & $(\%)$ & Vegetal & Mineral & \\
\hline 1 & 83,49 & 15,60 & 0,91 & 16,51 \\
2 & 92,57 & 6,30 & 0,53 & 6,83 \\
3 & 91,35 & 7,70 & 0,95 & 8,65 \\
4 & 87,72 & 11,30 & 0,98 & 12,28 \\
5 & 91,02 & 8,10 & 0,88 & 8,98 \\
6 & 92,75 & 6,30 & 0,95 & 7,25 \\
7 & 84,74 & 14,30 & 0,96 & 15,26 \\
8 & 83,56 & 15,40 & 1,04 & 16,44 \\
\hline M & 88,40 & 10,70 & 0,90 & 11,60 \\
\hline
\end{tabular}

TABELA 20. Determinações Percentuais dos componentes da matéria estranha nas cargas de cana-queimada - Campo 2.

\begin{tabular}{ccccc}
\hline Repetição & Colmos & \multicolumn{2}{c}{ Matéria estranha \% } & Total \\
\cline { 3 - 4 } & $(\%)$ & Vegetal & Mineral & \\
\hline 1 & 95,36 & 3,44 & 1,20 & 4,64 \\
2 & 94,96 & 4,04 & 1,00 & 5,04 \\
3 & 96,77 & 2,13 & 1,10 & 3,23 \\
4 & 96,72 & 2,48 & 0,80 & 3,28 \\
5 & 93,78 & 5,02 & 1,20 & 6,22 \\
6 & 91,73 & 6,87 & 1,40 & 8,27 \\
7 & 95,51 & 3,79 & 0,70 & 4,49 \\
8 & 95,00 & 4,32 & 0,68 & 5,00 \\
\hline$M$ & 94,98 & 4,01 & 1,01 & 5,02 \\
\hline
\end{tabular}


TABELA 21. Perdas no campo em kg de material industrializável no campo após colheita de cana-crua - Campo 1.

\begin{tabular}{cccccc}
\hline Repetição & Pontas & Tocos & Frações/colmos & Rebolos & Total \\
\hline 1 & 2,10 & 3,60 & 0,80 & 3,75 & 10,25 \\
2 & 2,20 & 3,00 & 0,75 & 6,90 & 14,85 \\
3 & 2,15 & 2,70 & 0,68 & 5,80 & 14,33 \\
4 & 2,25 & 0,60 & 0,65 & 4,20 & 11,70 \\
5 & 4,30 & 1,00 & 0,90 & 3,50 & 14,70 \\
6 & 3,50 & 0,85 & 1,35 & 2,20 & 13,90 \\
7 & 2,25 & 0,85 & 1,20 & 3,10 & 14,40 \\
8 & 2,80 & 1,00 & 0,60 & 3,30 & 15,70 \\
\hline $\mathbf{M}$ & 2,69 & 1,70 & 0,86 & 4,09 & 9,34 \\
\hline
\end{tabular}

TABELA 22. Perdas no campo em kg de material industrializável no campo após colheita de cana-queimada - Campo 1.

\begin{tabular}{cccccc}
\hline Repetição & Pontas & Tocos & Frações/colmos & Rebolos & Total \\
\hline 1 & 0,50 & 0,65 & 1,60 & 2,35 & 5,10 \\
2 & 0,38 & 0,75 & 1,50 & 2,60 & 7,23 \\
3 & 0,50 & 0,40 & 0,20 & 1,50 & 5,60 \\
4 & 0,35 & 0,30 & 0,14 & 1,60 & 6,39 \\
5 & 0,23 & 0,45 & 0,30 & 0,90 & 6,88 \\
6 & 0,45 & 0,50 & 0,45 & 1,10 & 8,50 \\
7 & 0,45 & 0,30 & 0,60 & 1,80 & 10,15 \\
8 & 0,41 & 0,25 & 0,65 & 2,00 & 11,31 \\
\hline M & 0,41 & 0,45 & 0,33 & 1,73 & 2,92 \\
\hline
\end{tabular}


TABELA 23. Perdas no campo em kg de material industrializável no campo após colheita de cana-crua - Campo 2.

\begin{tabular}{cccccc}
\hline Repetição & Pontas & Tocos & Frações/colmos & Rebolos & Total \\
\hline 1 & 0,20 & 0,40 & 1,00 & 0,90 & 2,50 \\
2 & 0,40 & 1,40 & 0,30 & 1,60 & 5,70 \\
3 & 0,50 & 1,30 & 0,50 & 1,70 & 7,00 \\
4 & 0,30 & 3,00 & 0,20 & 4,10 & 11,60 \\
5 & 0,60 & 0,80 & 0,30 & 0,80 & 7,50 \\
6 & 0,20 & 1,40 & 1,00 & 2,30 & 10,90 \\
7 & 0,90 & 0,80 & 1,60 & 4,20 & 14,50 \\
8 & 0,20 & 1,30 & 1,30 & 0,80 & 11,60 \\
\hline M & 0,41 & 1,30 & 0,77 & 2,05 & 4,53 \\
\hline
\end{tabular}

TABELA 24. Perdas no campo em kg de material industrializável no campo após colheita de cana-queimada - Campo 1.

\begin{tabular}{cccccc}
\hline Repetição & Pontas & Tocos & Frações/colmos & Rebolos & Total \\
\hline 1 & 0,90 & 1,30 & 1,30 & 2,80 & 6,30 \\
2 & 0,30 & 1,10 & 1,00 & 1,60 & 6,00 \\
3 & 0,20 & 2,10 & 0,90 & 1,80 & 8,00 \\
4 & 1,00 & 0,50 & 0,10 & 0,60 & 6,20 \\
5 & 0,10 & 1,60 & 1,00 & 1,80 & 9,50 \\
6 & 0,30 & 0,80 & 0,50 & 1,40 & 9,00 \\
7 & 0,60 & 1,00 & 0,70 & 2,00 & 11,30 \\
8 & 0,20 & 0,70 & 1,00 & 2,50 & 12,40 \\
\hline M & 0,45 & 1,13 & 0,81 & 1,81 & 4,20 \\
\hline
\end{tabular}


TABELA 25. Determinação dos componentes do palhiço - Cana-crua - Campo 1 (kg/parcela).

\section{Repetições}

\begin{tabular}{cccccccc}
\hline 1 & 2 & 3 & 4 & 5 & 6 & 7 & 8 \\
\hline 37,20 & 31,90 & 41,00 & 39,40 & 43,20 & 34,10 & 33,90 & 42,20 \\
41,50 & 42,20 & 37,90 & 35,70 & 36,10 & 33,90 & 41,70 & 37,40 \\
40,20 & 37,80 & 33,70 & 37,80 & 34,80 & 43,00 & 38,40 & 33,40 \\
35,70 & 33,40 & 42,20 & 41,50 & 37,50 & 37,90 & 39,70 & 36,00 \\
38,60 & 40,90 & 39,30 & 36,60 & 38,80 & 38,90 & 36,40 & 37,90 \\
41,10 & 38,40 & 36,80 & 39,20 & 33,90 & 39,00 & 41,30 & 39,90 \\
36,80 & 39,60 & 39,70 & 41,40 & 41,80 & 41,20 & 38,70 & 42,10 \\
34,40 & 40,20 & 34,60 & 39,80 & 39,40 & 38,40 & 39,10 & 39,60 \\
\hline M 38,19 & 38,05 & 38,15 & 38,93 & 38,19 & 38,30 & 38,65 & 38,56 \\
\hline
\end{tabular}

TABELA 26. Determinação dos componentes do palhiço - Cana-queimada - Campo 1 ( $\mathrm{kg} /$ parcela).

\begin{tabular}{cccccccc}
\hline 1 & 2 & 3 & 4 & 5 & 6 & 7 & 8 \\
\hline 21,90 & 22,40 & 19,70 & 23,90 & 22,90 & 23,80 & 26,70 & 19,20 \\
20,40 & 23,40 & 23,40 & 17,30 & 20,50 & 19,30 & 20,40 & 23,40 \\
19,40 & 25,40 & 22,70 & 26,40 & 26,90 & 25,40 & 25,00 & 26,80 \\
23,80 & 18,90 & 20,00 & 19,40 & 24,80 & 19,40 & 23,30 & 24,50 \\
22,90 & 22,90 & 26,70 & 25,40 & 22,10 & 20,30 & 22,90 & 21,80 \\
22,80 & 23,40 & 19,90 & 23,40 & 20,20 & 22,90 & 31,80 & 23,30 \\
25,90 & 25,20 & 22,40 & 24,80 & 26,90 & 22,40 & 21,50 & 21,90 \\
22,40 & 19,70 & 23,10 & 25,10 & 24,90 & 26,70 & 19,50 & 25,10 \\
\hline M 22,44 & 22,66 & 22,24 & 23,21 & 23,65 & 22,53 & 23,89 & 23,25 \\
\hline
\end{tabular}


TABELA 27. Determinação dos componentes do palhiço - Cana-crua - Campo 2 (kg/parcela).

\begin{tabular}{cccccccc}
\hline 1 & 2 & 3 & 4 & 5 & 6 & 7 & 8 \\
\hline 65,30 & 62,70 & 65,40 & 68,40 & 68,40 & 68,70 & 66,90 & 69,50 \\
68,20 & 72,50 & 71,60 & 65,70 & 71,50 & 66,60 & 65,00 & 66,70 \\
62,70 & 72,00 & 70,40 & 73,00 & 63,30 & 68,80 & 72,40 & 71,40 \\
69,10 & 77,00 & 70,60 & 72,10 & 67,40 & 73,40 & 69,70 & 70,70 \\
73,20 & 63,50 & 67,90 & 62,40 & 70,40 & 75,60 & 71,20 & 67,40 \\
69,40 & 63,30 & 69,10 & 67,50 & 71,90 & 66,40 & 72,60 & 69,30 \\
70,10 & 71,40 & 68,70 & 71,00 & 70,80 & 68,40 & 68,00 & 71,10 \\
71,30 & 70,30 & 69,40 & 69,90 & 69,10 & 68,40 & 67,80 & 66,30 \\
\hline 68,66 & 69,09 & 69,14 & 68,75 & 69,10 & 69,54 & 69,20 & 69,05 \\
\hline
\end{tabular}

TABELA 28. Determinação dos componentes do palhiço - Cana-queimada - Campo 2 (kg/parcela).

\begin{tabular}{cccccccc}
\hline 1 & 2 & 3 & 4 & 5 & 6 & 7 & 8 \\
\hline 29,40 & 28,40 & 31,30 & 27,40 & 25,70 & 30,30 & 24,90 & 31,00 \\
26,70 & 27,90 & 26,40 & 26,80 & 31,40 & 25,90 & 30,40 & 27,70 \\
34,20 & 24,80 & 27,90 & 34,20 & 25,80 & 30,00 & 29,00 & 29,30 \\
31,00 & 29,10 & 24,80 & 31,20 & 30,40 & 31,40 & 25,70 & 26,60 \\
30,40 & 28,00 & 32,80 & 26,20 & 27,40 & 26,70 & 28,40 & 33,50 \\
26,40 & 32,40 & 31,30 & 30,10 & 28,30 & 22,90 & 31,30 & 32,10 \\
30,10 & 31,00 & 29,40 & 29,90 & 30,40 & 26,70 & 33,10 & 28,40 \\
30,40 & 30,10 & 30,00 & 27,10 & 31,30 & 31,80 & 28,60 & 29,10 \\
\hline 29,83 & 29,00 & 29,24 & 29,11 & 28,84 & 28,21 & 28,93 & 29,71 \\
\hline
\end{tabular}


TABELA 29 - Número de colmos por metro e determinações do porte do canavial Campo 1.

\begin{tabular}{|c|c|c|c|c|c|c|c|c|c|}
\hline & & \multicolumn{8}{|c|}{ Repetições } \\
\hline & & 1 & 2 & 3 & 4 & 5 & 6 & 7 & 8 \\
\hline $\mathrm{N}^{0}$ colm & & 10 & 8 & 11 & 10 & 12 & 10 & 11 & 9 \\
\hline & E & 10 & 7 & 11 & 9 & 10 & 10 & 10 & 9 \\
\hline \multirow[t]{2}{*}{ PORTE } & A & - & 2 & - & - & 2 & - & 1 & - \\
\hline & D & - & - & - & 1 & - & & - & - \\
\hline
\end{tabular}

TABELA 30 - Número de colmos por metro e determinações do porte do canavial Campo 2.

\begin{tabular}{|c|c|c|c|c|c|c|c|c|c|c|c|}
\hline & \multicolumn{10}{|c|}{ Repetições } \\
\hline & & 1 & 2 & 3 & 4 & 5 & 6 & 7 & 8 & 9 & 10 \\
\hline \multicolumn{2}{|c|}{$\mathrm{N}^{0 .} \operatorname{colmos} / \mathrm{m}$} & 9 & 14 & 12 & 12 & 10 & 13 & 16 & 12 & 11 & 14 \\
\hline & E & 9 & 14 & 12 & 10 & 13 & 16 & 12 & 11 & 14 & 12 \\
\hline \multirow[t]{2}{*}{ PORTE } & A & - & - & - & - & - & - & - & - & - & \\
\hline & D & - & - & - & - & - & - & & - & - & \\
\hline \multicolumn{12}{|c|}{$E=$ Erecto,$A=$ Acamado,$D=$ Deitado } \\
\hline \multicolumn{12}{|c|}{$N^{0}$ colmos $/ m=12,3$} \\
\hline \multicolumn{12}{|c|}{ Porte $=100 \%$ erecto } \\
\hline
\end{tabular}

